\title{
Synthesis of enantioenriched sulfoxides
}

\author{
Graham E. O’Mahony, ${ }^{\text {' Padraig Kelly, Simon E. Lawrence, }}{ }^{\text {a }}$ \\ and Anita R. Maguire ${ }^{b_{*}}$ \\ ${ }^{a}$ Department of Chemistry, Analytical and Biological Chemistry Research Facility, \\ University College Cork, Cork, Ireland \\ ${ }^{b}$ Department of Chemistry and School of Pharmacy, Analytical and Biological Chemistry \\ Research Facility, University College Cork, Cork, Ireland \\ E-mail: a.maguire@ucc.ie
}

\begin{abstract}
This review discusses strategies for the asymmetric synthesis of sulfoxides, compounds with many applications in stereoselective synthesis and in some cases with pharmaceutical application. The review describes asymmetric oxidation, including metal catalyzed and nonmetal and biological oxidation processes, in addition to synthetic approaches via nucleophilic substitution of appropriately substituted precursors. Kinetic resolution in oxidation of sulfoxides to the analogous sulfones is also discussed; in certain instances, access to enantioenriched sulfoxides can be achieved via a combination of asymmetric sulfide oxidation and complementary kinetic resolution in sulfoxide oxidation.
\end{abstract}

Keywords: Sulfide oxidation, sulfoxides, asymmetric synthesis, enantioselective synthesis, kinetic resolution

\section{Table of Contents}

1. Introduction

2. Asymmetric Sulfide Oxidation

2.1 Metal catalyzed asymmetric sulfide oxidation

2.1.1 Titanium catalyzed oxidation

2.1.2 Vanadium catalyzed oxidation

2.1.3 Iron catalyzed oxidation

2.1.4 Manganese catalyzed oxidation

2.1.5 Copper catalyzed oxidation

2.1.6 Niobium catalyzed oxidation

2.1.7 Tungsten catalyzed oxidation 


\subsubsection{Osmium catalyzed oxidation}

2.1.9 Zirconium catalyzed oxidation

2.1.10 Molybdenum catalyzed oxidation

2.1.11 Aluminum catalyzed oxidation

2.2 Non-metal catalyzed asymmetric sulfide oxidation

2.2.1 Chiral oxidants

2.2.2 Chiral catalysts

2.3 Electrochemical asymmetric sulfide oxidation

2.4 Biological asymmetric sulfide oxidation

2.4.1 Oxidation using whole cells

2.4.2 Oxidation using isolated enzymes

3. Kinetic Resolution of Sulfoxides

3.1 Oxidative kinetic resolution

3.1.1 Biological methods

3.1.2 Chiral oxidants

3.1.3 Chiral catalysts

3.2 Non-oxidative kinetic resolution

3.2.1 Chemical Methods

3.2.2 Biological Methods

4. Nucleophilic Displacement

\section{Introduction}

Optically pure sulfoxides have attracted a great deal of interest in the past three decades due to their use as chiral auxiliaries in a broad range of synthetic reactions. The sulfinyl group has been shown to be an efficient chiral auxillary in carbon-carbon ${ }^{1,2}$ and carbon-oxygen ${ }^{3}$ bond forming reactions, in cycloaddition reactions, ${ }^{4}$ radical addition reactions ${ }^{5,6}$ and in asymmetric catalysis. ${ }^{7}$ The success of the sulfinyl group as a chiral controller is because: (1) it is configurationally stable at room temperature (generally stable up to $200{ }^{\circ} \mathrm{C}$ ), (2) it is accessible in both enantiomeric forms, and (3) it is an excellent carrier of chiral information. ${ }^{8}$ A number of reviews have been published dealing with the use of enantiopure sulfoxides in asymmetric synthesis. ${ }^{9}$

Enantiopure sulfoxides have also found use in the pharmaceutical industry due to their important biological activity. Omeprazole, the world's highest selling drug in 1997 (\$5 billion U.S.), ${ }^{10}$ is a proton pump inhibitor used to treat acid-induced inflammation and ulcers of the stomach and duodenum. A number of other acid secretion inhibitors based on the framework of omeprazole have also been developed (Figure 1). Esomeprazole, the $(S)$-form of omeprazole, was launched in Europe in 2000 and the USA in 2001 under the trade name Nexium $^{\mathrm{TM}}$. 
<smiles>COc1ccc2[nH]c(S(=O)Cc3nc(C(C)C)cc(C)c3C)nc2c1</smiles><smiles>Cc1c(OCC(F)(F)F)ccnc1CS(=O)c1nc2ccccc2[nH]1</smiles><smiles>COc1ccnc(CS([O-])=[S+](c2nc3ccc(OC(F)F)cc3[nH]2)c2cccnc2OC)c1OC</smiles>

2

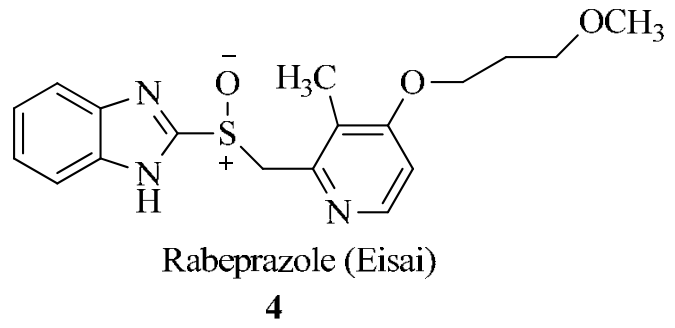

\section{Figure 1}

Other biologically active compounds containing the sulfinyl moiety include Modafinil $\mathbf{5}$ and Sulindac 6, which have been used to treat narcolepsy and inflammation respectively (Figure 2). ${ }^{11,12}$ A number of reviews outlining the asymmetric synthesis of biologically active sulfoxides have been reported. ${ }^{13}$<smiles>NC(=O)CS(=O)C(c1ccccc1)c1ccccc1</smiles>

5

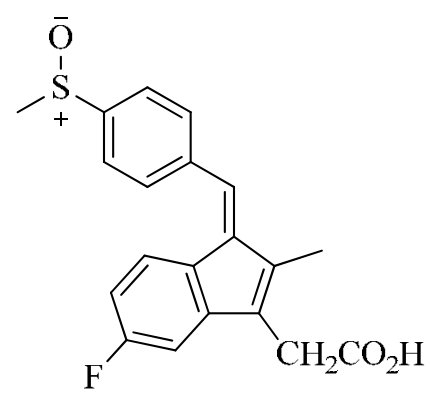

6

\section{Figure 2}

There are two principal routes to enantiopure sulfoxides; $;$

- Oxidation

- Nucleophilic substitution

The oxidation route is by far the most popular because of its versatility in that the same route can be used to oxidise many sulfides. 


\section{Asymmetric Sulfide Oxidation}

The most attractive method for the preparation of enantiopure sulfoxides is asymmetric sulfide oxidation. ${ }^{14 a}$ Developing a novel oxidation method that involves simply treating a sulfide with an oxidising reagent/complex to form the enantiopure sulfoxide has been, and still is, the goal of many research groups.

Peracids were used to carry out the first asymmetric sulfide oxidations, however, results obtained were very modest with enantioselectivity rarely greater than $10 \%$ ee. ${ }^{15}$ Since the $1980 \mathrm{~s}$ a number of practical and efficient asymmetric sulfide oxidation methods have been reported. ${ }^{16}$ Most asymmetric sulfide oxidations are metal catalyzed though a number of non-metal catalyzed oxidations and biological oxidations also exist.

\subsection{Metal catalyzed asymmetric sulfide oxidation}

2.1.1 Titanium catalyzed oxidation. The first major advance in metal catalyzed asymmetric sulfide oxidation was reported by Kagan in 1984 (Scheme 1). ${ }^{17,18}$ Also in 1984, Modena independently reported a similar oxidation method (Scheme 2). ${ }^{19}$ Both the Kagan and Modena oxidation methods are based on the Sharpless asymmetric epoxidation. ${ }^{20,21}$ These asymmetric sulfide oxidation methods represented the first practical and efficient oxidation methods for the metal catalyzed asymmetric oxidation of sulfides. The methods are not substrate specific and are relatively straightforward.

The differences between the methods are relatively minor. Both methods use a titanium catalyst, diethyl tartrate (DET) as the chiral auxiliary, tert-butyl hydrogen peroxide (TBHP) as the oxidant and are carried out at $-20{ }^{\circ} \mathrm{C}$. The Kagan method uses dichloromethane as the solvent and also involves the addition of water to the oxidation. The Modena method uses dichloroethane (DCE) as the solvent but does not involve the addition of water to the oxidation. The fact that these reactions were catalyzed by titanium is unsurprising given its pivotal role in so many enantioselective reactions. ${ }^{22}$ Elucidation of the structure of the Kagan-Modena catalysts has proved challenging. ${ }^{23,24}$

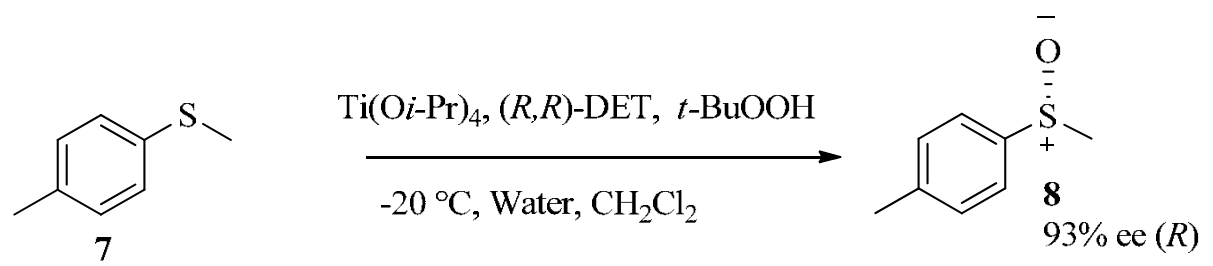

Kagan Oxidation

\section{Scheme 1}




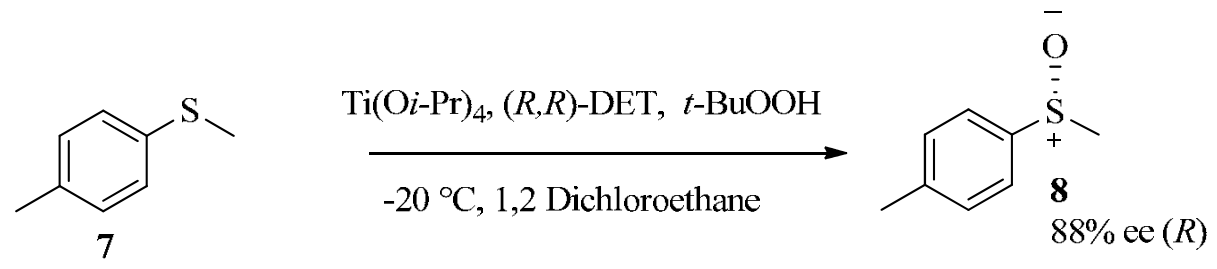

Modena Oxidation

\section{Scheme 2}

The Kagan oxidation method has received more attention than the Modena oxidation method. Using cumene hydroperoxide (CHP) instead of TBHP with the Kagan oxidation method resulted in higher enantioselectivity in the oxidation of 7, with 8 being obtained in $96 \%$ ee in almost quantitative yield. $^{25}$ The role of water in the Kagan oxidation was investigated because it is based on the Sharpless asymmetric epoxidation ${ }^{20,21}$ and water is a known catalyst poison in this reaction. ${ }^{26}$ In the Kagan oxidation, water deactivates the catalyst for epoxidation but promotes enantioselective sulfide oxidation. ${ }^{17,18}$ The effect of water in the Kagan oxidation was also investigated by Uemura, who reported that too little or too much water present in the reaction could impact detrimentally on the enantioselectivity of the reaction. ${ }^{27}$

Most of the investigations into titanium mediated sulfur oxidation have focussed on using different chiral auxiliaries to establish if the scope and enantioselectivity of the reaction can be improved. Uemura utilised a binaphthol chiral auxiliary, 9, with the Kagan oxidation method and obtained sulfoxides in good yield and high enantiopurity (Scheme 3 ). ${ }^{27}$

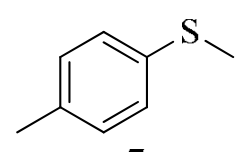

7

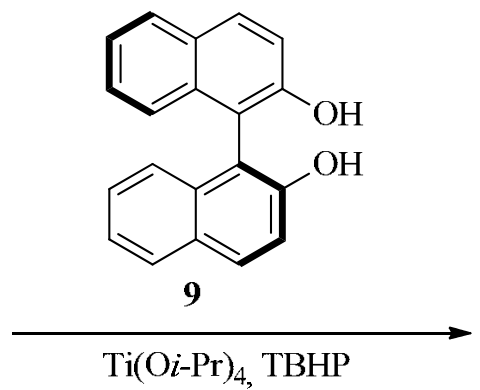

$-20^{\circ} \mathrm{C}, \mathrm{H}_{2} \mathrm{O}$, Toluene

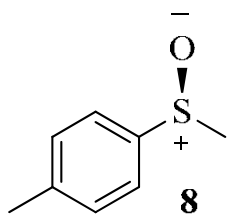

$73 \%$ ee $(S)$

\section{Scheme 3}

Imamoto used the hexanediol $\mathbf{1 0}$ as a chiral auxiliary in a titanium mediated sulfide oxidation. $^{28}$ Both Kagan and Uemura demonstrated that water was crucial for the enantioselectivity of the oxidation, however Imamoto observed that the oxidation using $\mathbf{1 0}$ as the chiral auxiliary proceeded with the highest degree of enantiopurity when conducted in the presence of molecular sieves. Sulfoxides were obtained in good yield and with good 
enantioselectivity by Imamoto using cumene hydroperoxide (CHP) as oxidant (Scheme 4). Imamoto developed further diol-type chiral auxiliaries but these were less effective than $\mathbf{1 0}{ }^{29}$<smiles>CSc1ccc(C)cc1</smiles>
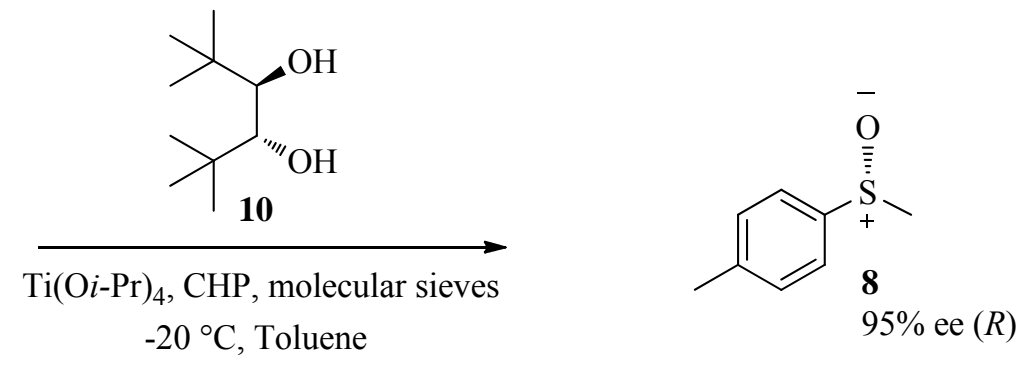

\section{Scheme 4}

Superchi and Rosini also used diols as chiral auxiliaries following a similar procedure to Uemura; the oxidant used was TBHP and the reaction was carried out in the presence of water. ${ }^{30}$ The ligand was $(S, S)$-1,2-diphenylethan-1,2-diol 11 with carbon tetrachloride as solvent and the reaction was carried out at $0{ }^{\circ} \mathrm{C}$. The sulfoxide 8 was obtained with $80 \%$ ee in $62 \%$ yield.

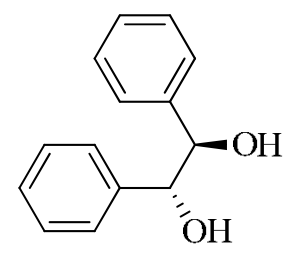

11

Similar diols 14 have recently been used by the same research group to prepare enantiopure aryl benzyl sulfoxides (Scheme 5). ${ }^{31}$<smiles>c1ccc(CSc2ccccc2)cc1</smiles><smiles>CC(C)(C)c1ccc([C@@H](O)[C@H](O)c2ccc(C(C)(C)C)cc2)cc1</smiles><smiles>O=[S@@]([O-])(Cc1ccccc1)c1ccccc1</smiles>

\section{Scheme 5}


Bolm and Dabard used a steroid derived BINOL derivative $\mathbf{1 5}$ as a chiral auxiliary. ${ }^{32}$ Similar to Uemura's use of 9, a water addition was crucial for the enantioselectivity of the oxidation (Scheme 6).
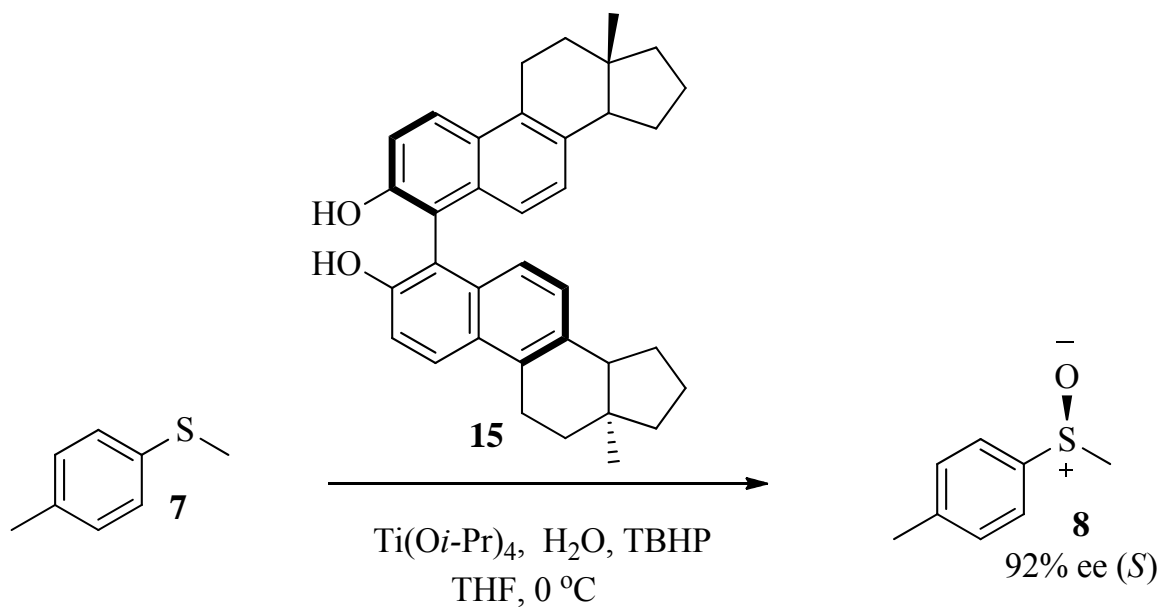

\section{Scheme 6}

Martyn et al. used a fluorinated BINOL ( $\left.\mathrm{F}_{8} \mathrm{BINOL}\right)$ derivative 16, reasoning that it should interact differently with the titanium catalyst than BINOL (Scheme 7). ${ }^{33}$ Carrying out the reaction at room temperature, using chloroform as the solvent and CHP as the oxidising agent, 16 significantly outperformed $\mathbf{9}$ in terms of enantioselectivity and efficiency. Also significant is the stereoselectivity of the reaction, using 9 the $R$ enantiomer is preferentially formed while using 16 the $S$ enantiomer is preferentially formed. The reason given for the better performance of 16 over 9 was the increased acidity of the hydroxyl groups. Ligand $\mathbf{1 6}$ has also been used in other asymmetric synthetic transformations. ${ }^{34}$

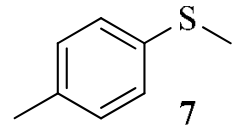

7

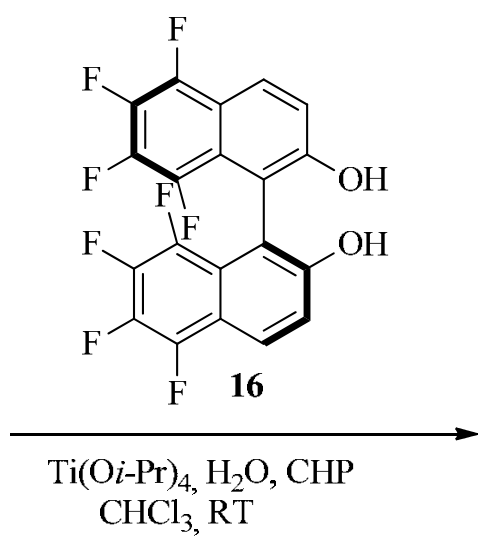<smiles>Cc1ccc([Si](C)=O)cc1</smiles>

$\begin{array}{cl}\text { Chiral Ligand } & \% \text { ee } \\ \mathbf{9} & 3(R) \\ \mathbf{1 6} & 80(S)\end{array}$

\section{Scheme 7}


Camphanediols, such as $\mathbf{1 7}$, have also been used to prepare enantioenriched sulfoxides using this methodology. ${ }^{35}$ It is proposed that the oxidation in this case occurs by an intramolecular nucleophilic oxygen transfer to the coordinated sulfide. This method oxidised thioanisole 18 to its sulfoxide 19 in poor yield but with excellent enantioselectivity (up to $99 \%$ ee).
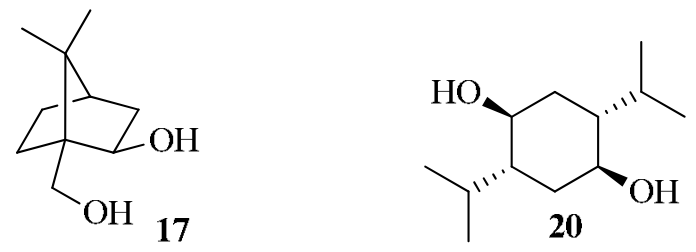

2,5-Dialkylcyclohexane-1,4-diols, e.g. 20, have been used to generate a variety of enantioenriched aryl methyl sulfoxides (up to $84 \%$ ee). ${ }^{36}$

Mandelic acid was used as a chiral auxiliary to synthesise 22 on a large scale. ${ }^{37}$ Significantly this oxidation can be carried out at room temperature and is not sensitive to atmospheric moisture, unlike the Kagan and Modena oxidation methods. ${ }^{37 b}$ The sulfoxide 22 was obtained in good yield and high enantiopurity. Recrystallization afforded enantiopure 20; a key intermediate in the synthesis of the platelet adhesion inhibitor 23 (Scheme 8).
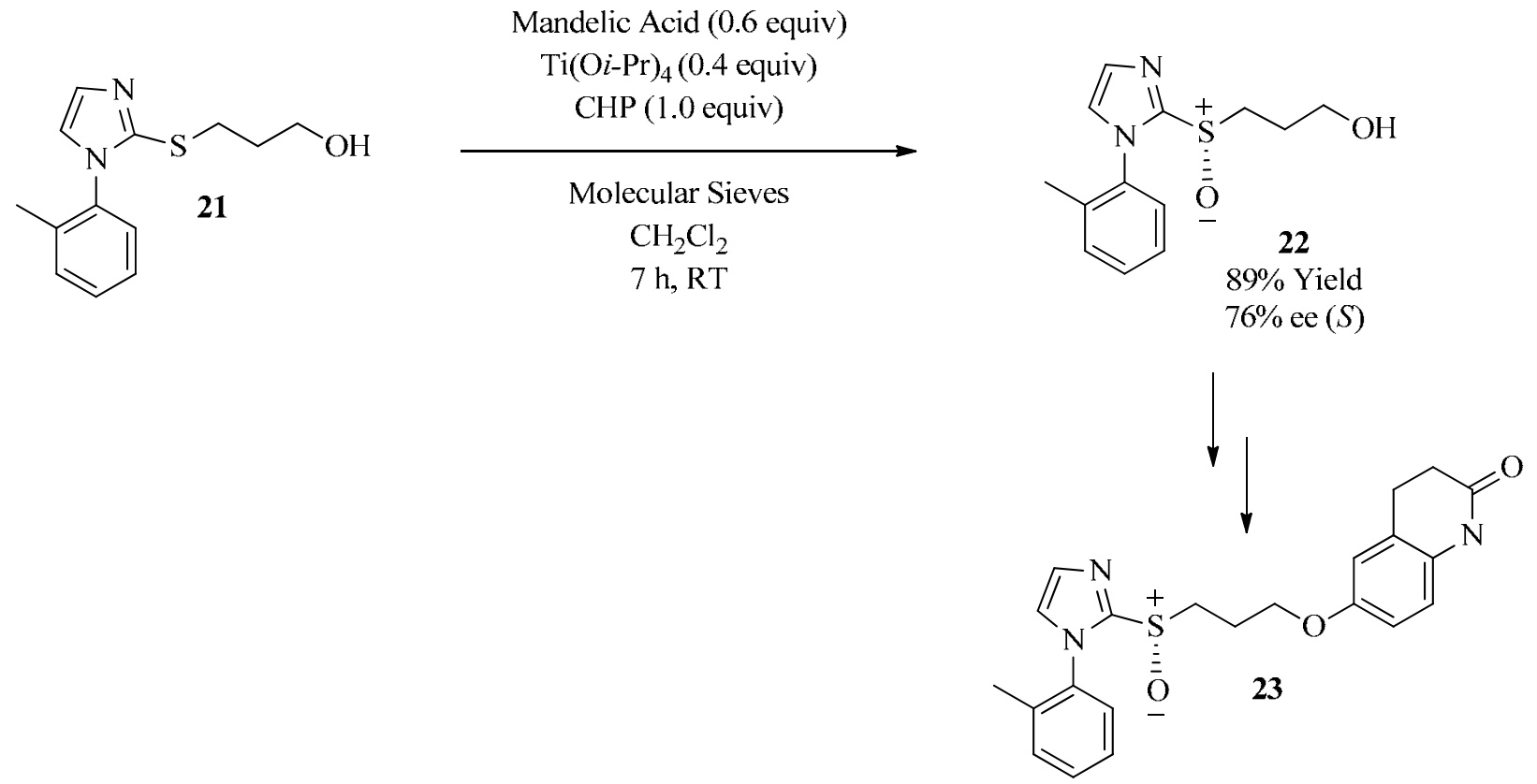

\section{Scheme 8}

Bryliakov and Talsi employed an amino alcohol derived Schiff base ligand $\mathbf{2 4}$ as the chiral auxiliary with hydrogen peroxide as the oxidant (Scheme 9). ${ }^{38}$ Modest results were obtained. 
<smiles>c1ccc(CSc2ccccc2)cc1</smiles>

12

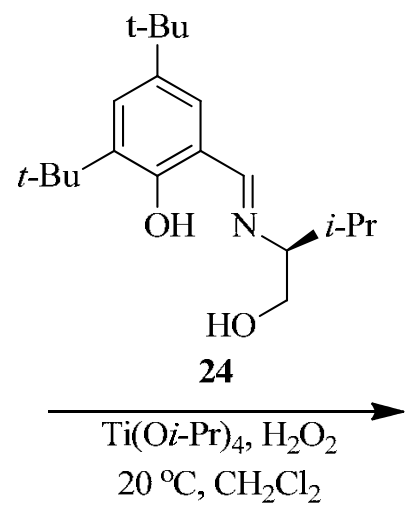

$20^{\circ} \mathrm{C}, \mathrm{CH}_{2} \mathrm{Cl}_{2}$

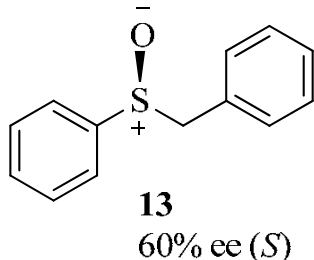

$60 \% \operatorname{ee}(S)$

\section{Scheme 9}

Bryliakov and Talsi have also reported the titanium-salen catalyzed oxidation of sulfides that employed hydrogen peroxide as the oxidant. ${ }^{39}$ The titanium-salen system reported is best suited to oxidise bulky sulfides such as benzyl phenyl sulfide. Poorer results were obtained for the oxidation of aryl alkyl sulfides. Notably, this asymmetric sulfide oxidation is accompanied by complementary kinetic resolution of the sulfoxide.

While most of the research into the Kagan-Modena oxidation methods have focussed on the chiral auxiliary used, Adam et al. investigated the use of a chiral hydroperoxide 25 (Scheme 10). ${ }^{40}$ Results obtained were modest, with moderate to good enantiopurities, but considerable sulfone formation accompanied the reactions. The significance of the sulfone formation will be discussed later, see section 3.

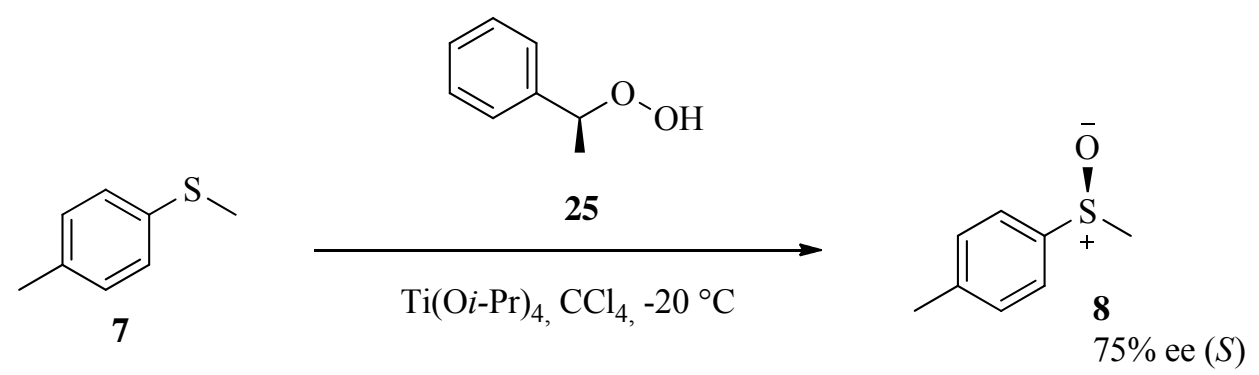

\section{Scheme 10}

Scettri et al. also investigated the effect of using hydroperoxides as the oxidising agents. ${ }^{41}$ Using the conditions proposed by Modena, with an achiral tertiary furyl hydroperoxide oxidising agent, 8 was obtained in good yield and $90 \%$ ee. ${ }^{41 a}$ Secondary furyl hydroperoxides were also investigated to see if enantioselectivity could be improved, and it was found that use of the furyl hydroperoxide $\mathbf{2 6}$ resulted in a further improvement in enantioselectivity and yield (Scheme 11). ${ }^{41 \mathrm{a}}$ Compound 26 possesses a stereocentre and was used in enantioenriched form. During the oxidation kinetic resolution of $\mathbf{2 6}$ occurred. 


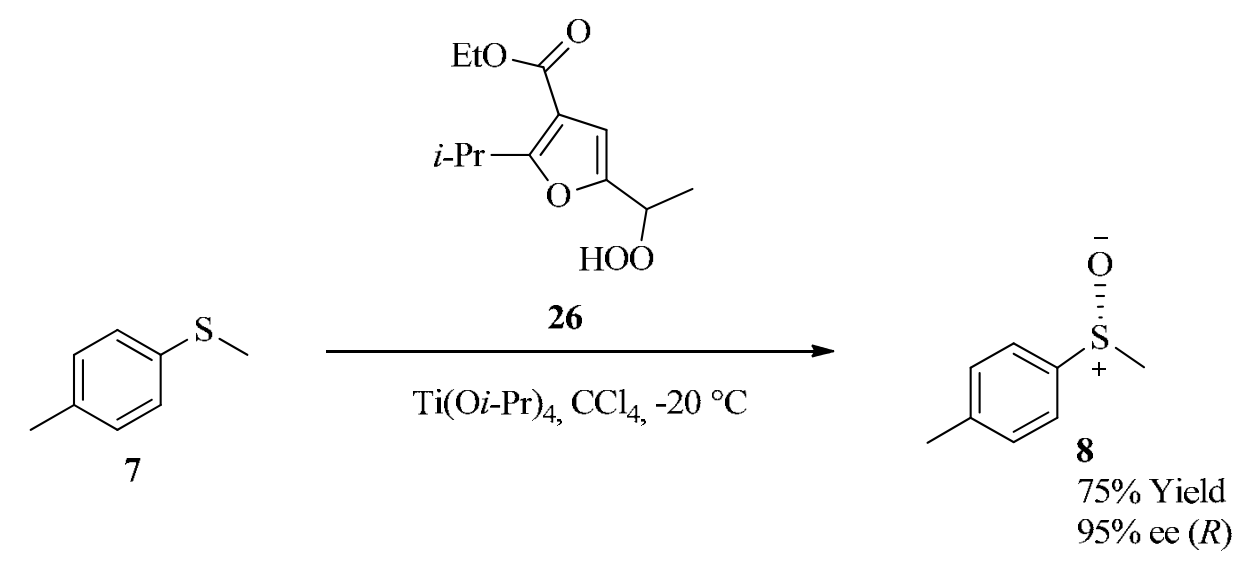

\section{Scheme 11}

Reaction times were reduced using the steroidal furyl hydroperoxide 27 but this resulted in a decrease in the enantioselectivity of the oxidation. ${ }^{41 \mathrm{~g}}$

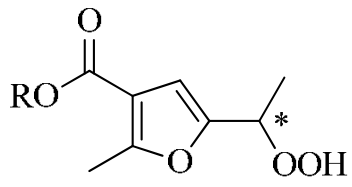

27

$\mathrm{R}=5 \mathrm{a}-$ cholestan-3B-yl

Various camphor derived furyl hydroperoxides have been developed and used by Lattanzi and Scettri. ${ }^{41 \mathrm{~g}, 42-43}$ Unlike other hydroperoxides, the use of a chiral auxiliary with the camphor furyl hydroperoxides is not necessary. It was proposed that steric interactions between the sulfide and the camphor derived oxidant resulted in the preferential formation of one sulfoxide enantiomer. ${ }^{42}$ The furyl hydroperoxides were reduced to the alcohol in the oxidation; which can be used to regenerate the hydroperoxide. Overall, the enantioselectivity of the oxidations was only moderate, with the highest enantioselectivity reported in the oxidation of paramethoxyphenyl methyl sulfide 28 using the $(S)$-norcamphor derived furyl hydroperoxide 30 (Scheme 12). ${ }^{42}$ Sulfone formation was a significant feature for all the camphor derived furyl hydroperoxides.<smiles>COc1ccc(SC)cc1</smiles>

28

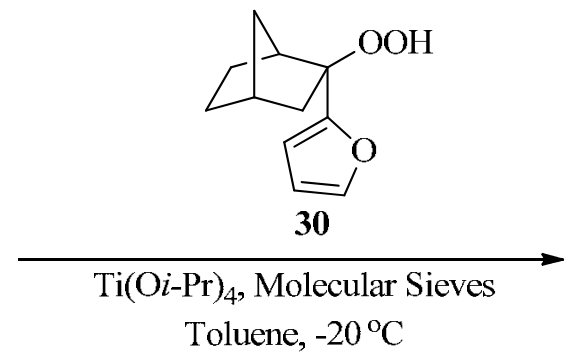

Toluene, $-20^{\circ} \mathrm{C}$

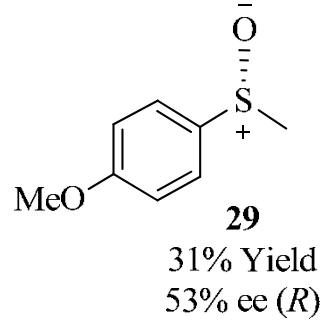

\section{Scheme 12}


Recently, Liebscher used chiral hydroperoxide moieties for the asymmetric oxidation of aryl methyl sulfides (Scheme 13). ${ }^{44}$ When 1.1 equivalents of $\mathrm{H}_{2} \mathrm{O}_{2}$ (oxidant) was used the $(R)$ sulfoxide was obtained in a $55 \%$ yield and $23 \%$ ee, with some over-oxidation to the sulfone. However, the use of 3.3 equivalents of $\mathrm{H}_{2} \mathrm{O}_{2}$ produced the $(R)$-sulfoxide in a $16 \%$ yield and $>$ $99 \%$ ee with a large amount of over-oxidation, indicating that kinetic resolution was taking place.<smiles>CSc1ccccc1</smiles>

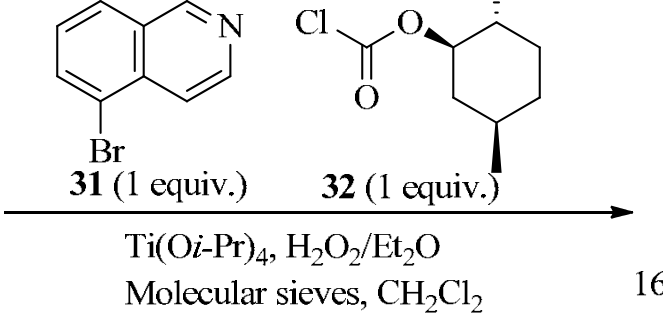

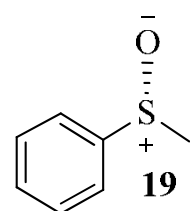

$16 \%$ Yield $>99 \%$ ee $(R)$

\section{Scheme 13}

Titanium mediated sulfide oxidation has been successfully used to prepare esomeprazole $\left(\right.$ Nexium $^{\circledR}, 1 S$ ) which is the enantiopure form of omeprazole $1{ }^{45}$ The method used is based on the Kagan method, however the catalyst complex is prepared in the presence of the sulfide at an elevated temperature. The oxidation is carried out in the presence of $N, N$-diisopropylamine at 30 ${ }^{\circ} \mathrm{C}$ (Scheme 14). The role of this amine is unclear but is necessary for the enhanced enantioselectivity.<smiles>COC1=CC2N=C(SCc3ncc(C)c(OC)c3C)NC2C=C1</smiles>

\section{Scheme 14}

The preparation of esomeprazole using a chiral complex with two chiral ligands (DET and a chiral amine) has been reported. ${ }^{46}$ More recently a high yielding and highly enantioselective titanium mediated oxidative preparation of esomeprazole and similar heteroaromatic sulfoxides has been reported by Jiang et al. ${ }^{47}$ This method employed a brominated aromatic diol 34 as chiral auxiliary and TBHP as the oxidant (Scheme 15). 
<smiles>COC1=CC2N=C(SCc3ncc(C)c(OC)c3C)NC2C=C1</smiles>

33<smiles>O[C@@H](c1ccccc1Br)[C@H](O)c1ccccc1Br</smiles>

$\mathrm{Ti}(\mathrm{O} i-\mathrm{Pr})_{4}, \mathrm{TBHP}$

$-20{ }^{\circ} \mathrm{C}$, Toluene $/ \mathrm{H}_{2} \mathrm{O}$<smiles>COC1=CC2N=C([S@](=O)Cc3ncc(C)c(OC)c3C)NC2C=C1</smiles>

$96 \%$ ee $(S)$ 92\% Yield

\section{Scheme 15}

Delamare et al. reported a new titanate $(+)-(1 R, 2 S)$-cis-1-amino-2-indanol system 37 for the asymmetric synthesis of $(S)$-tenatoprazole. The procedure involved the use of the polar aprotic solvent $N$-methyl-2-pyrrolidone (NMP) and afforded the sulfoxide in high yield (90\%) and enantioselectivity $(>99 \%)$ (Scheme 16). ${ }^{48}$<smiles>COc1ccc2[nH]c(SCc3ncc(C)c(OC)c3C)nc2n1</smiles>

\section{Scheme 16}

Highly enantioenriched Sulindac 6 has been prepared using the Kagan procedure by Maguire et al., Scheme $17 .{ }^{49}$ Naso et al., employing the oxidant TBHP and a different chiral auxiliary, has also prepared highly enantioenriched 6 using the Kagan procedure. ${ }^{50}$

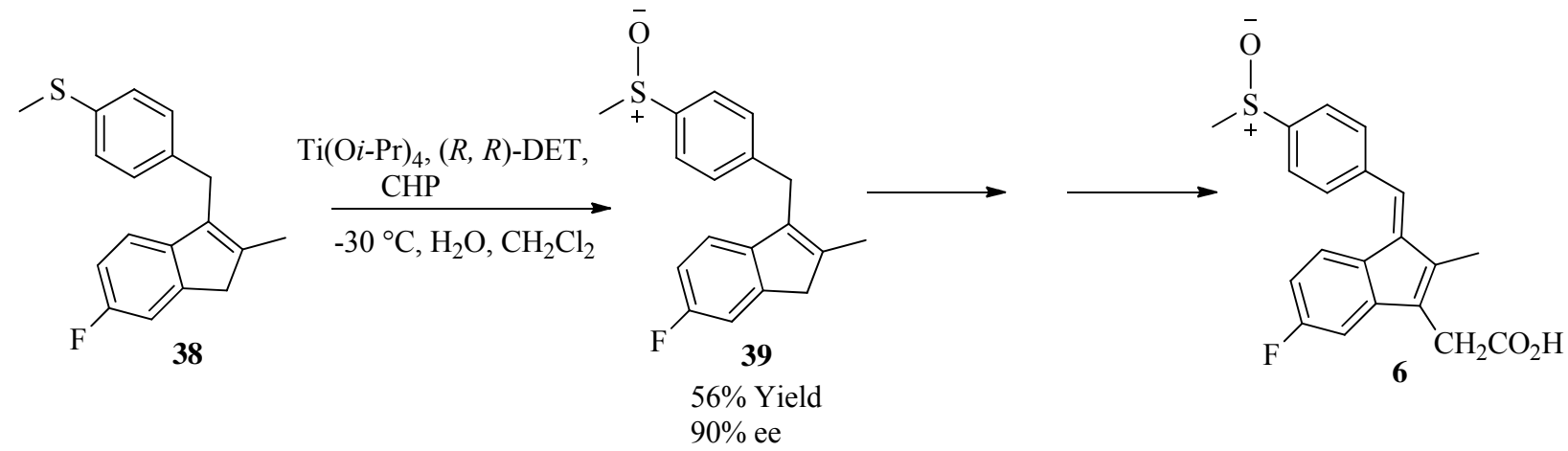


Cardellicchio et al. investigated aryl benzyl sulfides using the titanium hydrobenzoin complex 42 as the catalyst. Interestingly, the $(R)$-sulfoxide was obtained when $(S, S)$ hydrobenzoin was used, whereas the reaction afforded the $(S)$-sulfoxide in the presence of $(R, R)$ hydrobenzoin. Aryl benzyl sulfoxides were obtained in excellent yields and enantioselectivities (Scheme 18). ${ }^{51}$
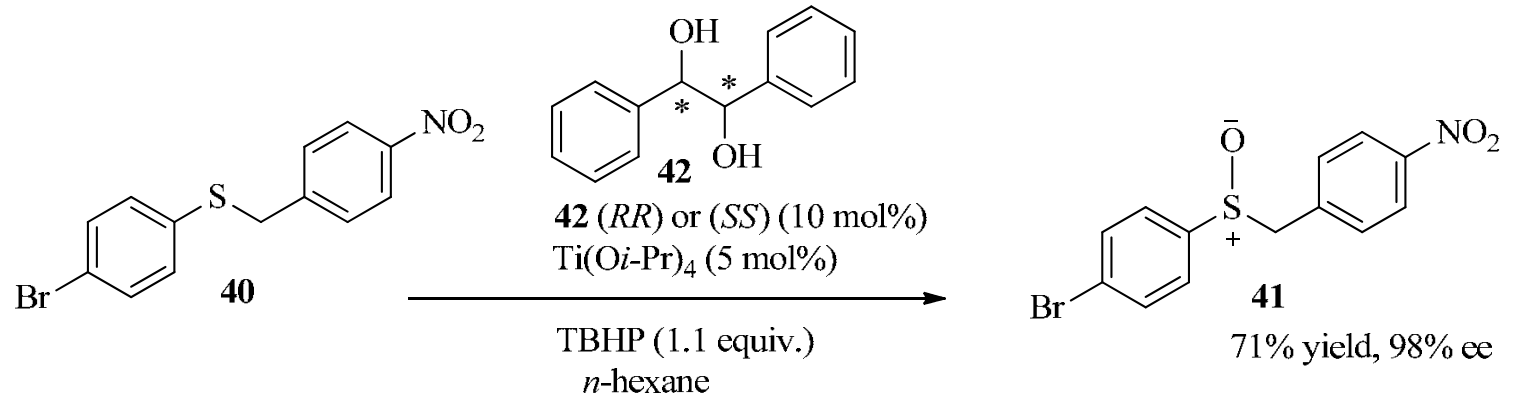

\section{Scheme 18}

The Modena oxidation method was re-investigated using a range of different oxidising reagents. ${ }^{52}$ High enantioselectivity was achieved using CHP or recyclable furyl hydroperoxides in the presence of reduced amounts of the titanium- DET complex.

The use of immobilised catalysts is attracting a lot of interest as it may impact favorably on the efficiency of the reaction, as well as addressing environmental concerns by enabling easy recycling of the catalyst and reducing waste. ${ }^{53}$ Iwamoto et al. carried out the Kagan methodology using a titanium catalyst which was immobilised on mesoporous silica. ${ }^{54}$ The results obtained were modest with only moderate enantioselectivity being observed. Considerably better results were reported by Gao et al. using a soluble PEG supported tartrate chiral auxiliary 45 (Scheme 19). ${ }^{55}$

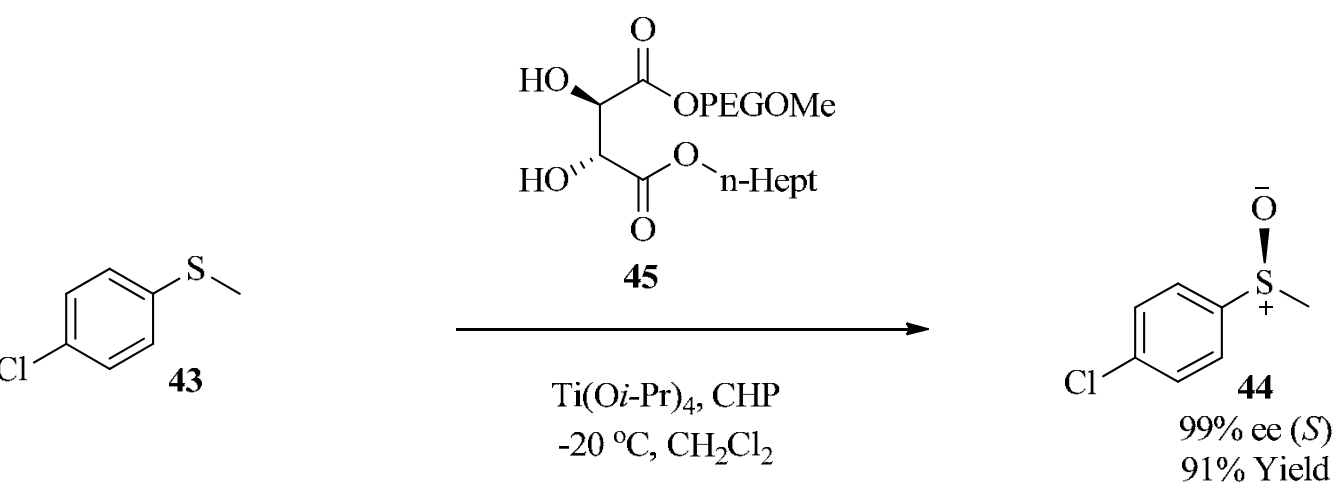

\section{Scheme 19}


Yuan et al. designed and synthesised a series of chiral Ti-1,1'-bi-2-naphthol coordination polymers and used them as catalysts. A range of sulfides were oxidised by this system, producing sulfoxides in excellent enantioselectivities, albeit in modest yield (Scheme 20). ${ }^{56}$

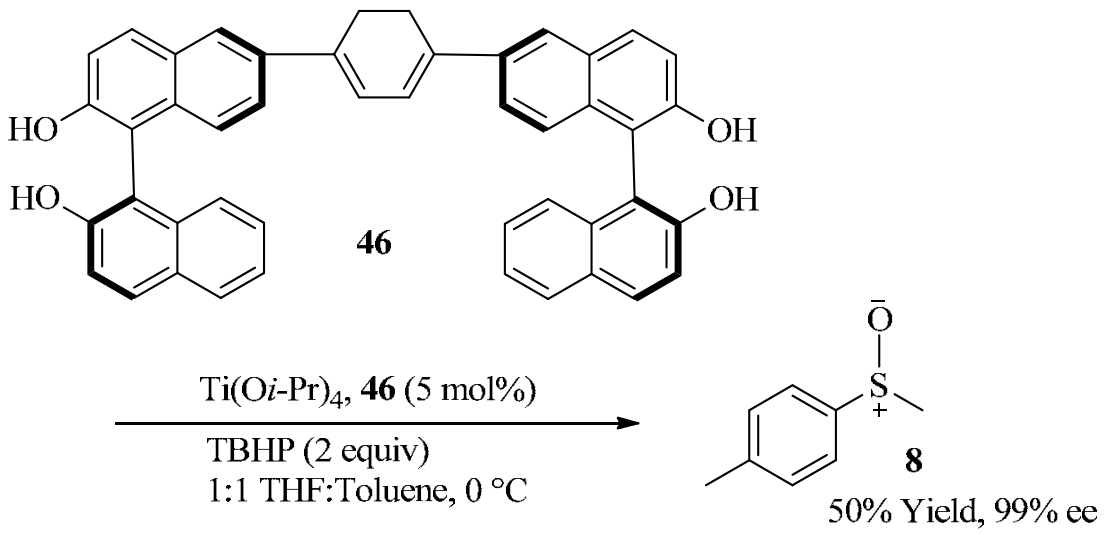

\section{Scheme 20}

Impressive results were reported by Sahoo et al. using an immobilised titanium-binol complex to prepare a variety of enantiopure aryl methyl sulfoxides. ${ }^{57}$ This asymmetric oxidation was accompanied by complementary kinetic resolution. The chiral catalyst was immobilised using an ionic liquid modified mesoporous silica SBA 15 support. Essentially enantiopure phenyl methyl sulfoxide was obtained using only $60 \%$ enantiopure catalyst using this system. The immobilized catalyst employed proved to be quite robust and could be recycled without any loss of either enantioselectivity or activity over one month.

Zeng et al. used a 2,10-camphanediol derived titanium complex 47 in the asymmetric oxidation of thioanisole 18 (Scheme 21). It was discovered that the absolute configuration of the predominant sulfoxide product depended on the amount of CHP that was used. $(R)$-19 was found to be the major isomer when $<1.2$ equivalents of CHP was used while $(S)$-19 was the major isomer when $>1.6$ equivalents of CHP was used. In contrast, however, the absolute configuration of the predominant sulfoxide product was always the same when TBHP was used as the oxidant. ${ }^{46}$ The asymmetric oxidation was accompanied by complimentary kinetic resolution, producing the sulfoxide 19 of thioanisole $\mathbf{1 8}$ in $99 \%$ ee but in poor yield due to formation of the sulfone $48 .^{35}$ 


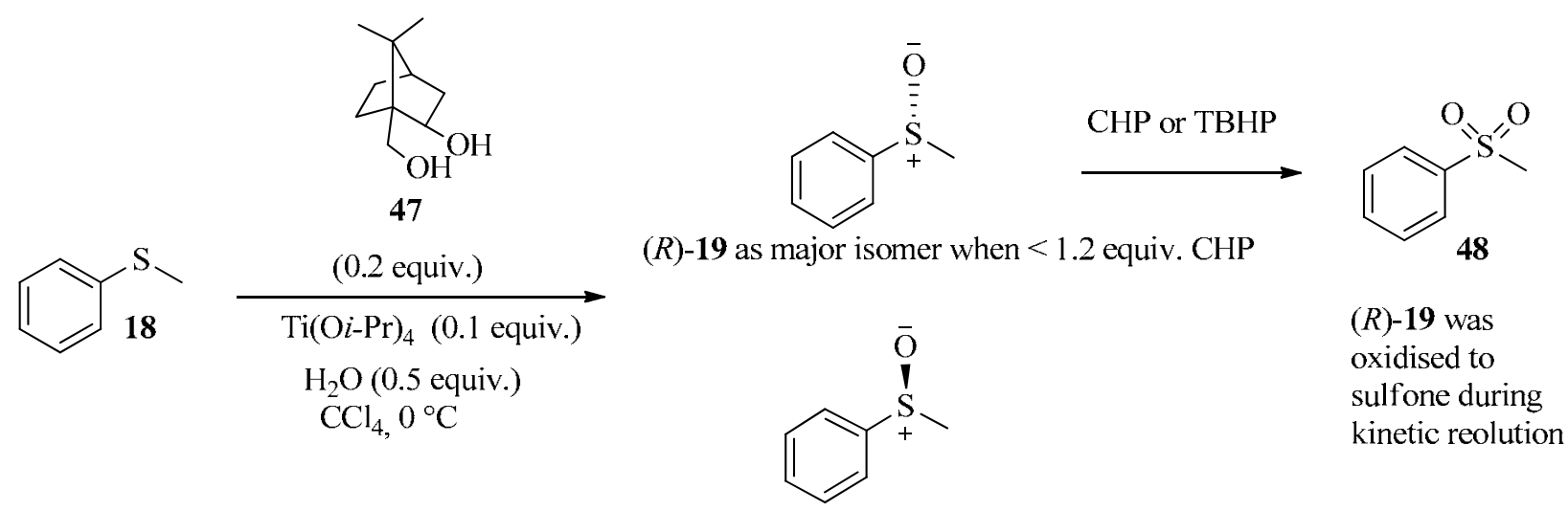

$(S)-19$ as major isomer when $>1.6$ equiv. CHP

\section{Scheme 21}

2.1.2 Vanadium catalyzed oxidation. After titanium, vanadium is the most popular metal catalysts in asymmetric sulfide oxidation. ${ }^{58}$ In one of the earliest reports of vanadium catalyzed sulfur oxidation, Modena successfully prepared racemic sulfoxides using TBHP as the oxidant and vanadyl acetylacetonate $\left[\mathrm{VO}(\mathrm{acac})_{2}\right]$ as the catalyst, identifying vanadium(IV) as the active oxidising species present. 59

Vanadium catalysts with Schiff base ligands. Vanadium was first successfully used in asymmetric sulfide oxidation by Fujita in the 1980s. ${ }^{60}$ Using a vanadium Schiff base complex 49 as the catalyst and CHP as the oxidant, enantiopurities of up to $40 \%$ ee were reported (Scheme 22). This oxidation proceeded in the presence of catalytic rather than stoichiometric amounts of the catalyst. The nature and preparation of the complexes has been investigated. ${ }^{61}$ The Schiff base ligands used were also used to form titanium Schiff base ligand complexes which were successfully used in asymmetric sulfide oxidation. ${ }^{62,63}$

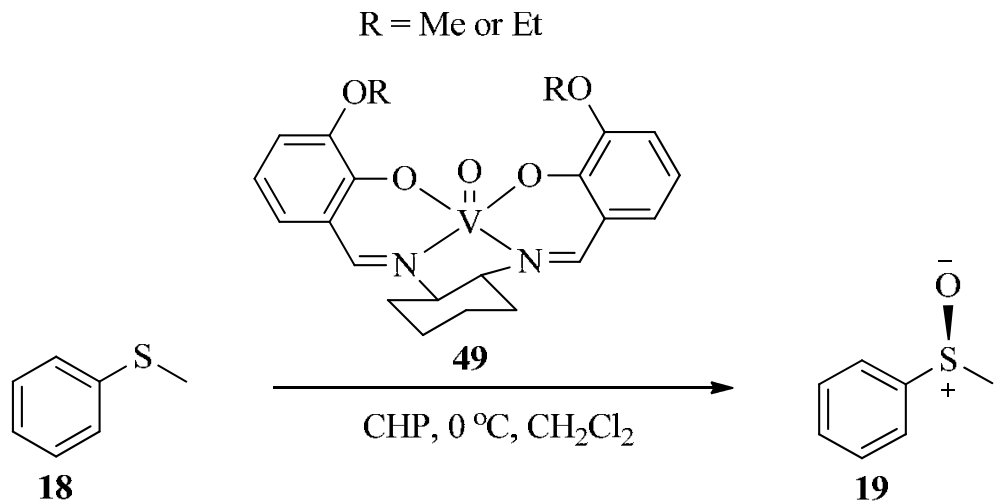

$40 \%$ ee $(S)$

\section{Scheme 22}


Later work on the vanadium Schiff base ligand catalysts involved the use of L-amino acids and salicylaldehyde to prepare the Schiff base. ${ }^{64}$ The results obtained using these complexes for the oxidation of thioanisole 18 were poor, with $14 \%$ ee being the highest enantioselectivity observed. The structures of this vanadium Schiff base ligand, complex 50, are shown below.

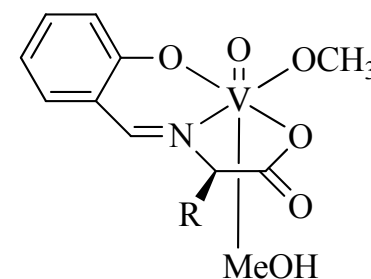

50 EXO

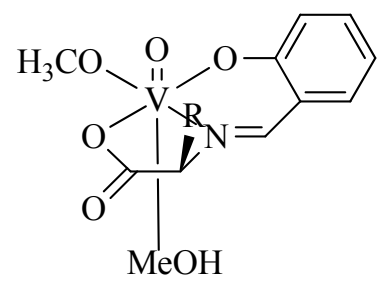

50 ENDO

Colonna et al. also used vanadium complexes similar to $\mathbf{5 0}$ to prepare racemic $\mathbf{8}$ in reasonable yield using TBHP as oxidant, although this was accompanied by significant sulfone formation $^{65}$.

Using slightly different Schiff base ligands, Bolm et al. reported a very significant improvement, with high levels of enantioselectivity achieved. Most significant was the use of atmospheric conditions for the oxidation, overcoming the extreme sensitivity associated with titanium catalyzed oxidations, and obviating the need for an inert atmosphere. The oxidation was catalyzed by a chiral vanadium Schiff base complex formed in situ by the reaction of $\mathrm{VO}(\mathrm{acac})_{2}$ and a Schiff base. The oxidant used was aqueous hydrogen peroxide, a cheap and environmentally benign oxidant. Asymmetric oxidation occurred even in the presence of 0.1 $\mathrm{mol} \%$ of the catalyst.

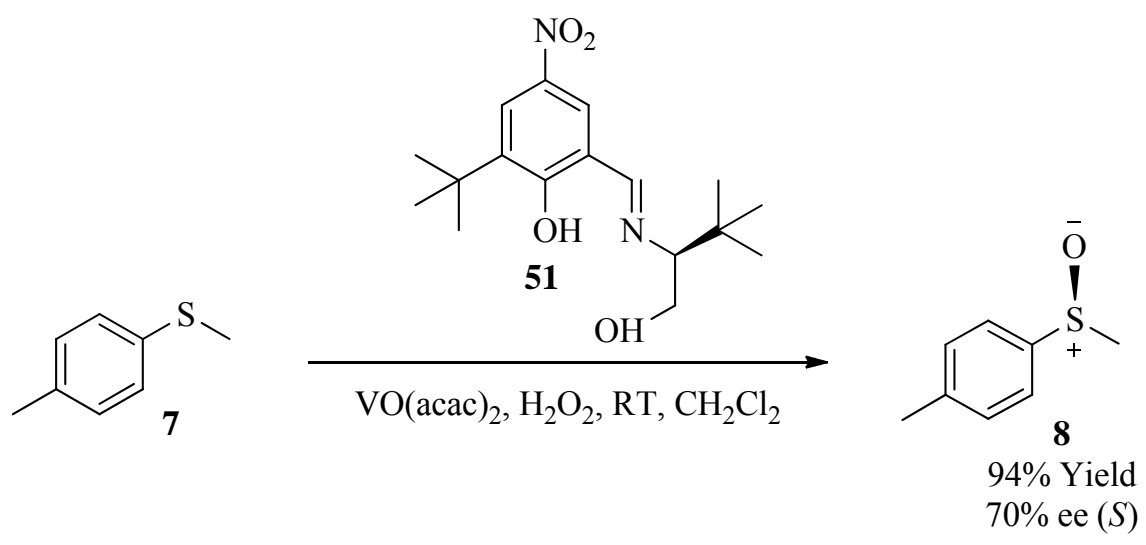

\section{Scheme 23}

This oxidation method is suitable for the asymmetric oxidation of a variety of sulfides including functionalised sterically hindered disulfides. ${ }^{67}$ 
Influence of ligand. The Schiff base ligands were easily formed by reacting the appropriate salicylaldehyde with enantiopure amino alcohols. ${ }^{58}$ In the absence of the ligand no oxidation takes place. The crucial role of the ligand has attracted considerable attention with many groups endeavouring to identify the optimum ligand for this synthesis. There are three positions in the ligand which are most suited to variation.

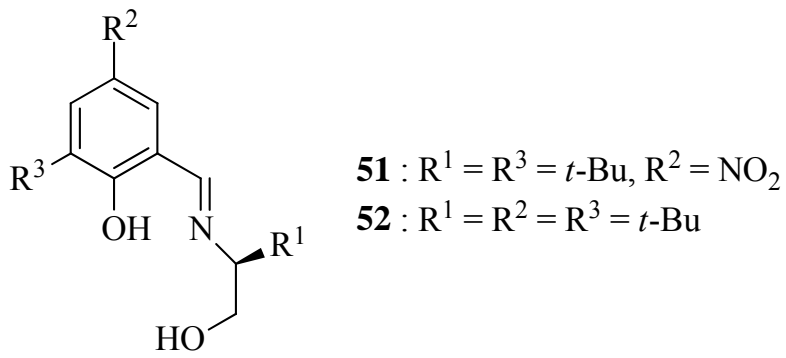

Bolm carried out a limited investigation into identifying the optimum ligand and results obtained indicated that the optimum ligand was substrate specific. ${ }^{66}$ Thus, the sulfoxide 19 of thioanisole 18 was obtained in $70 \%$ ee using 51, and in 59\% ee using ligand $\mathbf{5 2}$. However, oxidation of dithioacetal 53 produced the mono sulfoxide 54 in $76 \%$ ee using ligand 51 and $85 \%$ ee using ligand 52 (Scheme 24).
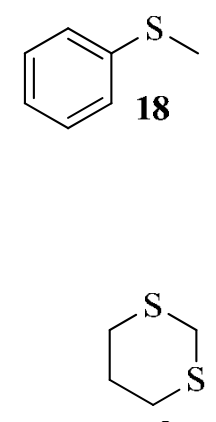

53
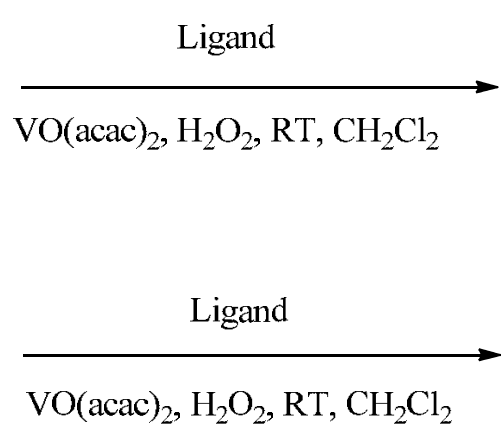

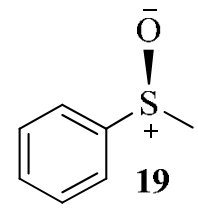

Ligand $\mathbf{5 1}-70 \%$ ee $(S)$

Ligand $52-59 \%$ ee $(S)$

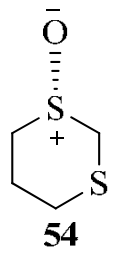

Ligand $51-76 \%$ ee $(S)$

Ligand 52 - 85\% ee $(S)$

\section{Scheme 24}

Ellman et al., investigating the asymmetric oxidation of tert-butyl disulfide $55,{ }^{68}$ carried out a more extensive study of the Schiff base ligands. ${ }^{69}$ It was found that when $\mathrm{R}^{1}=t$-butyl, optimal results were obtained. Investigations revealed that the substituent at $\mathrm{R}^{2}$ played no steric role in the oxidation, however the electronic effects of this substituent were important, for example when $\mathrm{R}^{2}=\mathrm{NO}_{2}$ or $\mathrm{OMe}$, there was a decrease in the enantioselectivity of the oxidation. Both the 
electronic and steric effects of $\mathrm{R}^{3}$ were significant. Overall, it was found that ligand $\mathbf{5 2}$ was the optimum ligand for the asymmetric oxidation of 55, Scheme 25.

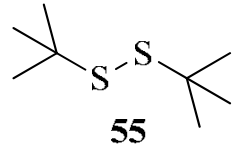

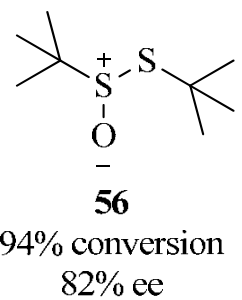

$82 \%$ ee

\section{Scheme 25}

A report by Maseras, based on computational studies and experimental results, confirms that the $\mathrm{R}^{2}$ substituent of the ligand has little or no effect on the enantioselectivity of the oxidation using this system for the oxidation of $55 .^{70}$ However, both $\mathrm{R}^{1}$ and $\mathrm{R}^{3}$ are critical to the selectivity of the oxidation, as these substituents are near the active site of the vanadium Schiff base oxidising complex. This report was based on the oxidation of 55 and only the steric effect of the ligand substituents was investigated.<smiles>CSc1ccccc1Br</smiles>

57

Berkessel carried out an extensive study of ligand structure while trying to optimise the asymmetric oxidation of thioanisole 18 and ortho-bromo thioanisole 57. ${ }^{71}$ Once again the optimum ligand was substrate specific with ligand 58 being the optimum ligand for the oxidation of 18, while ligand 59 was optimum for the oxidation of 57.
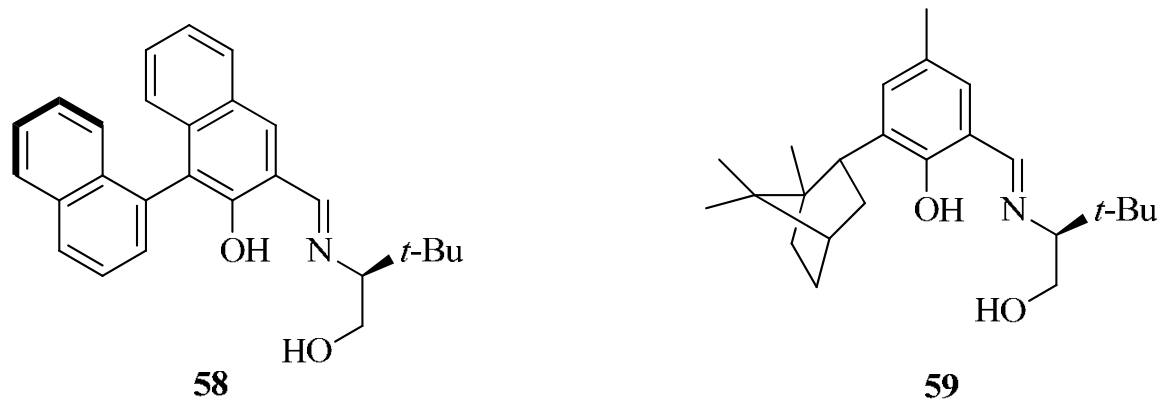

59

The most significant difference between the ligands used by Berkessel and those used by Ellman and Bolm is that the ligands used by Berkessel possess two elements of chirality. The 
extra chiral feature was found not to affect the stereoselectivity of the oxidation, and stereoselectivity was determined only by the chiral centre of the amino alcohol moiety.

Katsuki, encouraged by Berkessel's results, investigated more sterically hindered ligands, such as ligand 60, which gave the sulfoxide 19 of thioanisole 18 in $88 \%$ ee. $^{72}$

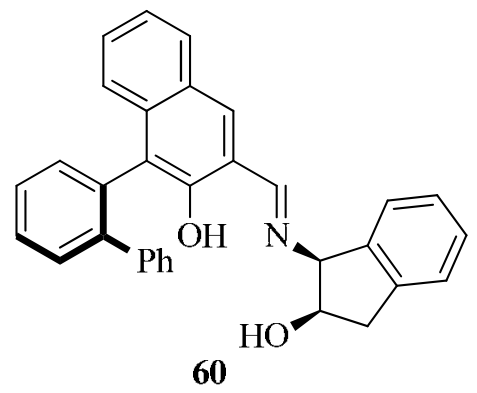

Jackson et al. utilised a solid phase array approach to identify the optimum ligand for the asymmetric oxidation of aryl alkyl sulfides. ${ }^{73}$ Synthesizing a variety of Schiff bases mounted on a Merrifield resin solid support, allowed screening of a large number of amino alcohols and salicylaldehydes. Ligands 61 and 62 were identified as the two best ligands. Ligand $\mathbf{6 1}$ has become the ligand of choice for this oxidation method and is also used in iron-Schiff base catalyzed oxidations. $^{74}$
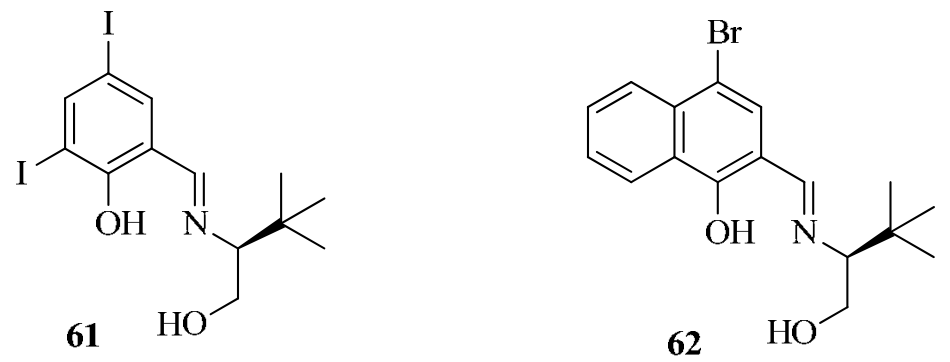

A number of Schiff base ligands were investigated by Maguire et al. for use in asymmetric oxidation of aryl benzyl sulfides. ${ }^{75,76}$ Ligand $\mathbf{6 1}$ gave the best results, with excellent enantioselectivities, which were achieved through a combination of asymmetric oxidation and complimentary kinetic resolution (Scheme 26).

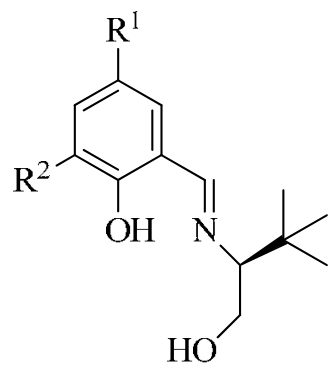

$61 \mathrm{R}^{\mathrm{I}}=\mathrm{I}, \mathrm{R}^{2}=\mathrm{I}$

$63 \mathrm{R}^{1}=\mathrm{Br}, \mathrm{R}^{2}=\mathrm{Br}$

$64 \mathrm{R}^{\mathrm{l}}=\mathrm{H}, \mathrm{R}^{2}=t$-Bu

$65 \mathrm{R}^{\mathrm{l}}=\mathrm{Cl}, \mathrm{R}^{2}=\mathrm{H}$ 


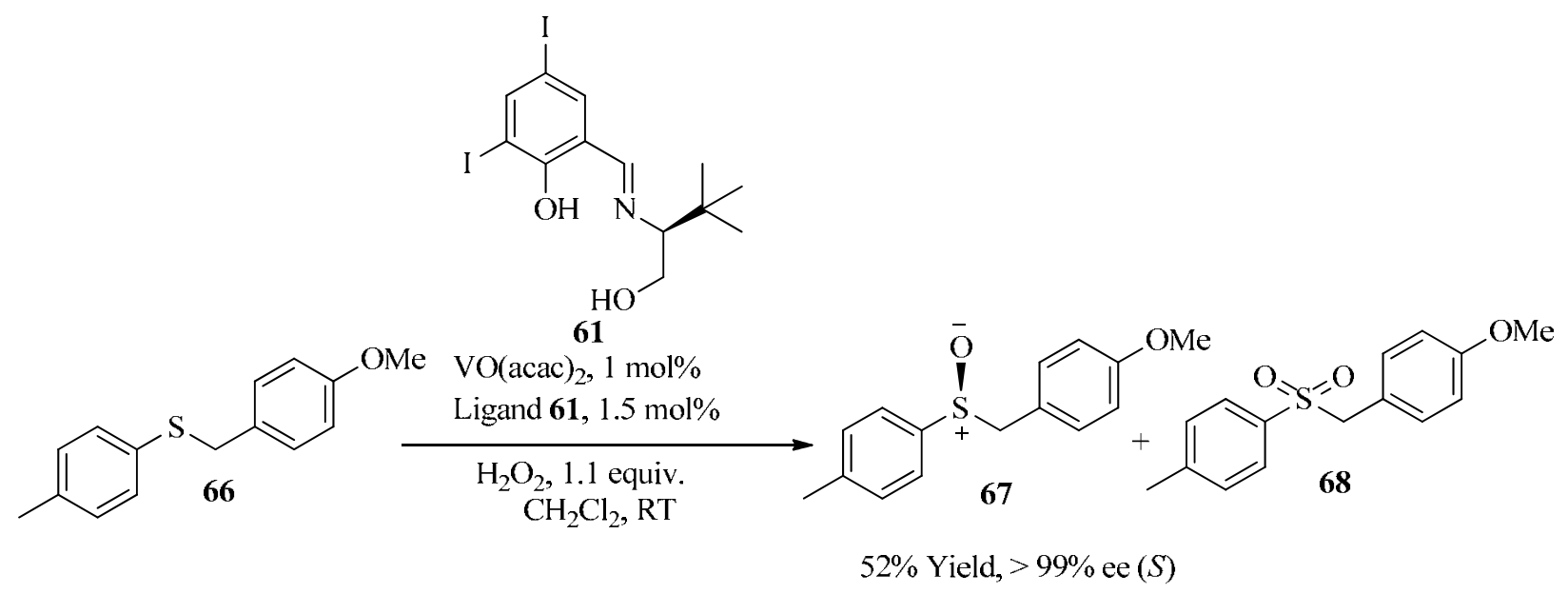

\section{Scheme 26}

From the results reported by Ellman, ${ }^{69}$ Bekessel $^{71}$ and Katsuki, ${ }^{72}$ it is clear that steric considerations are very important in ligand design. Ahn investigated sterically hindered ligands derived from BINOL, ${ }^{77}$ similar to those used by Berkessel and Katsuki. The best ligand identified, 69, was used to obtain the sulfoxide 19 in $90 \%$ yield and $86 \%$ ee.

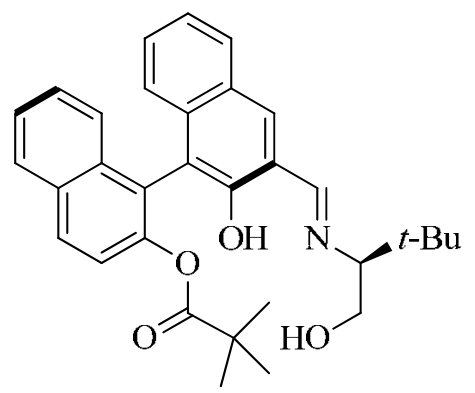

69

Ahn investigated the effect of a more sterically hindered amino acid in the Schiff base ligand, using ligand 70. ${ }^{78}$ No improvement was observed in the oxidation of 18, however, benzyl phenyl sulfoxide 13 was obtained in over $80 \%$ yield and $96 \%$ ee for both enantiomers. Interestingly, $(S)$ $\mathbf{7 0}$ produced $(R)-\mathbf{1 3}$, while $(R)-\mathbf{7 0}$ produced $(S)-\mathbf{1 3}$. 


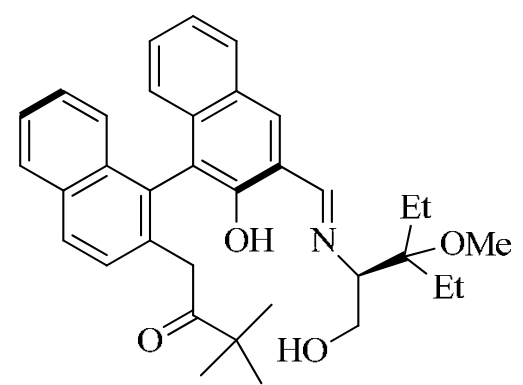

$(S)-70$

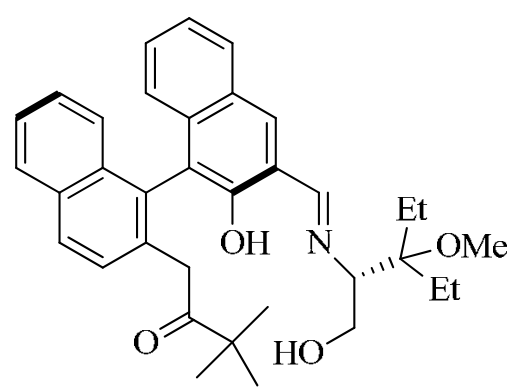

$(R)-70$

A report by Gao indicated that using (S)-valinol and the $i$-Pr substituted ligands $\mathbf{7 1}$ and $\mathbf{7 2}$, resulted in higher enantioselectivity than that achieved with their $i$-Bu analogues for the oxidation of thioanisole $18 .^{79}$<smiles>CCC[C@H](CO)N=Cc1cc(I)cc(I)c1O</smiles>

71<smiles>CC[C@H](CO)N=Cc1cc(Br)cc(Br)c1O</smiles>

72

Recently, Liu et al. investigated a series of salicylaldehyde derived Schiff base ligands for the asymmetric oxidation of aryl methyl sulfides. ${ }^{80}$ Ligand $\mathbf{7 5}$ gave the best result producing sulfoxide $\mathbf{7 4}$ in $85 \%$ yield and $90 \%$ ee (Scheme 27 ).<smiles>CC(C)(C)C(CO)N=Cc1cc(Br)cc(-c2ccc(Br)cc2)c1O</smiles><smiles>CSc1ccc2ccccc2c1</smiles>
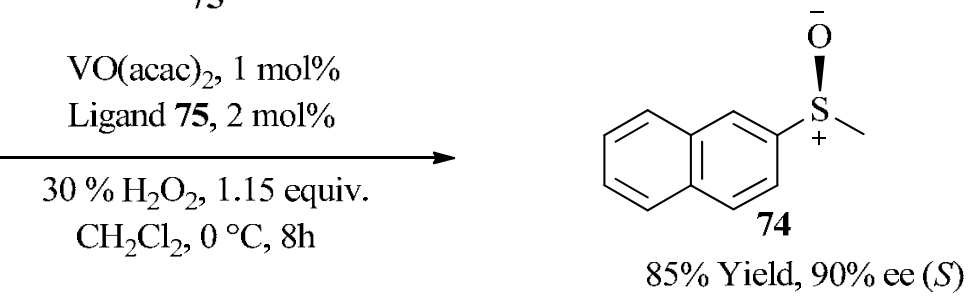

Scheme 27 
Liu et al. produced a novel chiral NOO-tridentate ligand $\mathbf{7 6}$ bearing a rigid tetrahydroquinoline framework, which was used in the oxidation of aryl methyl sulfides, producing sulfoxide 74 in $92 \%$ yield and $77 \%$ ee (Scheme 28$).{ }^{81}$

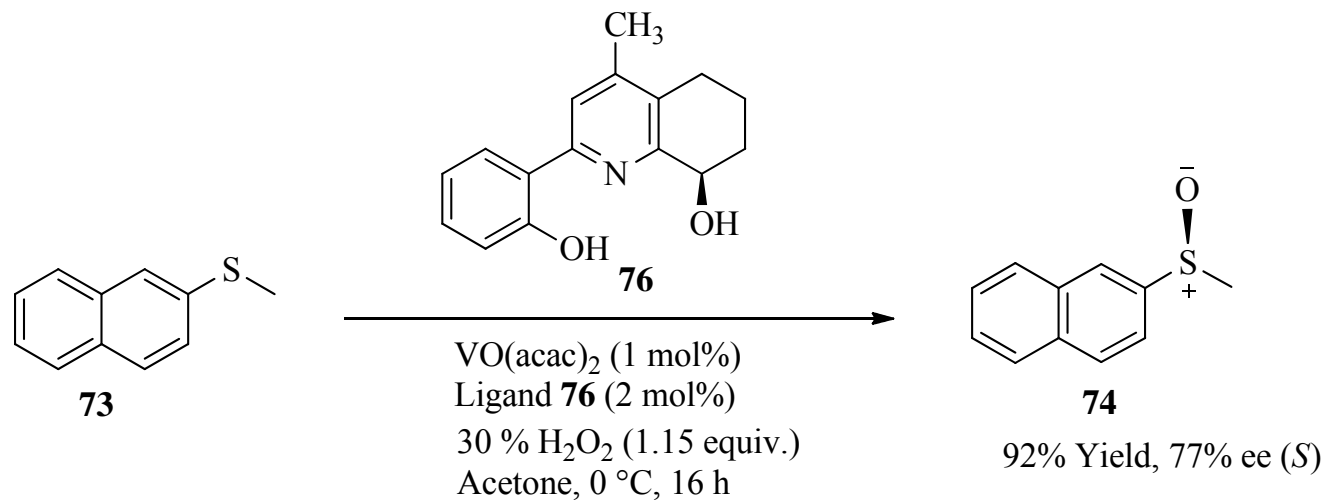

\section{Scheme 28}

Li et al. used Schiff base ligands with two stereogenic centers in the oxidation of aryl alkyl sulfides. Ligand 77 gave the best results, producing sulfoxide 19 in an $81 \%$ yield and $99 \%$ ee (Scheme 29). ${ }^{82}$ Complementary kinetic resolution was observed in oxidations using this ligand.<smiles>CCC(O)C(Cc1ccccc1)N=Cc1cc(I)cc(I)c1O</smiles>

77

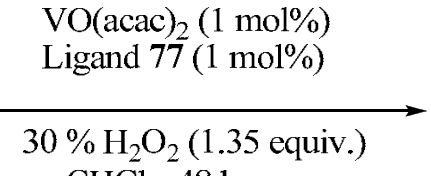

$\mathrm{CHCl}_{3}, 48 \mathrm{~h}$

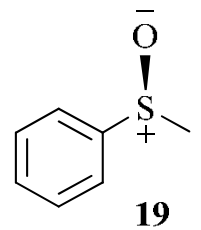

$81 \%$ Yield, $99 \%$ ee $(S)$

\section{Scheme 29}

Suresh et al. produced a series of trimeric variants of Bolm's original chiral vanadium salen catalysts (Figure 3). These $\mathrm{C}_{3}$-symmetric trinuclear Schiff bases were synthesised by condensing a variety of trialdehydes with optically active amino alcohols. 
<smiles>[R]c1cc([R])c(O)c(/C=N/C([R])CO)c1</smiles>

Bolm's vanadium Schiff base ligands

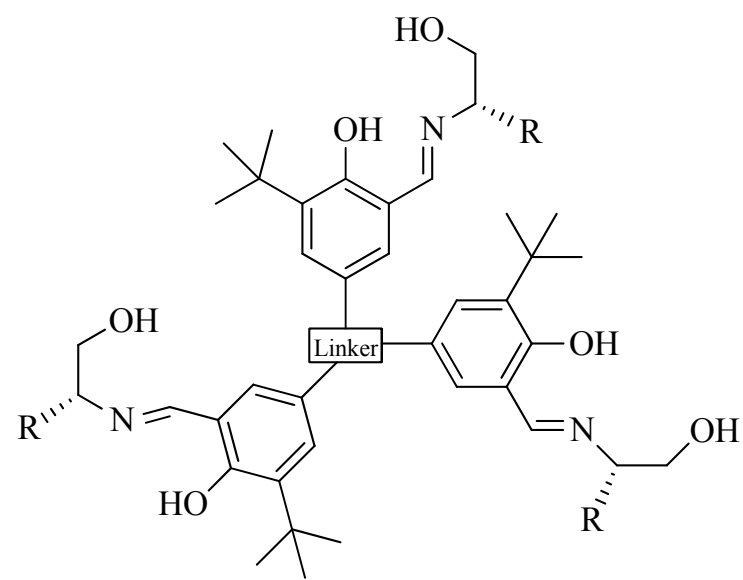

Trimeric variant of Bolm's catalyst

\section{Figure 3}

Ligand 78 was used in the oxidation of thioanisole 18, producing sulfoxide 19 in $92 \%$ yield and $70 \%$ ee (Scheme 30$){ }^{83}$
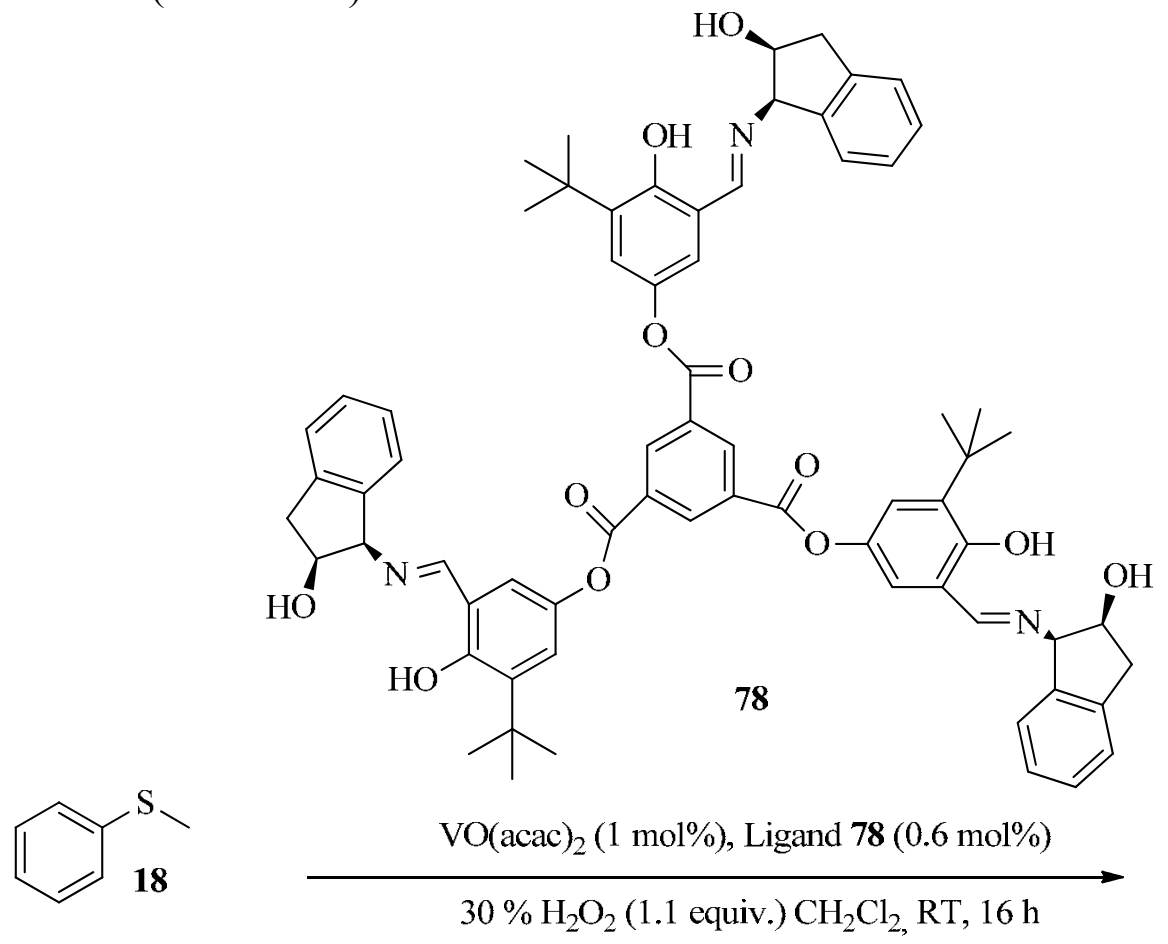

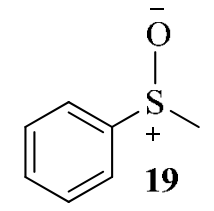

$92 \%$ Yield, $70 \%$ ee $(S)$

\section{Scheme 30}

Ligand 78 was also employed in the oxidation of 12 using the same conditions as outlined in Scheme 30, producing the sulfoxide 13 in $98 \%$ yield and $86 \%$ ee. 
Khiar et al. reported enantioselectivities of up to $96 \%$ ee oxidising thiosulfinates employing the carbohydrate derived ligand $79 .^{67}$<smiles>CC(C)(C)Cc1cc(C(C)(C)C)cc(C=N[C@H]2OC3CO[C@@H](c4ccccc4)OC3C2O)c1O</smiles>

79

Volcho et al. also investigated Schiff base ligands that possessed more than one chiral centre. ${ }^{13 \mathrm{~b}}$ The investigations employed $\alpha$-pinene and 3-carene derived Schiff base ligands (Figure 4). ${ }^{84,85}$ The results for the oxidation of thioanisole $\mathbf{1 8}$ using these ligands was modest. Interestingly, for the 3-carene derived ligand, the extent and direction of the enantioselectivity of the oxidation could be influenced by reaction temperature, while for the $\alpha$-pinene derived ligand the substituents on the aromatic ring could influence not only the extent but also the direction of enantioselectivity. It was speculated that these observations arise due to the existence of two distinct oxidative pathways.

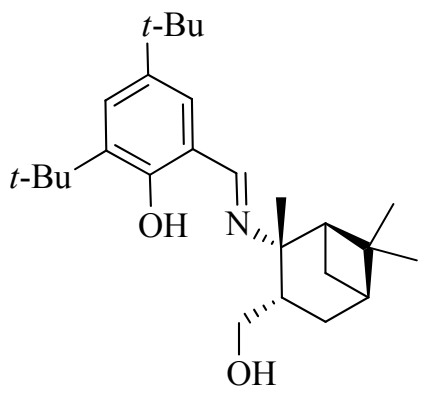

pinene ligand 80

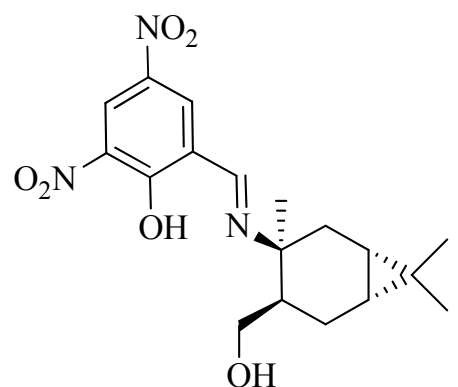

3-carene ligand 81

\section{Figure 4}

Barbarini et al. investigated the use of polymer supported vanadium Schiff base complexes. ${ }^{86}$ A number of Schiff base ligands were attached to polystyrene or polyacrylate backbones, and then reacted with $\mathrm{VO}(\mathrm{acac})_{2}$ to form the polymer supported complexes. For the oxidation of thioanisole 18, the highest enantiopurity reported was $61 \%$ ee, significantly poorer than those obtained using the 'free' vanadium Schiff base complex. However, the catalyst was recoverable and could be recycled up to four times without any significant loss in enantioselectivity or efficiency. A possible reason for this poorer enantioselection is that vanadyl acetylacetonate, in the presence of polystyrene, can catalyse non-enantioselective sulfide oxidation to the sulfoxide. The optimum supported Schiff base ligand identified was $\mathbf{8 2}$. 


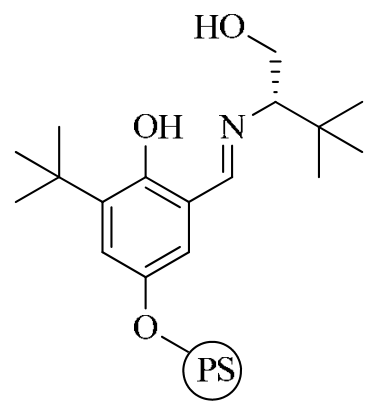

82

$\mathrm{PS}=$ polystyrene

Most procedures prepare the vanadium Schiff base ligand catalyst complex in situ and do not isolate the complex. In one report, Zeng and co-workers pre-formed and isolated a number of vanadium Schiff base ligand catalyst complexes, and subsequently employed them in asymmetric sulfide oxidation. ${ }^{87,88}$ The catalyst complex was prepared by heating the Schiff base ligand with $\mathrm{VO}(\text { acac })_{2}$ in methanol (Scheme 31 ).

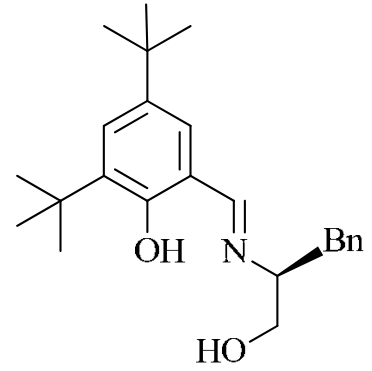

83

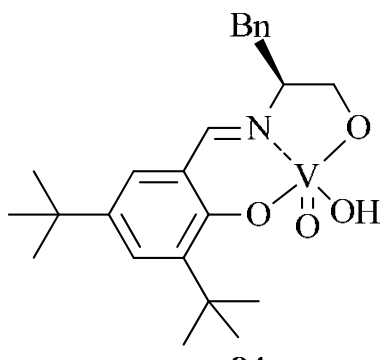

84

\section{Scheme 31}

Results obtained by Zeng using these pre-formed catalyst complexes were slightly superior to those obtained using in situ formed catalyst. ${ }^{12}$ The reason for this was attributed to the presence of unreacted $\mathrm{VO}(\mathrm{acac})_{2}$ in the reaction mixture, when the catalyst was formed in situ. Similar results were reported by Gau et al. employing pre-formed catalysts. ${ }^{89}$

Pre-formed catalyst complexes, using glucopyranose derived Schiff base ligands, were also investigated by Plass et al. ${ }^{90}$ Relatively poor enantioselectivity $(26 \%$ ee) was observed using these catalysts in the asymmetric oxidation of thioanisole $\mathbf{1 8 .}$

Romanoski et al. prepared and investigated pre-formed catalyst complexes using chiral diamine Schiff base ligands of the type shown in Figure 5 for the oxidation of thioanisole 18. ${ }^{91,92}$ Modest enantioselectivity was reported (up to $39 \%$ ee). ${ }^{92}$ 


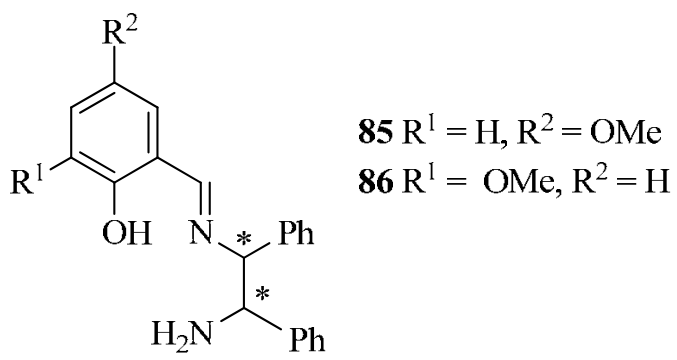

\section{Figure 5}

Influence of electronic effects of substituents of the sulfide. Investigations by Gao et al. indicated that the substituents on the aromatic ring of the sulfide can influence the enantioselectivity and efficiency of the asymmetric oxidations. ${ }^{79}$ These investigations showed that the presence of substituents such as the nitro group, resulted in a decline in the efficiency of the overall oxidation in terms of yield and enantioselectivity. Substituents, such as bromine, had the opposite effect (Scheme 32).
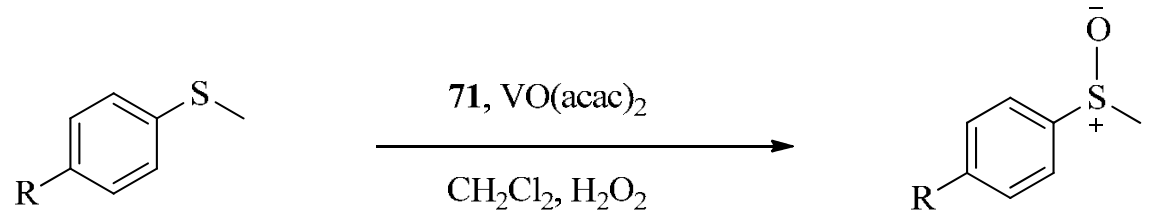

$19 \mathrm{R}=\mathrm{H}, 84 \%$ Yield, $88 \%$ ee

$27 \mathrm{R}=\mathrm{MeO}, 64 \%$ Yield, $70 \%$ ee

$87 \mathrm{R}=\mathrm{NO}_{2}, 51 \%$ Yield, $32 \%$ ee

$88 \mathrm{R}=\mathrm{Br}, 82 \%$ Yield, $92 \%$ ee

\section{Scheme 32}

This trend has been observed in other investigations, ${ }^{66,72,77,93}$ although to a lesser extent, indicating that the influence of the ligand is greater than that of the substituent on the aromatic ring of the sulfide. Interestingly, the report by Barbarini et al. employing a polymer supported ligand showed the opposite trend. ${ }^{86}$

Influence of solvent. Solvent is another variable that has been investigated. Bolm used dichloromethane as the solvent in his first report. ${ }^{66}$ Ellman found that using chloroform enhanced the enantioselectivity of the oxidation. The monosulfoxide $\mathbf{5 6}$ was obtained in $82 \%$ ee when the solvent was dichloromethane and $91 \%$ ee when chloroform was the solvent. ${ }^{68}$ Ellman also investigated acetonitrile, THF, carbon tetrachloride, toluene, tert-butyl alcohol and nitromethane, with inferior results compared to those obtained using either dichloromethane or chloroform. Katsuki et al. ${ }^{72}$, Liu et $a l .{ }^{80}$ and Li et al. ${ }^{82}$ also found dichloromethane, and chloroform to be superior to other solvents for this oxidation, confirming Ellman's results. 
A $2: 1$ toluene/dichloromethane solvent system was used by Gau et al. to oxidise thioanisole 18 using this system at $-20{ }^{\circ} \mathrm{C} .{ }^{89}$ This gave superior enantioselectivity (98\% ee) compared to dichloromethane $(90 \%$ ee), however, the yield obtained $(61 \%)$ was lower than when using dichloromethane (75\%). It should be noted that this work was carried out using pre-formed rather than in situ formed catalyst complexes.

Influence of temperature. A number of research groups investigated the influence of temperature on the enantioselectivity of the oxidation. Bolm's initial work undertook the oxidation at room temperature.66 Berkessel observed an increase in enantioselectivity carrying out the oxidation at $0{ }^{\circ} \mathrm{C} 71$ and Katsuki also reported similar results, 72 see Table 1.

Table 1. Results reported by Katsuki at different temperatures ${ }^{72}$

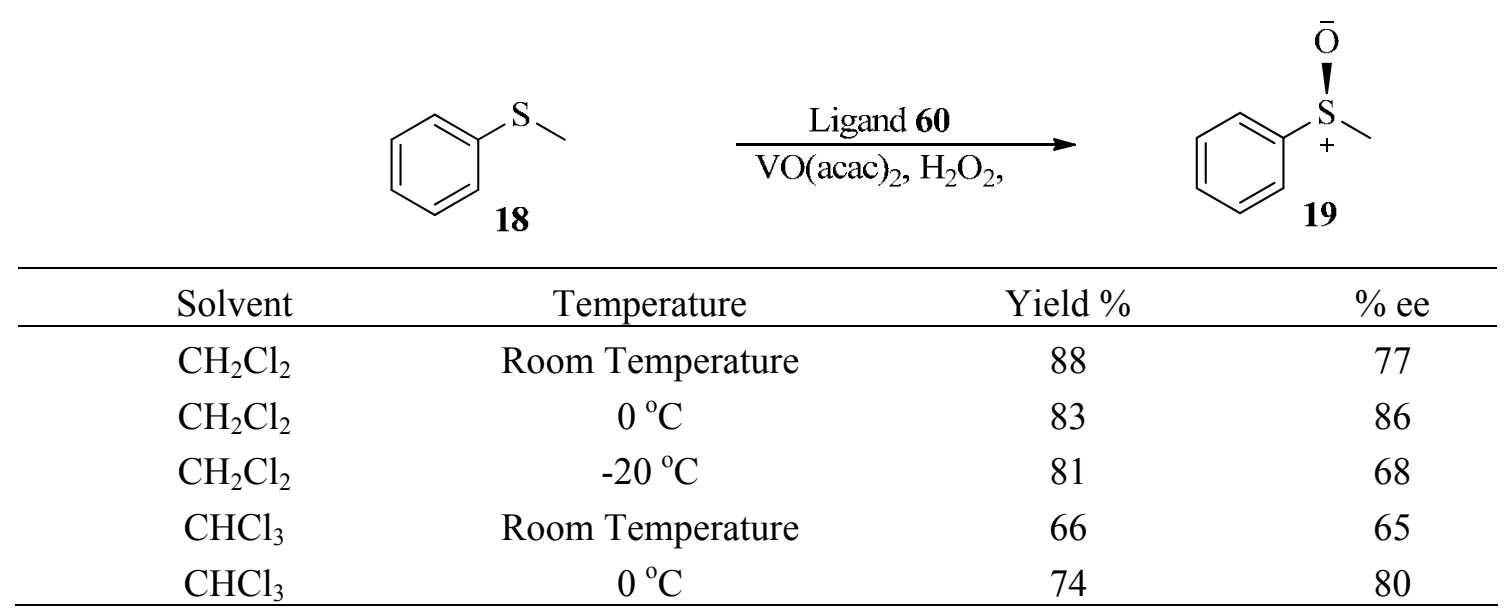

Gau et al. also reported increased enantioselectivity for the oxidation of thioanisole 18 with decreasing reaction temperature using pre-formed catalysts (Scheme 33). ${ }^{89}$

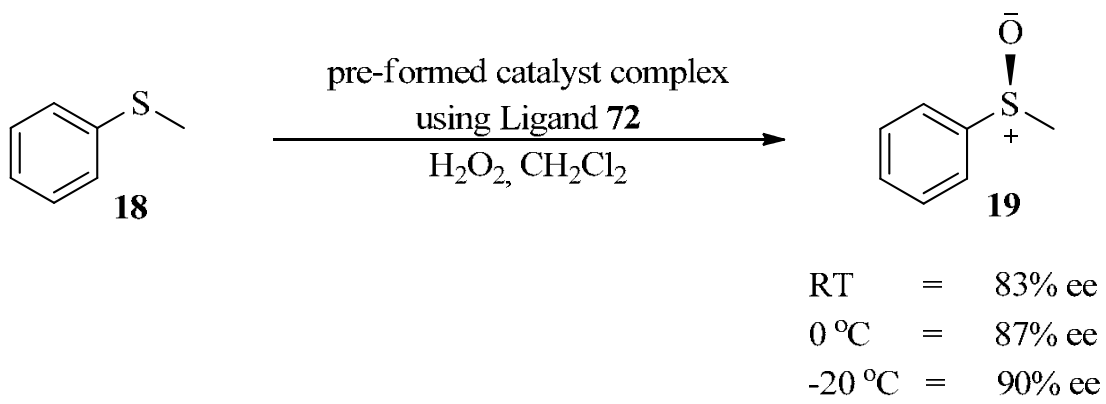

\section{Scheme 33}

Influence of rate of oxidant addition. The rate of addition of the oxidant has also been investigated for its impact on the enantioselectivity. In the first report using vanadium catalysts, the oxidant was added dropwise in one portion, since rapid addition resulted in an elevated 
reaction temperatures and led to overoxidation, forming the sulfone. ${ }^{66}$ Karpyshev et al. carried out a more extensive investigation, observing that rapid addition did cause an elevation in reaction temperature, albeit a small one $\left(<2{ }^{\circ} \mathrm{C}\right) .{ }^{94}$ It also led to reduced enantioselectivity and sulfoxide yield. They speculated that this was due to the increased presence of an achiral oxidising species formed by the rapid addition of the oxidising reagent. Using ${ }^{51} \mathrm{~V}$ NMR three principal vanadium complexes were identified in the oxidation reaction. ${ }^{94}$ Two of these complexes were identified as containing the ligand while the other complex was identified as the achiral oxidising species diperoxovanadium 89, as previously identified by Conte et al. ${ }^{95}$ The vanadium complex 89, $\left[\mathrm{VO}\left(\mathrm{O}_{2}\right)_{2}\right]$ - is a water soluble species, and it was confirmed by ${ }^{51} \mathrm{~V}$ NMR that its concentration increased when the oxidant was added rapidly. ${ }^{94}$

$$
\left[\begin{array}{c}
\mathrm{O}-\mathrm{O} \\
\mathrm{V}=\mathrm{O} \\
\mathrm{O}-\mathrm{O}
\end{array}\right]^{-}
$$

89

Ellman et al. investigated whether the effects seen due to different addition rates were influenced by the nature of the solvent. ${ }^{96}$ Oxidising 55 in chloroform, Ellman observed that fast addition of the oxidant did not impact on the enantioselectivity. In contrast, with solvents which are miscible with the oxidant, rapid addition of the oxidant produced racemic sulfoxide. This was attributed to the formation of the achiral vanadium species 89. Using these solvents, coupled with slow addition of oxidant, results in relatively high enantioselectivities $(>50 \%$ ee).

Nature of the catalyst. The exact nature of the oxidising complexes formed in this oxidation has yet to be fully elucidated. Bolm speculated that the oxidising species formed in this oxidation were vanadium(V) species having oxoperoxy groups $\mathbf{9 0} .{ }^{97}$

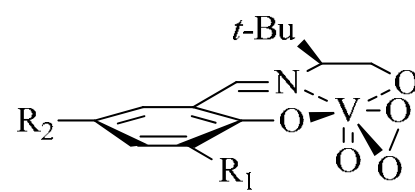

$90 \mathbf{a}$

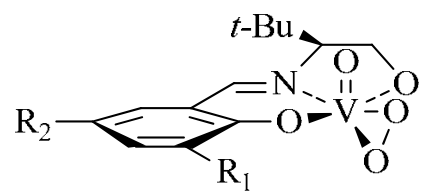

$90 \mathbf{b}$

Bryliakov conducted a more extensive investigation of the vanadium species formed using ${ }^{51} \mathrm{~V}$ NMR analysis and found that the monoperoxy species formed can exist in more than one form. ${ }^{98}$ Two principal species were proposed to be present in equilibrium with each other - an unchelated form 91 and a chelated form 92, in which the primary alcohol coordinates to the vanadium (Scheme 34). Due to the complicated NMR spectra obtained it was not possible to assign individual NMR signals to either 91 or 92. 


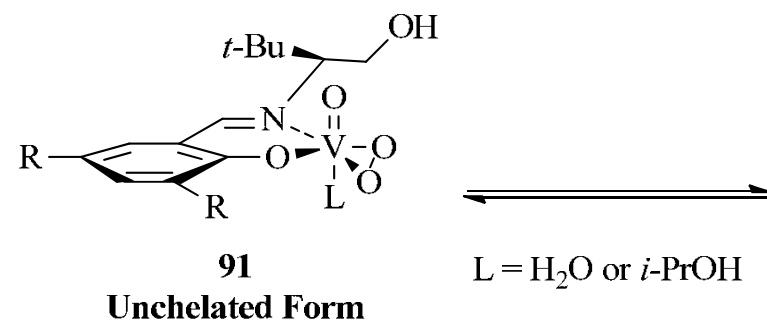

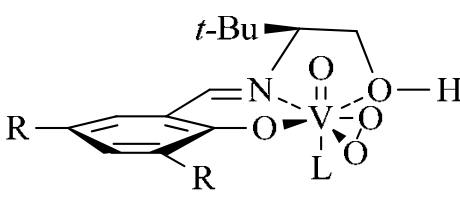

92

Chelated Form

\section{Scheme 34}

Ellman et al. proposed the formation of the vanadium ligand complex $\mathbf{9 3}\left(\mathrm{VOL}_{2}\right)$, which is then oxidised to form the chiral peroxy oxidising species 94 . This can be further oxidised to form the achiral diperoxy oxidising species 95, with loss of the chiral ligand (Scheme 35). ${ }^{96}$ This model suggests why rapid addition of the oxidant might lead to reduced enantioselectivity.

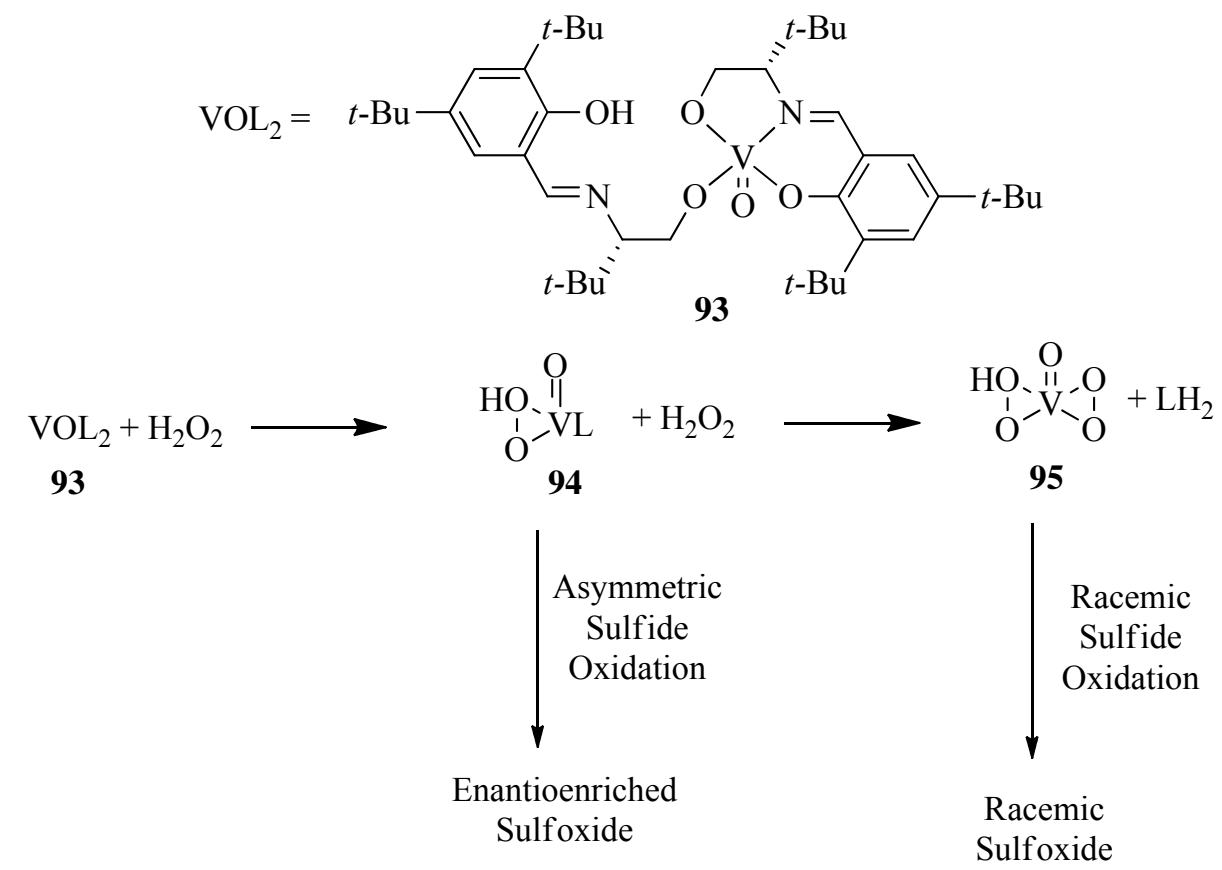

\section{Scheme 35}

Zeng et al. proposed a mechanism for this oxidation (Scheme 36) ${ }^{87}$ A peroxide molecule coordinates to the vanadium complex, followed by sulfide coordination to the vanadium, oxygen transfer from the peroxide to the sulfur, and dissociation of the sulfoxide product. The oxovanadium complex reforms and the catalytic cycle can continue. 


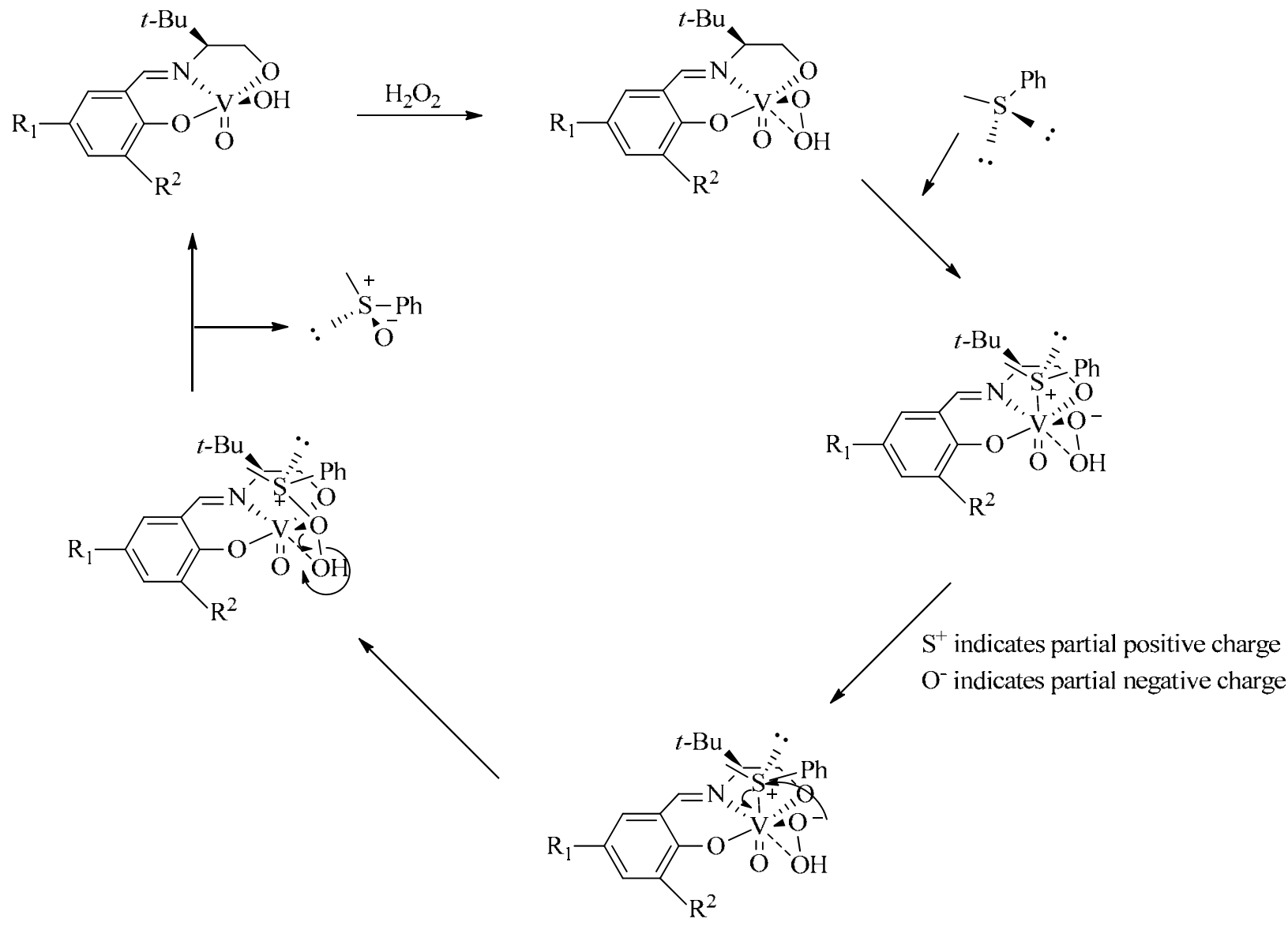

\section{Scheme 36}

The tert-butyl group, the $\mathrm{R}^{2}$ group and the nature of the sulfide are key to influencing which pair of electrons goes where - the greater this influence, the higher the enantioselectivity of the oxidation. This explains why higher enantioselectivity is observed when oxidising sulfides containing a naphthyl or a bulky group using this method. ${ }^{72}$ Thus, for ligand 58 developed by Berkessel, ${ }^{71}$ Zeng postulates the naphthyl groups limit the orientation of attack of the sulfide, improving the enantioselectivity of the oxidation, Figure 6.

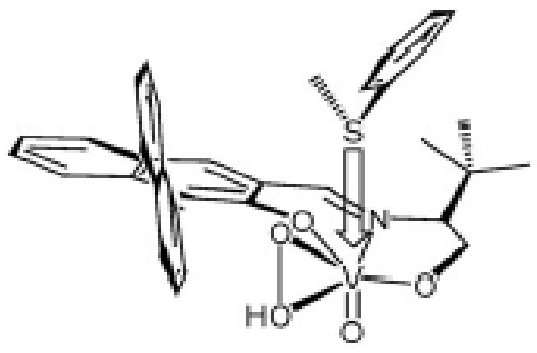

Figure 6. (reproduced from ref. 111 by permission of the Royal Society of Chemistry (RSC) for the Centre National de la Recherche Scientifique (CNRS) and the RSC) 
The rate-determining step is the coordination of the sulfide onto the vanadium complex. Studies by Ellman et al., using $\mathrm{H}_{2}{ }^{18} \mathrm{O}$, showed that the oxygen atoms of the sulfoxide and of the hydroxyl group in the oxovanadium complex come from the hydrogen peroxide, in agreement with Zeng's mechanism.

Zeng observed a dramatic drop in enantioselectivity using the sterically hindered ligand 96, ${ }^{87}$ which can be attributed solely to the presence of the phenyl groups. This suggests that the equilibrium between the unchelated 91 and chelated 92 forms of the vanadium complex proposed by Bryliakov is unlikely. However, it is also possible that $\mathbf{9 6}$ is simply not capable of asymmetric sulfide oxidation.

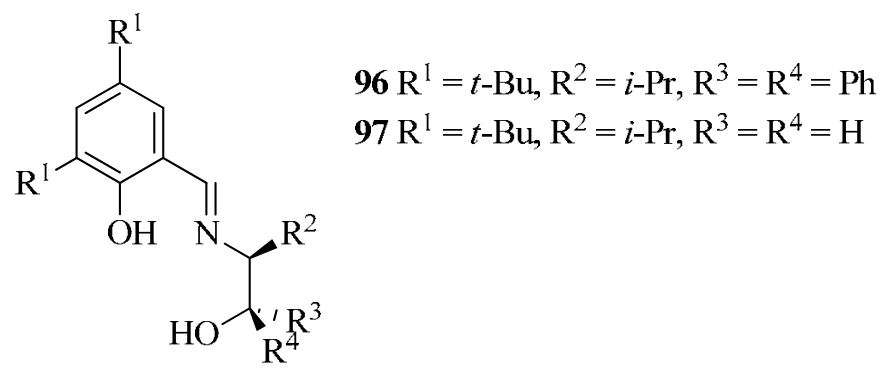

Maseras et al. proposed that there were two diastereomeric forms of the catalyst complex 90a and 90b both of which can oxidise sulfides, though with opposite stereoselectivity. ${ }^{70}$ Hence, there are two pathways in this reaction, one leading to the major sulfoxide enantiomer and the other to the minor sulfoxide enantiomer.

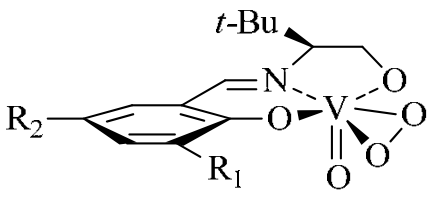

$90 \mathbf{a}$

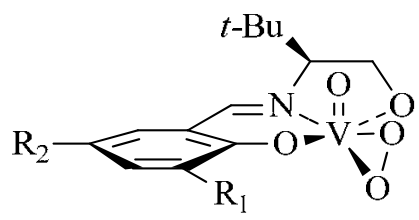

90b

The stereoselectivity of the oxidation is determined by the configuration of 90, i.e. employing a ligand derived from the $S$ tert-butyl amino alcohol leads to a stereo-outcome opposite to that which is observed employing the same ligand derived from the $R$ tert-butyl amino alcohol. The $\mathrm{R}^{1}$ substituent in $\mathbf{9 0}$ plays a role in the stability of the catalyst complex and is critical in determining which diastereomer predominates. Whichever form of the diastereomer predominates will influence the enantioselectivity of the oxidation, i.e. if the pro- $S$ form of the diastereomer predominates, the $S$ sulfoxide will be predominantly formed. It was found for the oxidation of 55 (tert-butyl disulfide) that as the steric bulk of $\mathrm{R}^{1}$ diminished, so too did the enantioselectivity of the oxidation. This was attributed to the possibility that both diastereomers of the oxidising complex were now of similar stability, so the extent to which one diastereomer form predominates over the other is reduced, hence lower enantioselectivity in the sulfide oxidation. Reducing the steric bulk of the $\mathrm{R}^{2}$ substituent had little effect on the enantioselectivity 
of the oxidation of 55. This was attributed to the fact that the $\mathrm{R}^{2}$ substituent is far away from the active site of the diastereomer unlike $\mathrm{R}^{1}$ and the tert-butyl group, so naturally it exerts a smaller effect on oxidation than the $\mathrm{R}^{2}$ substituent. Only the steric influence of $\mathrm{R}^{1}$ and $\mathrm{R}^{2}$ of the ligand was investigated during this study and only one substrate, 55 tert-butyl disulfide, was screened, accordingly the results of this study cannot be regarded as applicable to all ligands and substrates.

Influence of additives. Katsuki was the first to report an enhancement in the enantioselectivity attributable to the presence of an additive in the oxidation. ${ }^{72}$ Carrying out the oxidation of thioanisole $\mathbf{1 8}$ in the presence of a small amount of methanol at room temperature, Katsuki observed a slight improvement in enantioselectivity. Oxidising 18 at $0{ }^{\circ} \mathrm{C}$ in dichloromethane, the enhancement of enantiopurity due to the presence of methanol was up to $2 \%$. At $-20{ }^{\circ} \mathrm{C}$ the improvement was $15 \%$. The enantioselectivity was enhanced by up to $8 \%$ ee when the solvent was chloroform with a small amount of methanol. This enhancement was seen both at room temperature and at $0^{\circ} \mathrm{C}$. Katsuki surmised the enhancement of enantioselectivity in the presence of methanol was due to its donor effects, which may affect some of the peroxo-vanadium oxidising species present.

Investigations by Gao found that carrying out the vanadium catalyzed oxidation in the presence of 4-methoxybenzoic acid or a number of its salts did not enhance the enantioselectivity. ${ }^{79}$ This is in contrast to Bolm's observations with iron Schiff base catalyzed reactions. ${ }^{74 c, 74 d}$ Bolm attributed the improved efficiency and enantioselectivity to the formation of a monocarboxylate bridged diiron complex. ${ }^{74 \mathrm{~d}}$ Gao proposed that the analogous divanadium complex probably cannot form, and thus there is no improvement in enantioselectivity.

Vanadium salen catalysis. In 2004 Zhu reported that enantioenriched sulfoxides could be successfully prepared by oxidising sulfides in the presence of a vanadium salen complex. ${ }^{99}$ After screening a number of salen ligands, ligand $\mathbf{9 8}$ was found to be the optimum ligand for this oxidation method.

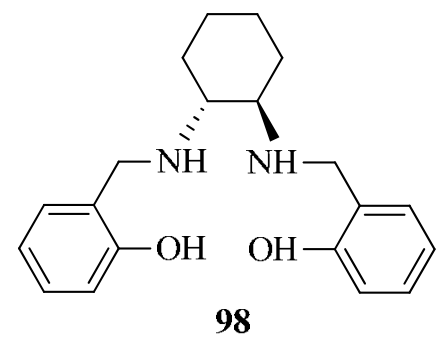

This ligand formed a complex with vanadyl acetylacetonate, which catalyzed asymmetric sulfide oxidation. The oxidant used was hydrogen peroxide. The enantioselectivity of the oxidation was very impressive with the sulfoxide 19 of thioanisole 18 obtained in $81 \%$ yield and 95\% ee. The mechanism proposed involved the nucleophilic attack of the sulfide on the 
vanadium salen complex to form an intermediate (Scheme 37). The reaction of this intermediate with hydrogen peroxide forms the sulfoxide and regenerates the vanadium salen complex.
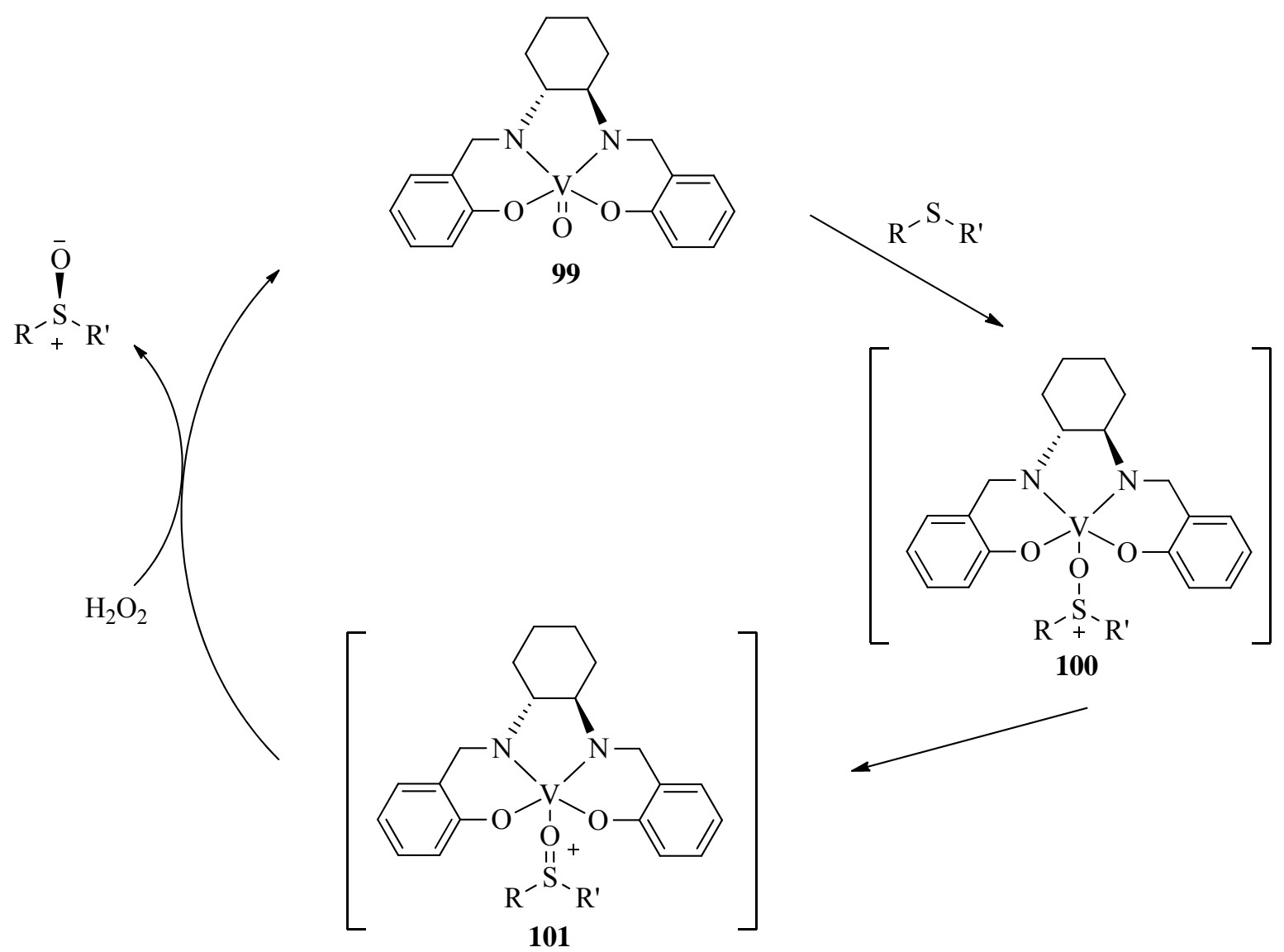

\section{Scheme 37}

2.1.3 Iron catalyzed oxidation. Ideally, in catalysis the catalyst used would be cheap and nontoxic, hence iron is attractive among the transition metals. Iron catalysts have been successfully used in asymmetric sulfide oxidation.

Groves and Viski used vaulted naphthyl metalloporphyrins $\mathbf{1 0 2}$ in a variety of asymmetric reactions, one of which was an asymmetric sulfide oxidation. ${ }^{100}$ The results of this oxidation, which employed iodosylbenzene as the oxidant, were modest in terms of enantioselectivity with methyl ortho-bromophenyl sulfoxide 103 being obtained in $74 \%$ yield with $48 \%$ ee. The sulfoxide 19 of thioanisole 18 was obtained in $84 \%$ yield with $24 \%$ ee. 


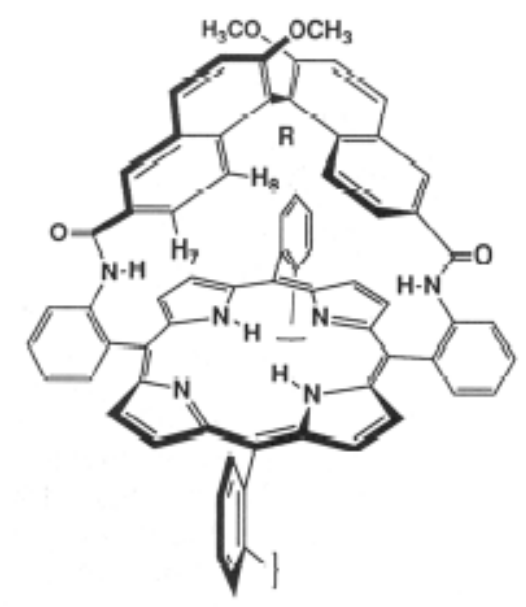

102 (re-produced from ref. 124)<smiles>C[S+]([O-])c1ccccc1Br</smiles>

103

Naruta et al. reported an enantioselective iron catalyzed sulfide oxidation. ${ }^{101,102}$ The method utilised iron complexes of 'twin coronet' porphyrins as the catalyst and iodosylbenzene as the oxidant.
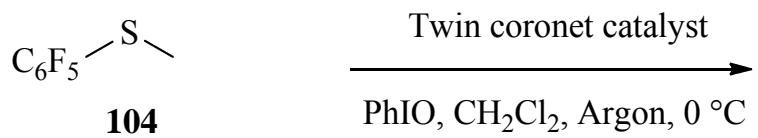

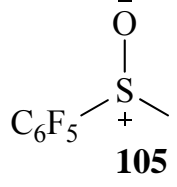

$31 \%$ ee

\section{Scheme 38}

A dramatic improvement occurred when the reaction was conducted in the presence of 1methylimidazole at $-15{ }^{\circ} \mathrm{C}$, with pentafluorophenyl methyl sulfoxide 105 being obtained in lower yield but much higher enantiopurity, $73 \%$ ee. The 1-methylimidazole was believed to coordinate to the active metal centre and enhance enantioselectivity by changing the porphyrin structure around the iron and preventing decomposition of the catalyst.

Inoue also successfully used iron porphyrins and reported similar results, with the enantioselectivity considerably enhanced when the oxidation was carried out in the presence of imidazole. ${ }^{103}$ Methoxymethyl phenyl sulfoxide 107 was obtained with $71 \%$ ee while 105 was obtained in $36 \%$ ee. 


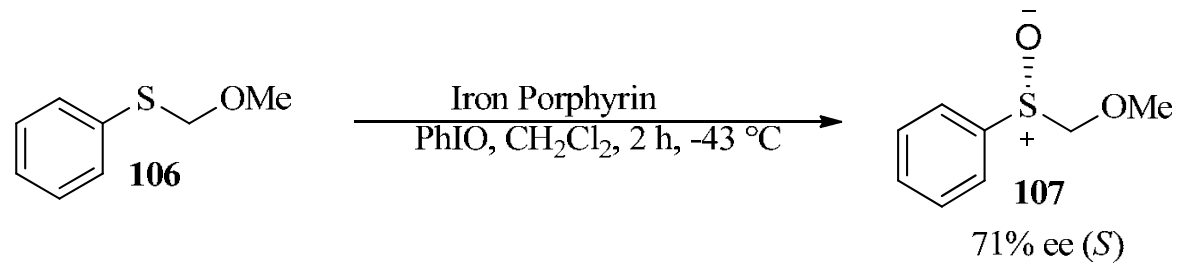

\section{Scheme 39}

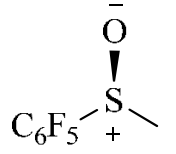

105

$36 \%$ ee $(S)$

Bryliakov reported modest enantioselectivity using the iron complex $\mathbf{1 0 8}$ and established that the active species is an iodosylbenzene(salen)-iron(III) complex. ${ }^{104}$ Identification of the active species will possibly enable further improvement of this method.

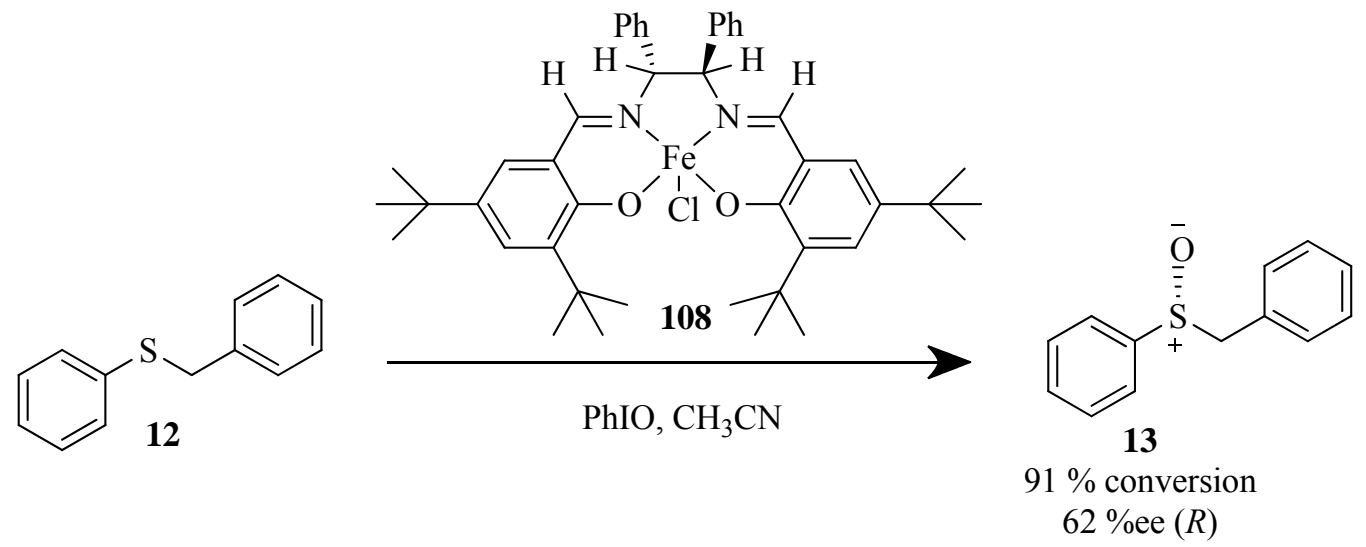

\section{Scheme 40}

In 2003 Bolm reported that the Schiff base ligands developed for vanadium were also successful with iron. ${ }^{66}$ This iron catalyzed oxidation is very practical and robust, using readily available reagents, such as aqueous hydrogen peroxide, and the reaction is performed in air, without an inert atmosphere.

The oxidation reported by Bolm involves the in situ formation of an iron Schiff base catalyst followed by the addition of the sulfide and then the oxidising agent. Initial results obtained using this method were modest in terms of chemical yield but enantioselectivity was high. 


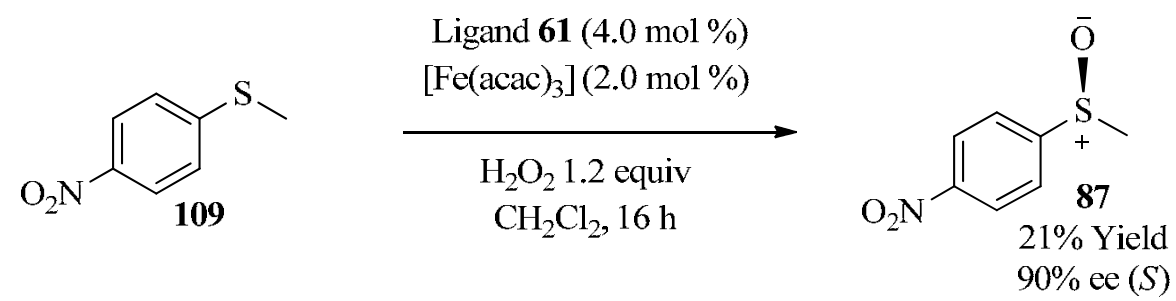

\section{Scheme 41}

The effect of carrying out the oxidation in the presence of an additive was found to have a beneficial effect on the enantioselectivity of the oxidation. ${ }^{74 \mathrm{c}, 74 \mathrm{~d}}$ Carrying out the oxidation in the presence of 4-methoxybenzoic acid or the lithium salt of 4-methoxybenzoic acid resulted in improvements in both enantioselectivity and yield. For example, $\mathbf{8 7}$ was isolated in a yield of $36 \%$ and $96 \%$ ee when the oxidation was carried out in the presence of the lithium salt of 4 methoxybenzoic acid. Enantioenriched Sulindac has been successfully prepared using this iron catalyzed asymmetric sulfide oxidation. ${ }^{74 a}$

Katsuki and Egami used a novel chiral Fe (salen) complex 110 for asymmetric oxidation of sulfides using hydrogen peroxide in water. ${ }^{105}$ This method was used to oxidize both alkyl aryl and methyl alkyl sulfides (Scheme 42).

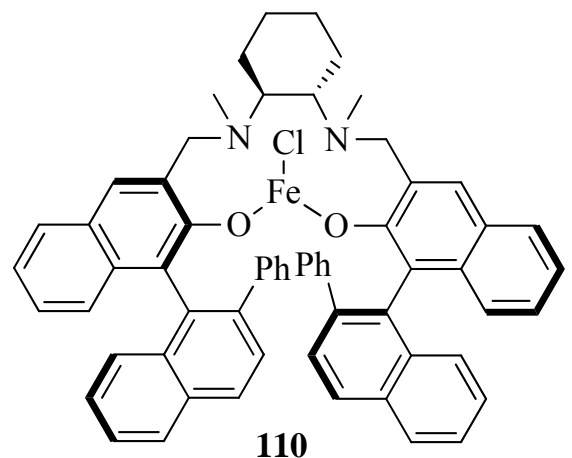

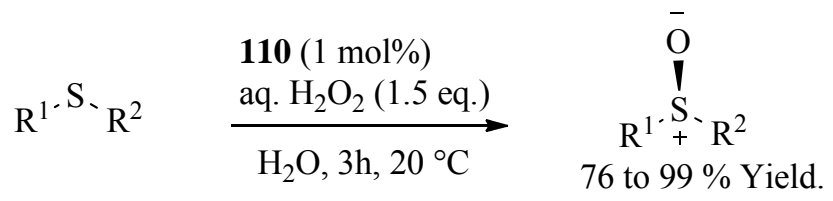

$$
\begin{aligned}
& \mathrm{R}^{1}=\text { aryl or alkyl } \quad \mathrm{R}^{1}=\text { aryl } 81-96 \% \text { ee }(S) \\
& \mathrm{R}^{2}=\mathrm{Me} \quad \mathrm{R}^{1}=\text { alkyl 87-94 \%ee }(S)
\end{aligned}
$$

\section{Scheme 42}


2.1.4 Manganese catalyzed oxidation. Manganese has been successfully used in asymmetric sulfide oxidation. Like titanium, manganese catalysts have been successfully used in asymmetric epoxidation reactions. ${ }^{105 c}$ Jacobsen was first to successfully use a manganese catalyst in asymmetric sulfide oxidation using complex 111 that exhibited highly selective asymmetric epoxidation. ${ }^{106}$ Results were encouraging in that enantioselectivity was observed, but overall the enantioselectivity was poor.

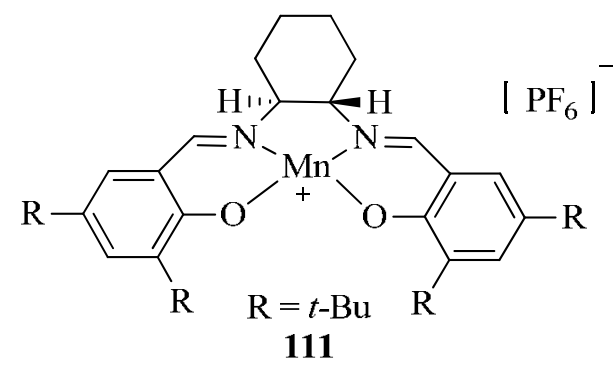

Work by Katsuki using a different manganese-salen catalyst 112a resulted in much improved enantioselectivity. ${ }^{107,108}$ Surprisingly the diastereomer of this complex 112b exhibits only poor enantioselectivity.

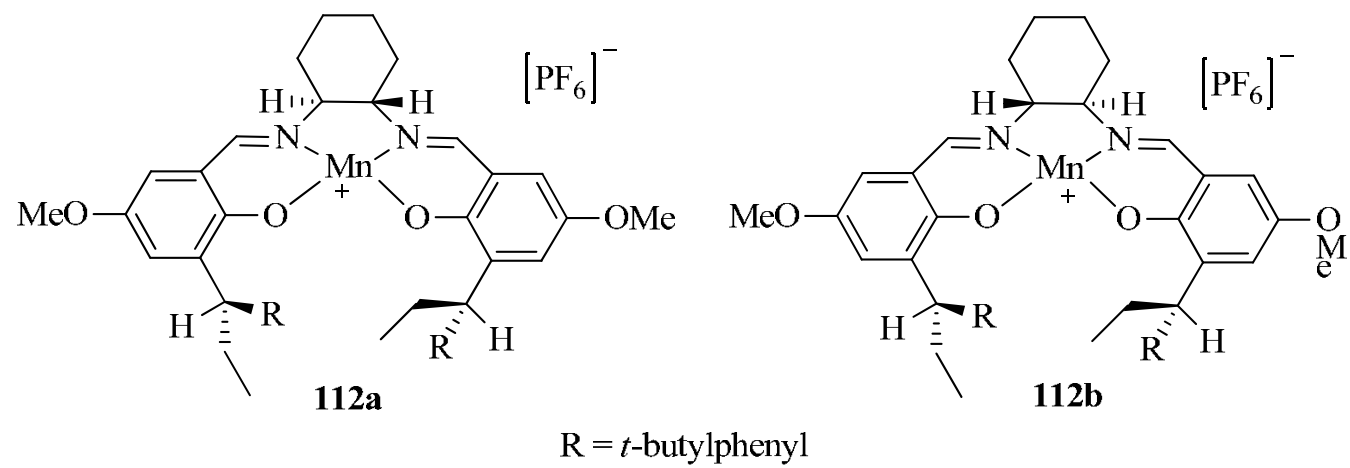

Different oxidants were evaluated by Katsuki, and overall iodosylbenzene (PhIO) was found to be the optimum oxidising agent (Scheme 43).<smiles>CSc1ccccc1[N+](=O)[O-]</smiles>

113 $\underset{0.01 \text { equiv Catalyst 112a, } \mathrm{CH}_{3} \mathrm{CN}}{\stackrel{\mathrm{PhIO}(1 \text { equiv }),-20^{\circ} \mathrm{C}, 1 \mathrm{~h}}{\longrightarrow}}$<smiles>C[SH]([O-])c1ccccc1[N+](=O)[O-]</smiles>

114

$51 \%$ Yield $90 \%$ ee

\section{Scheme 43}


The result obtained in oxidising 113, $90 \%$ ee, was described by Katsuki as the highest enantioselectivity obtained at the time using exclusively asymmetric sulfide oxidation. ${ }^{105 c}$ Further work by Katsuki resulted in the preparation of a new manganese complex 115, that enhanced the enantioselectivity of the oxidation with $\mathbf{1 1 4}$ being obtained in almost quantitative yield in $94 \%$ ee at room temperature. ${ }^{109}$ Katsuki also reported that in some cases carrying out the oxidation in the presence of 4-phenylpyridine $N$-oxide (4-PPNO) resulted in improved enantioselectivity. ${ }^{109}$ Similar results were obtained when carrying out manganese salen catalyzed epoxidations in the presence of 4-PPNO, where it acts as a donor ligand in the medium. ${ }^{110}$

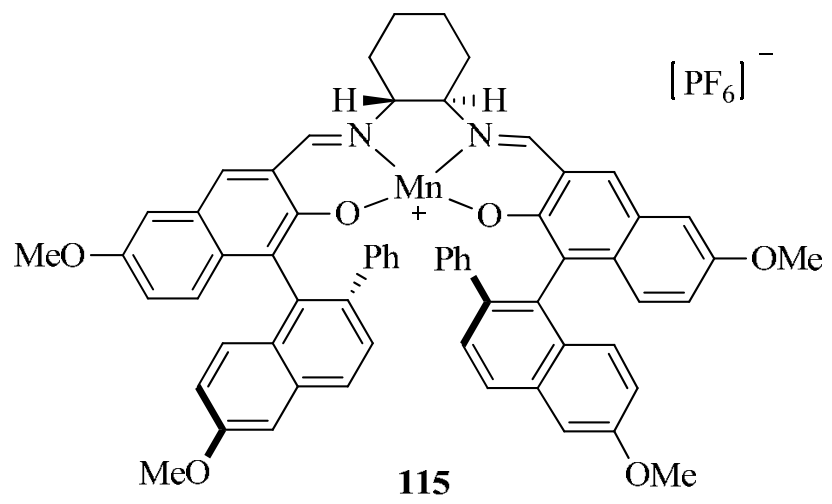

Recently, Ryu et al. used a similar manganese complex $\mathbf{1 1 6}$ to synthesize esomeprazole in $59 \%$ yield and $70 \%$ ee (Scheme 44$){ }^{111}$

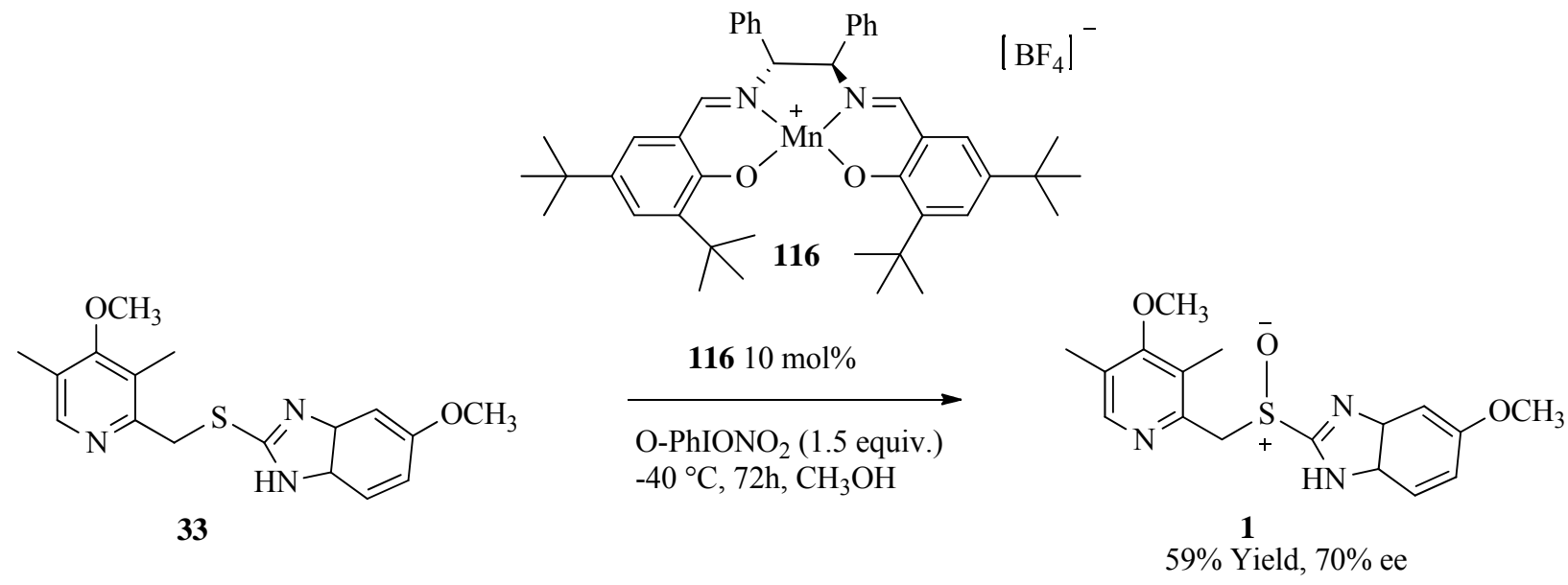

\section{Scheme 44}

Schoumacker et al. also investigated manganese catalyzed sulfide oxidation. ${ }^{112}$ Using a catalyst similar to that used by Katsuki, sulfoxides with modest enantioselectivities were prepared. The catalyst comprised of a manganese salt, either $\mathrm{Mn}(\mathrm{acac})_{2}$ or $\mathrm{Mn}\left(\mathrm{ClO}_{4}\right)_{2}$ and a salen type ligand 117. 


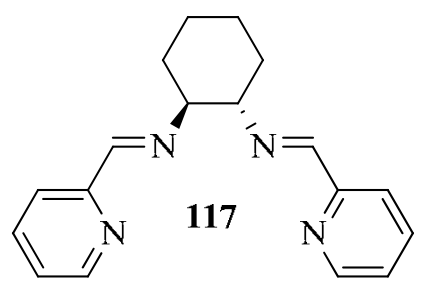

Manganese catalyzed oxidation has also been reported by Nagata et al. ${ }^{113,114}$ Enantioselective aerobic oxidation of sulfides into optically active sulfoxides was achieved by using pivalaldehyde in the presence of a catalytic amount of optically active $\beta$-oxo aldiminatomanganese(III) complexes.

Iglesias reported modest enantioselectivity using the manganese complex 118. ${ }^{115}$ Carrying out the oxidation using 118 under homogeneous conditions resulted in the sulfoxide being isolated with moderate enantioselectivity.
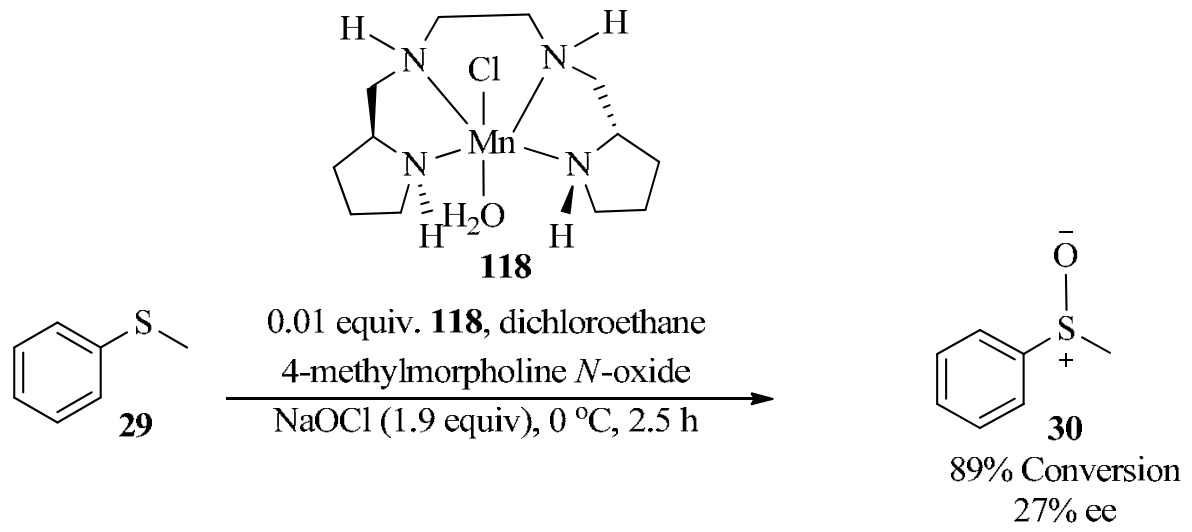

\section{Scheme 45}

Preparing the catalyst complex using a manganese zeolite resulted in the desired solid phase catalyst being isolated, which could be used in heterogeneous catalysis. Carrying out the oxidation using this solid phase catalyst and employing the same conditions as shown in Scheme 45 resulted in sulfoxides with poorer enantioenrichment being isolated. The lower enantioselectivity was attributed to the possible presence of unreacted $\mathrm{Mn}^{2+}$ in the zeolite, which could form an achiral oxidising species. The heterogeneous catalyst could be isolated by filtration and recycled without major loss of efficiency or activity.

Gao et al. recently reported the use of chiral salen-manganese complexes with a pyrrolidine backbone, 119. ${ }^{116}$ Results reported were modest with the highest enantioselectivity observed for the oxidation of 109. These type of complexes have proved very efficient catalysts in asymmetric epoxidation reactions. $^{117}$ 

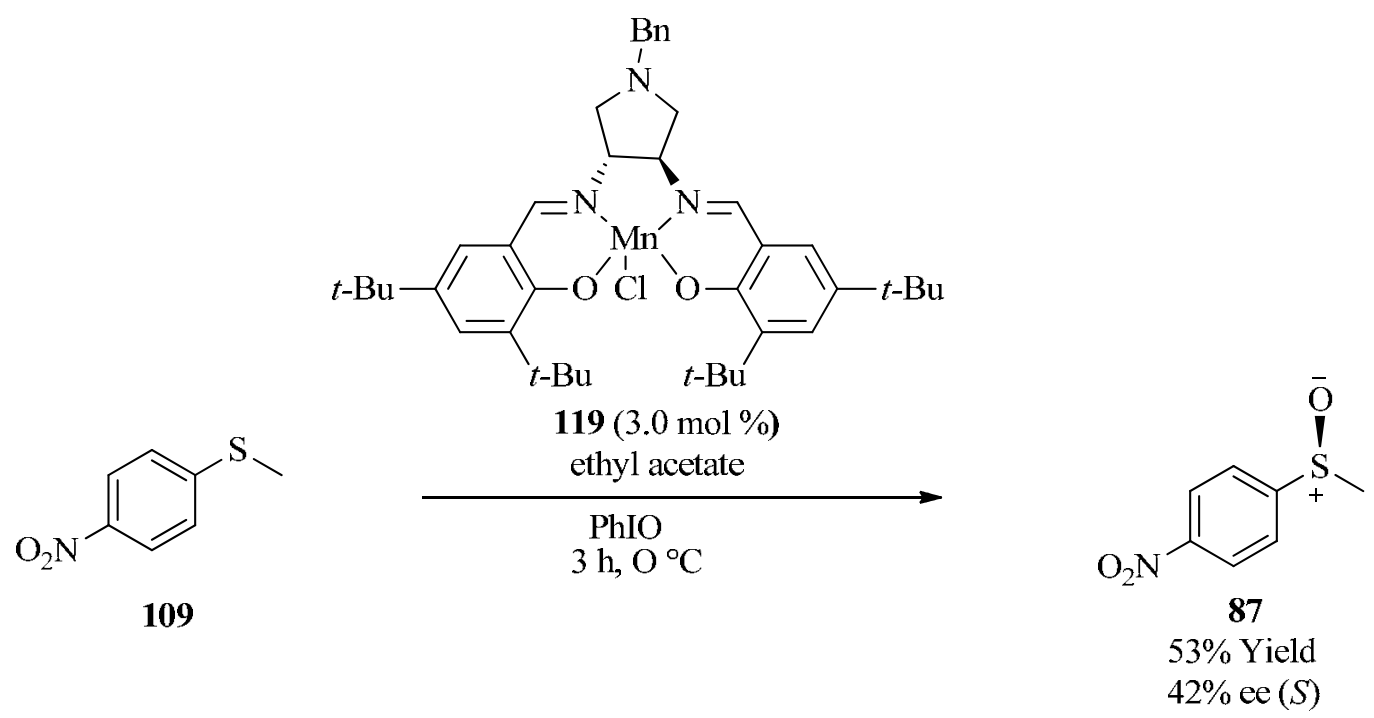

\section{Scheme 46}

Hirotsu et al. recently prepared dimanganese (III) complexes of salen-type ligands anchored by 9,9-dimethylxanthene-4,5-diyl spacers 120. These complexes were used in the asymmetric oxidation of thioanisole 18, but only modest enantioselectivities were obtained (Scheme 47). ${ }^{118}$

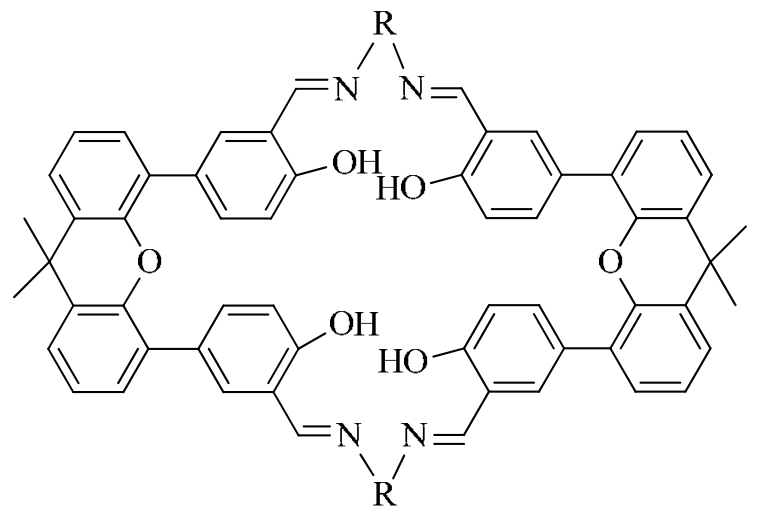

120<smiles>CSc1ccccc1</smiles>

29

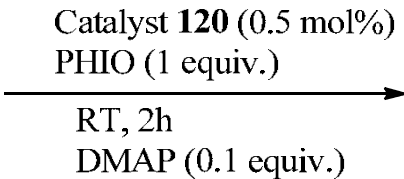

Catalyst $120(0.5 \mathrm{~mol} \%)$ RT, $2 \mathrm{~h}$
$\operatorname{DMAP}(0.1$ equiv. $)$<smiles>C[S+]([O-])c1ccccc1</smiles>

$57 \%$ Yield, 39\% ee $(S)$

\section{Scheme 47}


2.1.5 Copper catalyzed oxidation. Iglesias investigated using a copper catalyst similar to the manganese catalyst 118 used above. Under homogeneous conditions, the sulfoxide 19 of thioanisole 18 was successfully prepared in modest yield and $30 \%$ ee. ${ }^{115}$ A possible explanation of the modest yields was that the copper-oxo species formed was less stable than the corresponding manganese species, resulting in less oxidation. Attempts to carry out the oxidation using a solid phase copper catalyst were unsuccessful.

Cross reported enantiopurities of up to $14 \%$ ee for the oxidation of thioanisole 18 using the copper salen complex 121. ${ }^{119}$ Other copper salen complexes screened proved to be inactive.

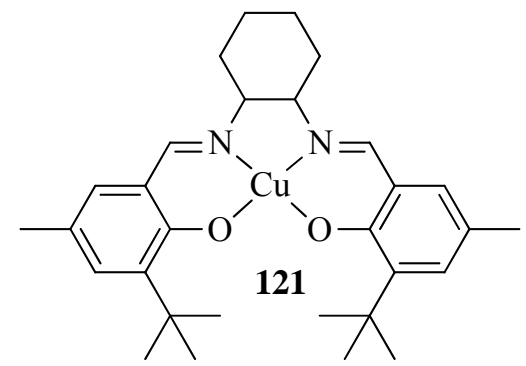

Zhu et al. used chiral copper(II) complexes of optically active Schiff bases 122, which have central seven-membered chelate rings. These produced sulfoxides in good yields $(>80 \%)$ but relatively low enantioselectivity (up to $17 \%$ ee) (Scheme 48 ). ${ }^{120}$

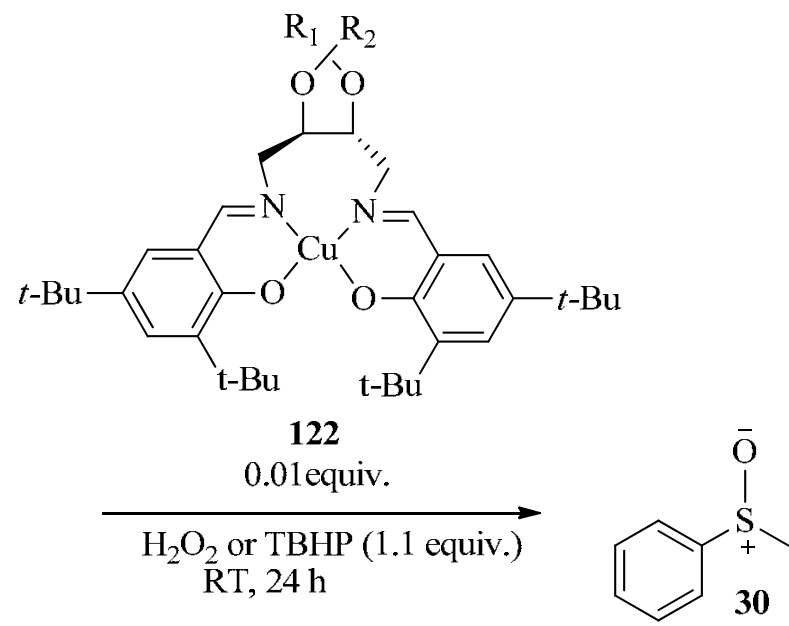

\section{Scheme 48}

Investigations by Kraemer using copper(II) salen-type complexes in asymmetric sulfide oxidation proved unsuccessful, with all copper complexes investigated proving inactive. ${ }^{121}$ Ayala et al., using an immobilized chiral copper salen complex in asymmetric sulfide oxidation, prepared aryl methyl sulfoxides in high yield but with poor enantioselectivity, up to $30 \%$ ee. $^{122}$ The immobilized catalyst could be recycled and TBHP was employed as the oxidant. 
Copper Schiff base mediated asymmetric oxidation of aryl benzyl sulfides has been reported by Maguire et al. ${ }^{123}$ The results reported compare favourably to other known copper mediated asymmetric sulfide oxidation methods, especially in terms of enantiocontrol (up to $81 \%$ ee), but yields and overall enantioselectivities are modest compared to other available methods. The method reported is similar to the vanadium and iron Schiff base mediated oxidations reported by Bolm in that the same oxidant and ligands are employed. Interestingly, the direction of the stereoselectivity observed is opposite to that observed for the iron/vanadium mediated methods. Best results were reported for sterically hindered aryl benzyl sulfides, and an improvement in the yield for this oxidation was observed in the presence of additives. No over-oxidation to the sulfone was observed (Scheme 49).

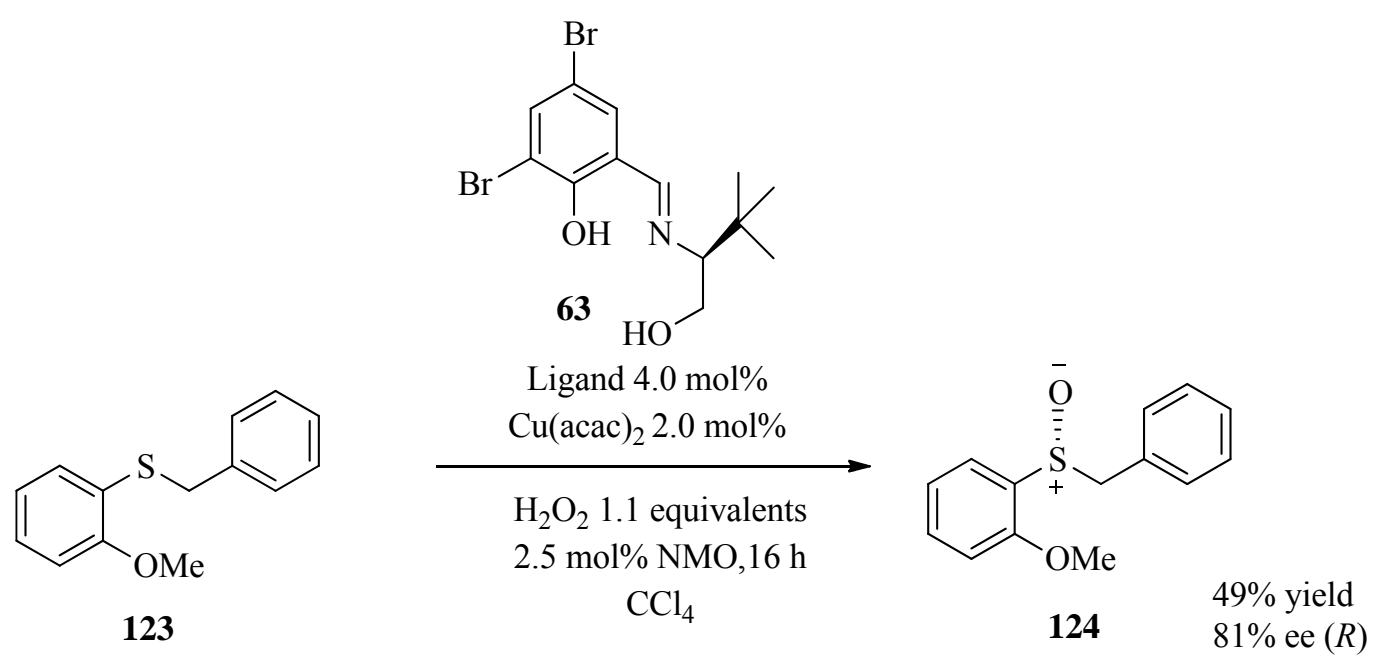

\section{Scheme 49}

2.1.6 Niobium catalyzed oxidation. Katsuki has successfully used a niobium salen, obtained from niobium chloride dimethoxyethane $\left[\mathrm{NbCl}_{3}(\mathrm{dme})\right]$ and salen $\mathbf{1 2 5}$, to carry out asymmetric sulfide oxidation. ${ }^{123 \mathrm{~b}}$ The salen ligand used was very similar to that used by Katsuki in manganese salen catalyzed asymmetric sulfide oxidation.

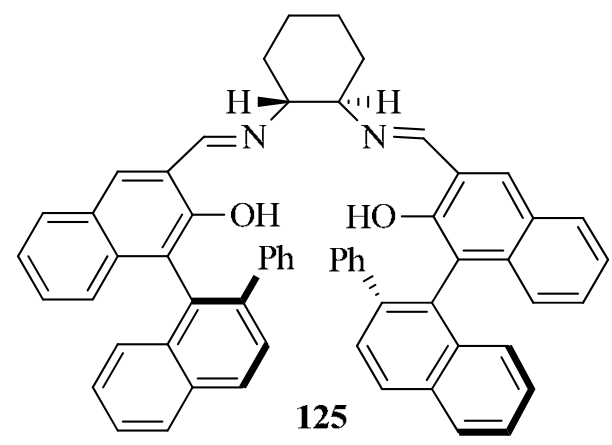


The oxidising reagent used was urea hydrogen peroxide adduct (UHP). Optimised conditions are as shown in Scheme 50. The highest enantiopurity was obtained oxidising ethyl phenyl sulfide 126.<smiles>CCSc1ccccc1</smiles>

126

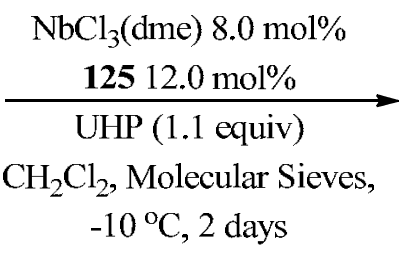

$-10^{\circ} \mathrm{C}, 2$ days

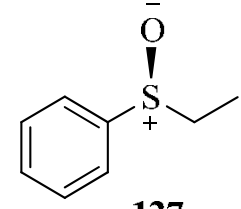

127

$58 \%$ Yield

$86 \%$ ee $(S)$

\section{Scheme 50}

Bolm et al. also carried out investigations into niobium catalyzed asymmetric sulfide oxidation but observed poor enantioselectivity $\left(<2 \%\right.$ ee) ${ }^{66}$

2.1.7 Tungsten catalyzed oxidation. In 2003, Thakur and Sudalai reported a tungsten catalyzed asymmetric sulfide oxidation. ${ }^{124}$ Using $\mathrm{WO}_{3}$ and a cinchona alkaloid 128 as the catalyst and aqueous hydrogen peroxide as the oxidant, sulfoxides with up to $65 \%$ ee were isolated in good yield. While the results obtained were modest in comparison to other oxidation methods, this represented the first successful asymmetric sulfide oxidation catalyzed by tungsten.

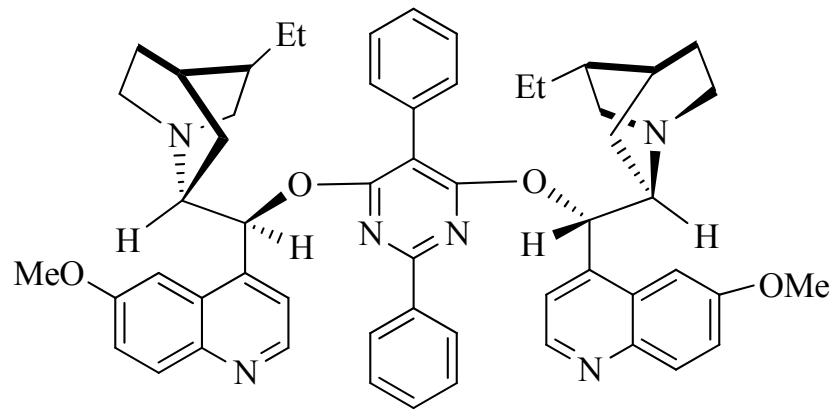

128

2.1.8 Osmium catalyzed oxidation. Kantam has reported asymmetric sulfide oxidation using an osmium catalyst supported on layered double hydroxides (LDH), a cinchona alkaloid as the chiral auxiliary and $N$-methylmorpholine $N$-oxide (NMO) as the oxidant. ${ }^{125}$ The results obtained were reasonable with good yields and enantiopurities (up to $51 \%$ ee). This method is more notable for its use of LDH than the enantioselectivity of the oxidation. The use of the catalyst supported on LDH permitted recovery of the catalyst, which could then be recycled. Recycled 
catalyst generally did not perform as well as new catalyst. Sulfone formation also accompanied this reaction.<smiles>CSc1ccccc1</smiles>

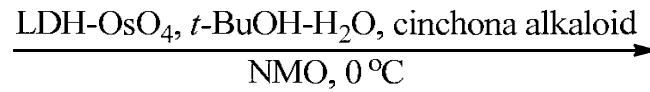<smiles>C[S+]([O-])c1ccccc1</smiles>
$67 \%$ Yield $51 \%$ ee

\section{Scheme 51}

2.1.9 Zirconium catalyzed oxidation. Modena reported in 1999 a highly stereoselective sulfide oxidation using a chiral zirconium(IV) catalyst. ${ }^{126,127}$ Oxidations of methyl- $p$-tolyl sulfide 7 using this methodology gave enantiopurities of $86 \%$ ee. Further stereoselective oxidations of aryl alkyl sulfides typically gave $80-90 \%$ ee. The chiral ligand $\mathbf{1 2 9}$ has also been successfully used in titanium catalyzed sulfide oxidations. ${ }^{128}$ Unfortunately with this system a significant amount of the corresponding sulfone is also produced. Using less oxidant (CHP) overcomes this problem but the resulting sulfoxide is effectively racemic.
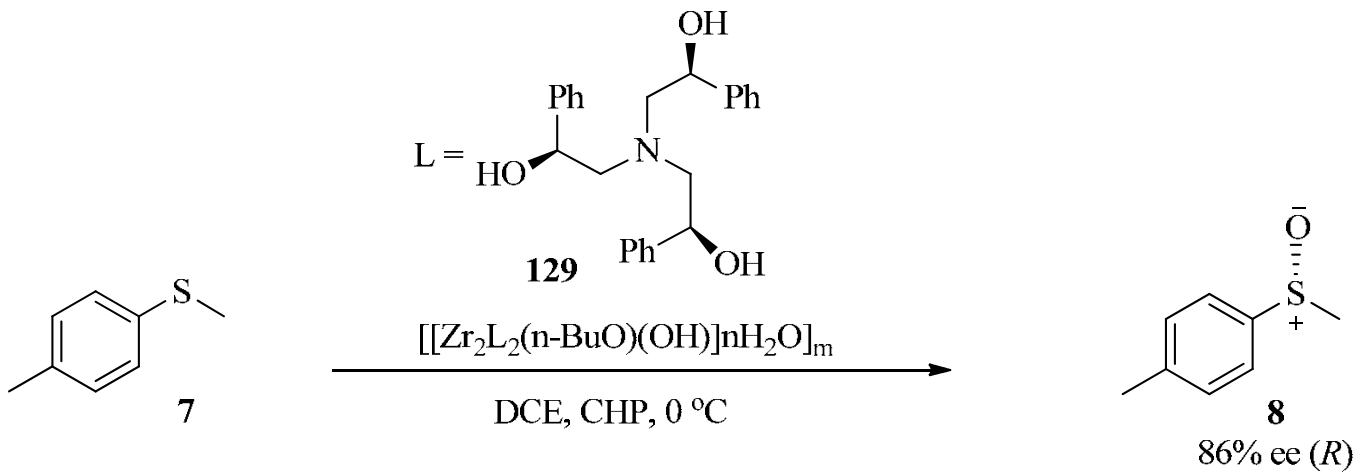

\section{Scheme 52}

2.1.1.0 Molybdenum catalyzed oxidation. Bonchio has also successfully carried out asymmetric sulfide oxidations catalyzed by molybdenum. ${ }^{129}$ Chirality is induced by carrying out the oxidation in the presence of a $\beta$-cyclodextrin $(\beta-C D)$ derived ligand 130. 
<smiles>CSc1ccccc1</smiles>

29

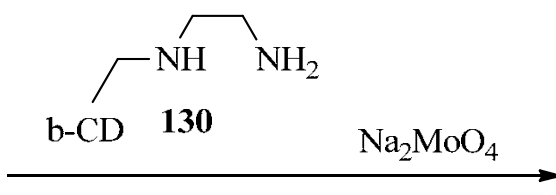

Water, $\mathrm{DCE}, \mathrm{H}_{2} \mathrm{O}_{2}, 20^{\circ} \mathrm{C}$<smiles>C[S+]([O-])c1ccccc1</smiles>

30

$98 \%$ Yield

$60 \% \operatorname{ee~}(R)$

\section{Scheme 53}

The ligand 130 (L), hydrogen peroxide and molybdenum salt form an oxodiperoxomolybdenum species, $\mathrm{MoO}\left(\mathrm{O}_{2}\right)_{2} \mathrm{~L}$ which oxidises the sulfide. The achiral $\mathrm{MoO}\left(\mathrm{O}_{2}\right)_{2}$ species is also believed to form in this oxidation, reducing the enantioselectivity of the oxidation. To overcome this problem the oxidation is carried out using a biphasic solvent system. The substrate will preferentially reside in the dichloroethane layer, but it is believed the $\beta-\mathrm{CD}$ catalyst can extract the sulfide from this organic layer into the aqueous layer, where it is oxidised. As the achiral oxidising species is only aqueous soluble, the potential for it to oxidise the sulfide, which is in the organic layer, will be reduced thus improving the overall enantioselectivity of the oxidation.

Basak et al. reported another molybdenum catalyst suitable for asymmetric sulfide oxidation. ${ }^{130}$ This method employs trityl hydroperoxide (THP) as the oxidant and the chiral auxiliary used is a bis-hydroxamic acid derivative 131.

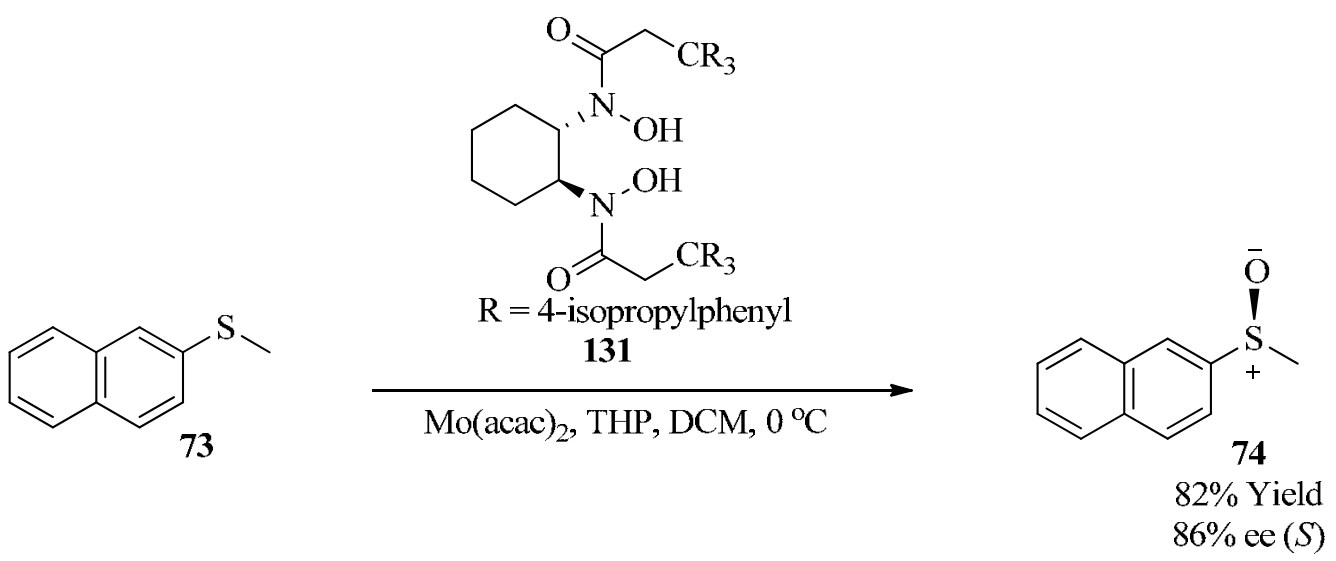

\section{Scheme 54}

Carrying out the oxidation using a ligand with less bulky groups $(\mathrm{R}=\mathrm{Ph})$ resulted in a drop in enantioselectivity. Using TBHP as an oxidant also resulted in decreased enantioselectivity. The enantioselectivity observed using CHP as the oxidant was similar to that observed using THP as the oxidant. 
2.1.11 Aluminum oxidation. A chiral aluminum catalyst 132 has recently been used in asymmetric sulfide oxidation by Katsuki and co-workers. ${ }^{131}$ The results obtained compare very favourably to existing methods, and furthermore the solvents and oxidant employed make this a very 'green' reaction. Some overoxidation to the sulfone occurs using this method to oxidize para substituted aryl methyl sulfides, though the extent of overoxidation is reduced considerably or completely when oxidizing more sterically hindered meta or ortho substituted aryl methyl sulfides. Interestingly, enantioselectivity improves slightly as the substrate becomes more sterically hindered. This method proved amenable to scale up and was suitable for the oxidation of thioacetals.
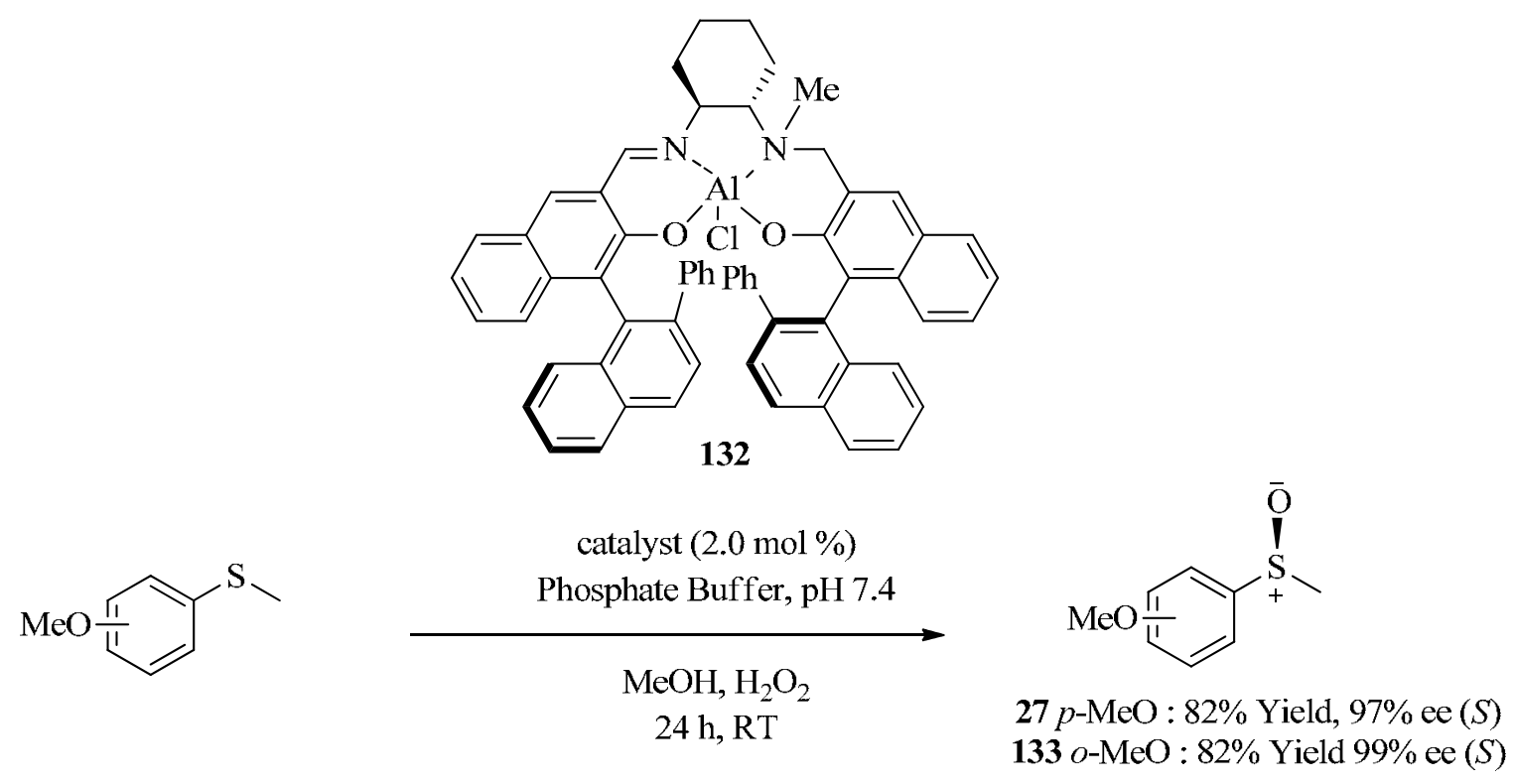

\section{Scheme 55}

\subsection{Non-metal catalyzed asymmetric sulfide oxidations}

In non-metal catalyzed asymmetric sulfide oxidation, enantioselectivity can be controlled either by using a chiral oxidant or by carrying out the oxidation in the presence of a chiral catalyst.

2.2.1 Chiral oxidants. Peracids. Early work on asymmetric sulfide oxidation involved the use of peracids to oxidise sulfides. ${ }^{15}$ Montanari investigated the use of optically active peroxy acids in asymmetric sulfide oxidation but results reported were poor. ${ }^{132}$

In 1977 Pirkle and Rinaldi reported that the enantioselectivity of monoperoxycamphoric acid 134 (MPCA) sulfide oxidations could be enhanced by the use of a single isomer of MPCA, rather than a mixture of the two MPCA isomers. ${ }^{133}$ Pirkle proposed MPCA could exist as two isomers 134a and 134b with opposite stereoselectivity to each other. Pirkle speculated that the results obtained in previous reports, where MPCA was used as the oxidant, could have been improved had only a single isomer of MPCA been used. 


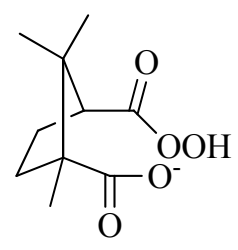

134a

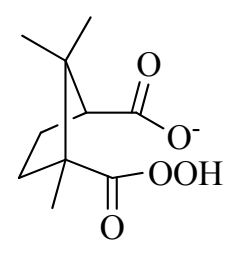

134b

Using MPCA as a mixture of isomers Pirkle obtained $\mathbf{3 0}$ in 6\% ee, however using the single isomer 134a, Pirkle obtained 30 in $9 \%$ ee. Single isomer MPCA was also successfully used to prepare enantioenriched epoxides and oxaziridines.

Chiral hydroperoxides. Seebach and Aoki used (4R,5R)-5-[(hydroperoxydiphenyl)methyl]-2,2dimethyl-1,3-dioxolan-4-yl \} diphenylmethanol 135 (TADOOH) derived from $\mathrm{H}_{2} \mathrm{O}_{2}$ and tetraaryl1,3-dioxolane-4,5-dimethanol (TADDOL) in asymmetric sulfide oxidation. ${ }^{134}$ Using this hydroperoxide as oxidant, $\mathbf{1 9}$ was prepared in good yield and high enantiopurity (Scheme 56).

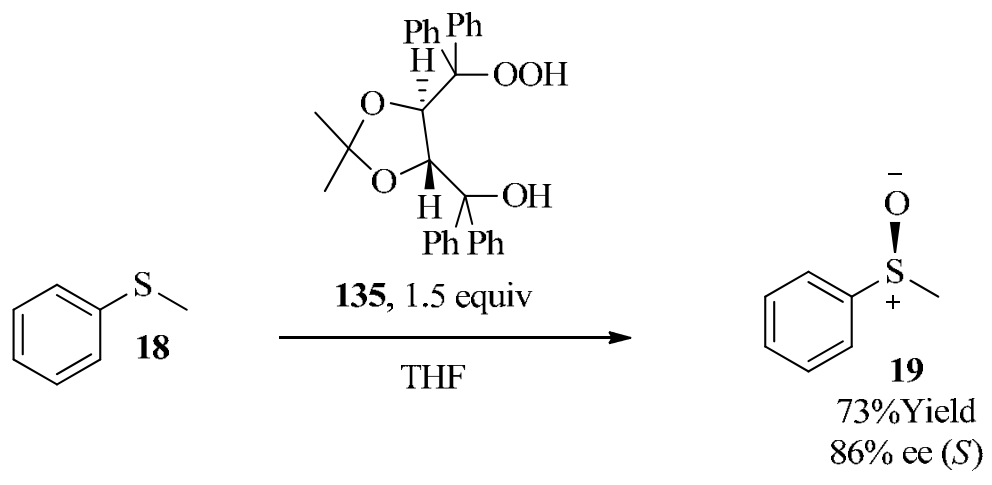

\section{Scheme 56}

Oxaziridines. Davis et al. reported a new class of aprotic oxidising agents for the oxidation of sulfur compounds in $1978 .{ }^{135}$ Using arenesulfonyl oxaziridines Davis successfully oxidised sulfides to sulfoxides in good yield. Subsequent work by Davis using these oxidising agents resulted in the development of a new chiral oxidising agent, 2-[(-)camphor-10-ylsulfonyl]-3(nitrophenyl)oxaziridine 136. ${ }^{136}$ Oxidising agent 136 was used by Davis to enantioselectively oxidise sulfides, for example the sulfoxide 19 of thioanisole 18 was obtained with modest enantiopurity, $14 \%$ ee. Like Pirkle, Davis used one isomer of the oxidising agent (33\% optically pure) rather than a mixture of isomers. 


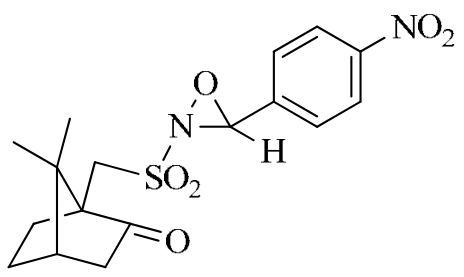

136

Significantly, Davis was able to conclude that the key to enhancing the enantioselectivity using oxaziridine oxidising reagents was the relationship between the electrophilic oxygen and chiral centres of the oxaziridine, as well as the restricted geometry of the oxaziridine.

Using the oxaziridine 139 reagent shown below Davis extended the scope of the oxidation, oxidising a variety of aryl alkyl sulfides. ${ }^{137}$ Highest enantioselectivity in this study was observed for the oxidation of sulfide 137 (Scheme 57).
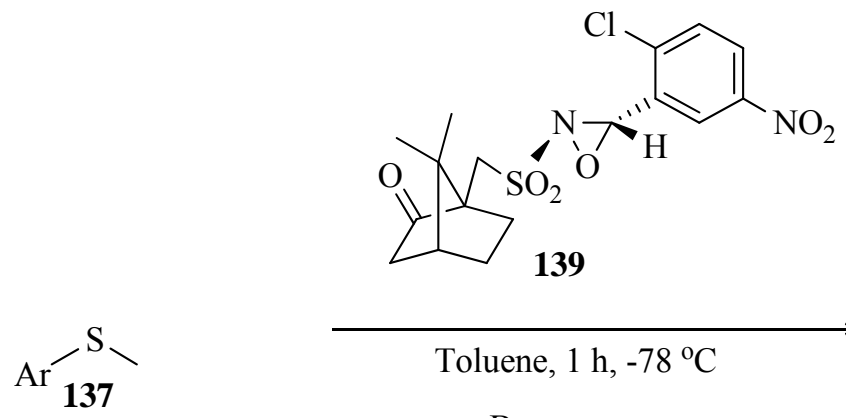

Toluene, $1 \mathrm{~h},-78^{\circ} \mathrm{C}$

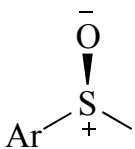

138

$46 \%$ ee $(S)$<smiles>[Al]#Cc1c(Br)cc(Br)cc1Br</smiles>

\section{Scheme 57}

The mechanism of the oxidation is believed to involve nucleophilic attack by the sulfide on the electrophilic oxygen of the oxaziridine, similar to oxidation with peracids. The stereoselectivity of the oxidation is due to the steric factors, with electronic effects and variation of solvent having no effect on the stereoselectivity of the oxidation.

Using the sulfamyl oxaziridine 142, Davis reported the highest enantioselectivity at the time obtained by asymmetric sulfide oxidation. ${ }^{138}$ 
<smiles>CSc1c2ccccc2cc2ccccc12</smiles>

140

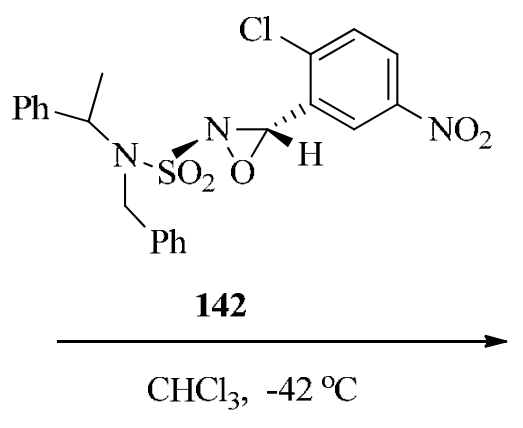

\section{Scheme 58}

The mechanism of the oxidation using the sulfamyl oxaziridine is believed to be similar to that of the sulfonyl oxaziridine. Sulfamyloxaziridines offer two practical advantages over sulfonyloxaziridines - it is easier to vary their structure and they are chromatographically more stable, and therefore, easier to purify and isolate. ${ }^{139}$

Davis investigated camphorylsulfonyloxaziridine 143 but the results obtained were inferior to those obtained using sulfamyloxaziridines. ${ }^{140}$

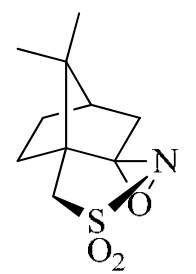

143

Later investigations by Davis using dichlorocamphorylsulfonyloxaziridine 144 were much more successful. ${ }^{141}$ Using 144, sulfoxides with very high enantiopurities could be prepared. Furthermore, the results obtained were at least comparable, if not superior, to those obtained using other available oxidation methods, and the oxidation was carried out at room temperature. $^{142}$

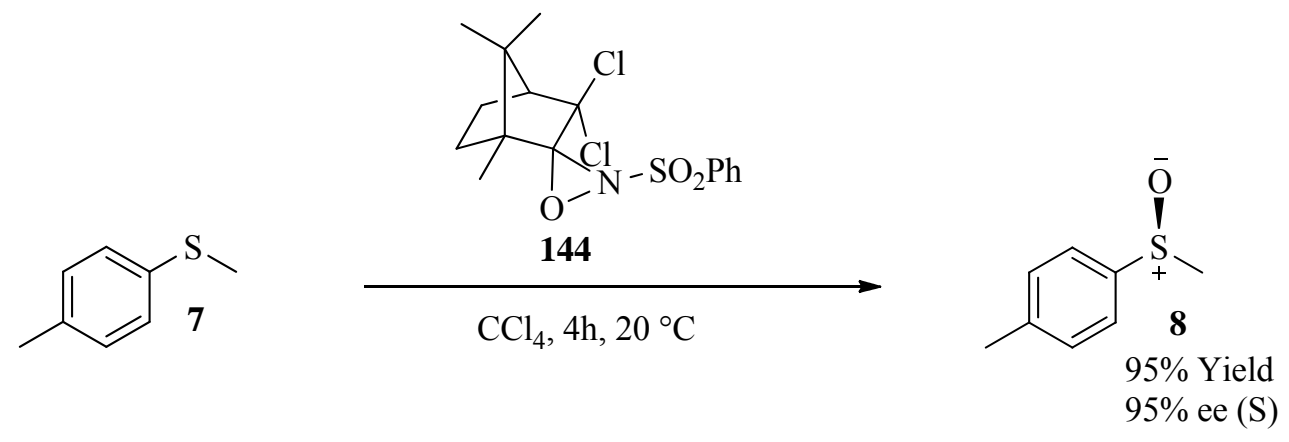

\section{Scheme 59}


Meladinis et al. also investigated camphorylsulfonyloxaziridine derivatives in asymmetric sulfide oxidation, obtaining 19 in good yield with high enantioselectivity, using $145 .{ }^{143}$

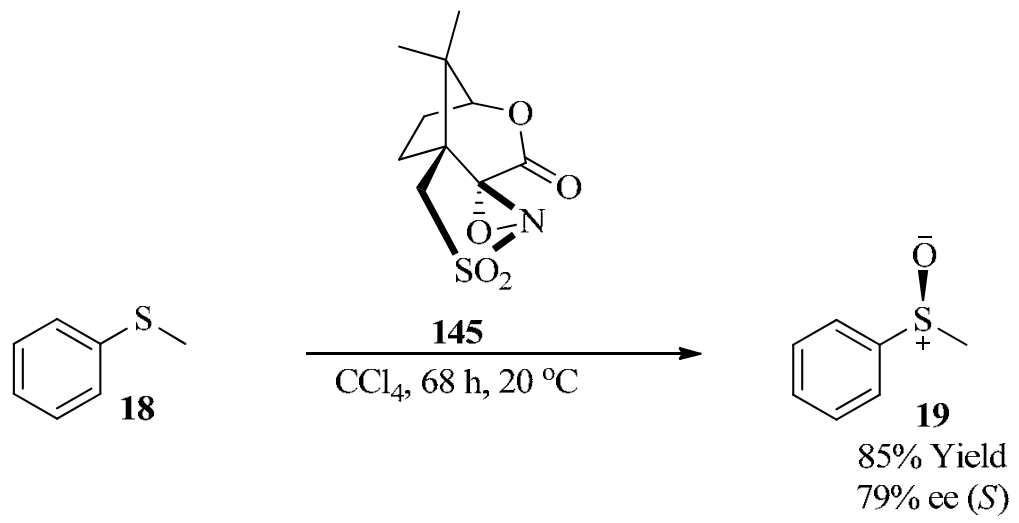

\section{Scheme 60}

Sulfonyloxaziridines derived from benzothiazole were also investigated by Davis but were found to be inferior to both the sulfamyloxaziridines and 144. ${ }^{144}$

Schwan successfully used 144 to asymmetrically oxidise a number of aryl/alkyl 2(trimethylsilyl)ethyl sulfides. ${ }^{145}$ In almost all of these oxidations the use of $\mathbf{1 4 4}$ as the oxidising agent resulted in higher enantioselectivity than other available asymmetric sulfide oxidation methods. The greatest degree of enantiocontrol was observed in the oxidation of tert-butyl sulfide 146, which was not surprising as investigations by Davis established that the stereocontrol exerted by the oxaziridine during the oxidation was due to steric effects (Scheme 61). ${ }^{137}$ Sulfides that did not possess a sterically demanding group were less susceptible to stereocontrol during the oxidation.

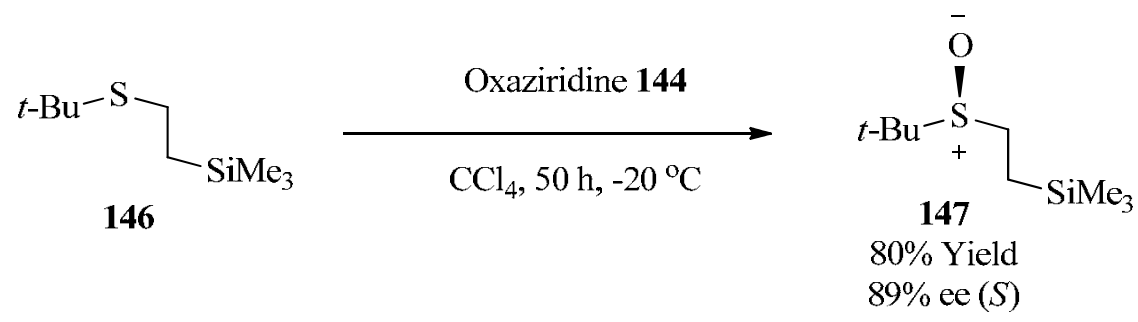

\section{Scheme 61}

In 1988, Davis reported a selective racemic oxidation of sulfides to sulfoxides, (Scheme 62). ${ }^{146}$ The significance of the method was that the oxaziridine oxidising reagent used was generated in situ by oxidising an imine. Given that some of the chiral oxaziridine oxidising reagents used in asymmetric sulfide oxidation were sensitive, this method offered the possibility of overcoming this problem. 

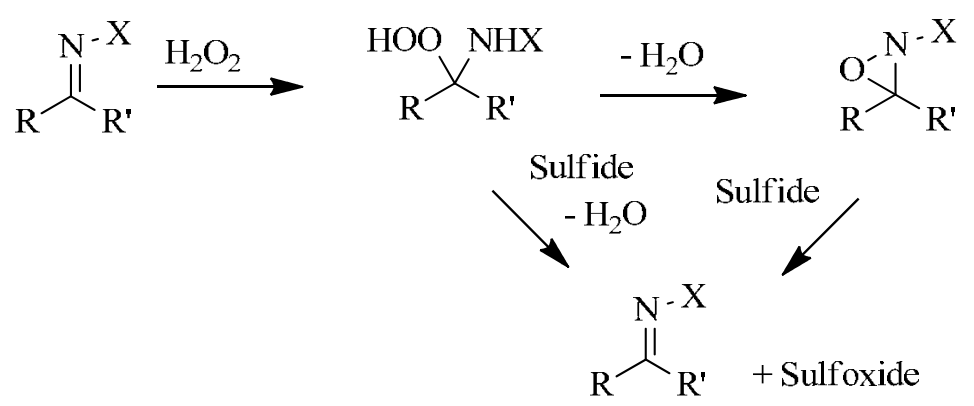

\section{Scheme 62}

Page et al. was first to report the successful asymmetric sulfide oxidation using an in situ generated oxidising reagent. ${ }^{147}$ Cyclic camphorsulfonylimine 148 was oxidised in a buffered solution using hydrogen peroxide to form the oxaziridine or hydroperoxide, both of which could act as potential oxidants of the sulfide. The basic buffer used suppressed direct oxidation of the sulfide by the hydrogen peroxide.

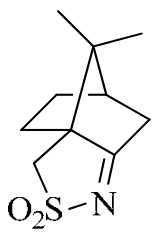

148

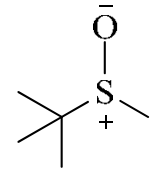

149

Using this in situ generated oxidising agent, tert-butyl methyl sulfoxide 149 was prepared in $83 \%$ yield and $42 \%$ ee. Later investigations by Page established that using the imines 150 and 151 resulted in much higher enantioselectivity, with 149 being obtained in quantitative yield and $86 \%$ ee when the dimethoxy imine 151 was used in the oxidation. ${ }^{148}$

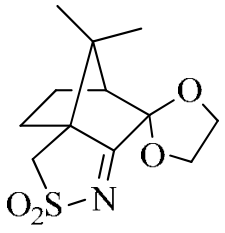

150

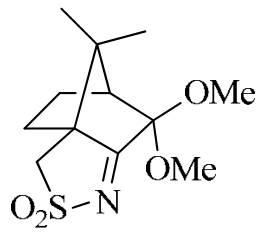

151

Page surmised that the primary oxidative species generated in situ using this oxidation method was the hydroperoxyamine as the stereoselectivity of the oxidation was opposite to that which would be expected if the oxidation was carried out using an oxaziridine. ${ }^{148}$ Trends observed in the results of the oxidation differed from those that would be expected if the oxaziridine was the oxidising reagent. ${ }^{147}$ Despite this, an investigation by Page using the oxaziridine of 151 as the oxidant and the imine 151 to generate oxidant in situ gave similar results, which could indicate that the oxaziridine was indeed the primary oxidative species 
generated in situ. ${ }^{149}$ Page investigated further imines to see if the enantioselectivity could be improved. ${ }^{150}$ However, the results obtained were inferior to those previously achieved.

It was first reported in 1988 that acid could catalyse the oxygen transfer from an oxaziridine to a sulfide. ${ }^{151}$ Bohé was first to use this knowledge in asymmetric sulfide oxidation using methanesulfonic acid (MSA) and an oxaziridine derived from dihydroisoquinoline 152 to carry out the oxidation (Scheme 63). ${ }^{152}$ Overall the results obtained using this method were modest compared to other oxidative methods that were available at that time.

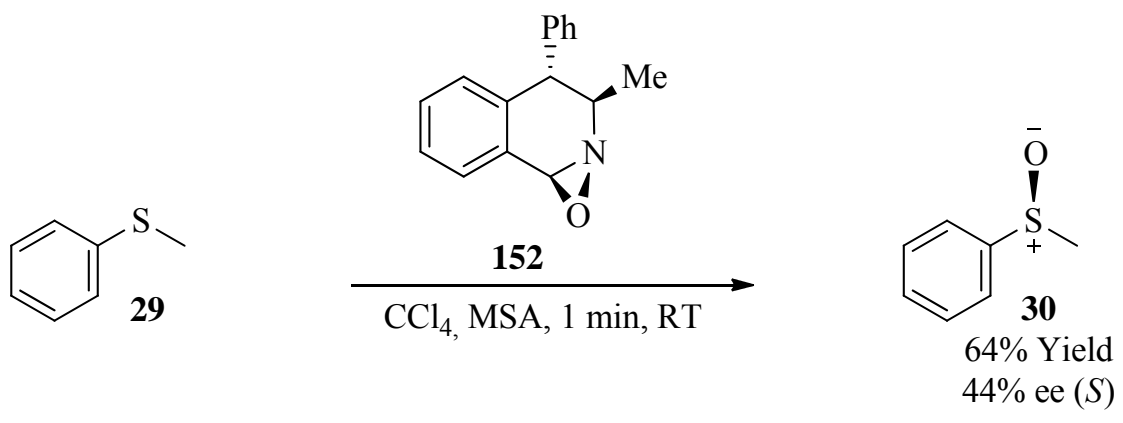

\section{Scheme 63}

Schoumacker et al. also used acids to promote oxygen transfer from oxaziridines in asymmetric sulfide oxidation. ${ }^{153}$ Using a Lewis acid with the oxaziridine 153, benzyl phenyl sulfoxide 13 was isolated in good yield with moderate enantioselectivity, 63\% ee. Zinc chloride was found to be the best Lewis acid for these sulfide oxidations. While the results were modest, this represented the first Lewis acid promoted asymmetric oxidation of sulfides by oxaziridines.
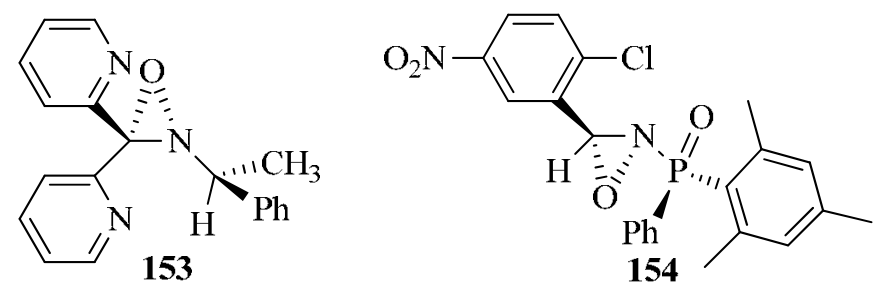

Jennings et al. used $N$-phosphinoyloxaziridines 154 to carry out asymmetric sulfide oxidations obtaining 9-anthryl $n$-butyl sulfoxide 155 in $70 \%$ ee. ${ }^{154}$ The oxidation could be carried out at $0{ }^{\circ} \mathrm{C}$ in dichloromethane and the chiral imine by-product could, in principle, be recycled back to the oxaziridines.

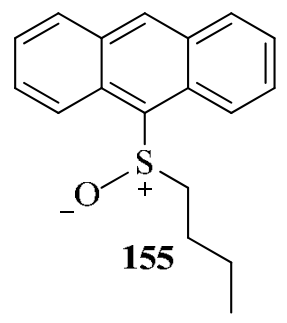


Recently, Bohé et al. prepared enantiopure 8 in good yield (88\%) using a cholesterol derived oxaziridinium salt as the oxidising agent. The oxaziridinium salt used was the first oxaziridinium salt derived from cholesterol. ${ }^{155}$

Hanquet et al. reported acid promoted asymmetric sulfoxidations using binaphthyl-derived oxaziridines 156. The oxidations of dialkyl or diaryl sulfides produced the corresponding sulfoxides in good yield (up to 86\%) with no sulfone formation and with enantiopurities ranging from $20 \%$ to $80 \%$ ee. ${ }^{156}$ The enantioselectivity varied depending on reaction time, temperature and the acid used. Interestingly, the configuration of the resulting major sulfoxide enantiomer varied with the structure of the sulfide used.

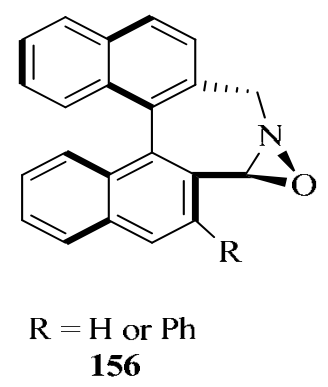

Iodine based reagents. Zhdankin et al. reported the racemic and asymmetric oxidation of sulfides using iodine based oxidising reagents. ${ }^{157}$ In 2006, Zhdankin et al. used a chiral benziodoxazine derivative 157, developed from $(S)$-proline, in the asymmetric oxidation of sulfide 7, producing sulfoxide 8 in $84 \%$ yield and $29 \%$ ee (Scheme 64$).{ }^{157 \mathrm{c}}$

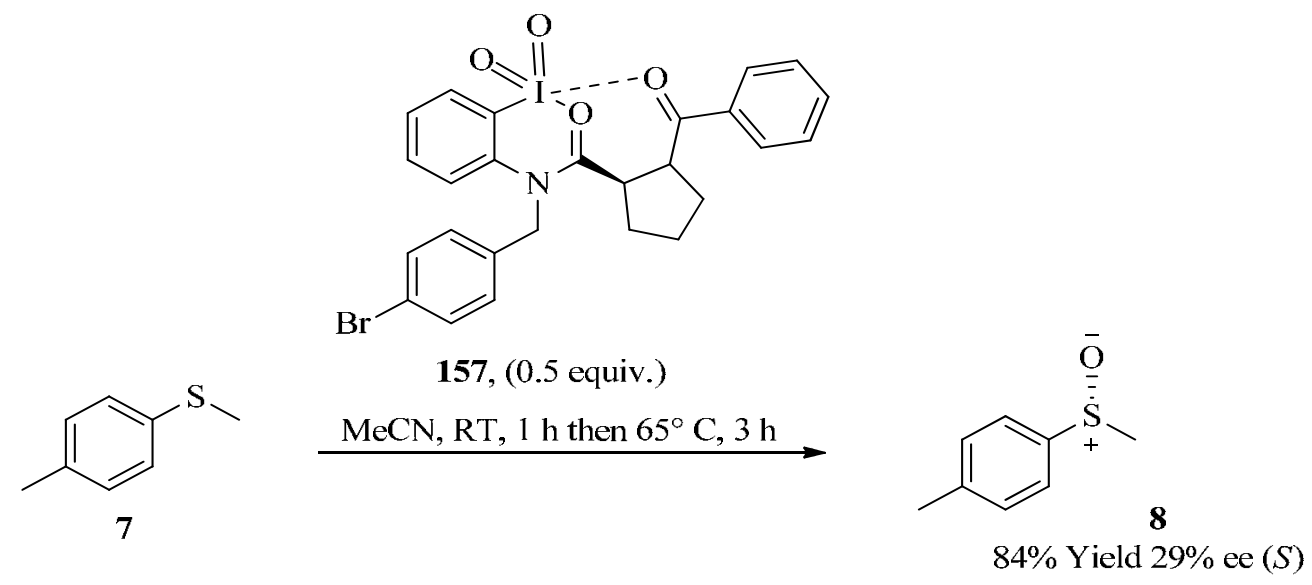

\section{Scheme 64}

2.2.2 Chiral catalysts. One of the earliest reported uses of a chiral catalyst in the asymmetric oxidation of sulfides was reported by Pitman, who used iodine as the oxidant and D-2-methyl-2phenylsuccinate as the buffer; benzyl methyl sulfoxide 158, was obtained with just over $6 \%$ 
ee. ${ }^{158}$ Repeating the oxidation in the presence of a non-chiral phthalate buffer resulted in the isolation of racemic sulfoxide.

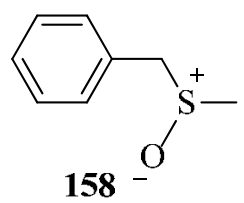

Cyclodextrins. Surendra et al. investigated a cyclodextrin catalyzed sulfide oxidation. ${ }^{159}$ The oxidation was accompanied by limited asymmetric induction. The oxidation is catalyzed by the chiral auxiliary $\beta$-cyclodextrin $(\beta-C D)$ and the oxidant used is NBS. The enantioselectivity of the oxidation is poor, less than $10 \%$ ee. While the results are not very encouraging, this method uses mild conditions and with further development may become an attractive viable asymmetric sulfide oxidation method. Rossi observed similar results while investigating $\mathrm{FeBr}_{3}-$ cyclodextrin catalyzed sulfide oxidation obtaining sulfoxides with low enantiopurities. ${ }^{160}$

Earlier work by Czarnik using cyclodextrin as a chiral auxiliary in asymmetric sulfide oxidation yielded more encouraging results. ${ }^{161}$ Carrying out the oxidation under the conditions in Scheme 65 , sulfoxides with over $30 \%$ ee were obtained. This compared very favourably to other asymmetric oxidation methods available at the time.

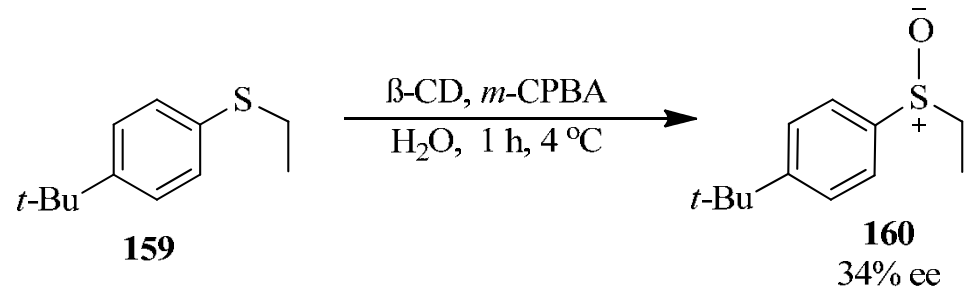

\section{Scheme 65}

Other oxidising reagents besides $m$-CPBA were screened by Czarnik. Results obtained using hydrogen peroxide, tert-butyl hydroperoxide and $\mathrm{PhI}(\mathrm{OAc})_{2}$ were inferior to those obtained using $m$-CPBA. Drabowicz also reported asymmetric sulfide oxidation catalyzed by $\beta$-cyclodextrin, with hydrogen peroxide as oxidant, and enantiopurities up to $30 \%$ ee were achieved. ${ }^{162}$

Bovine serum albumin. Sugimoto oxidised a number of aromatic sulfides in the presence of bovine serum albumin (BSA) using sodium metaperiodate as the oxidant. ${ }^{163}$ The results obtained were impressive with 162 being obtained with an optical purity of $81 \%$ (Scheme 66). 


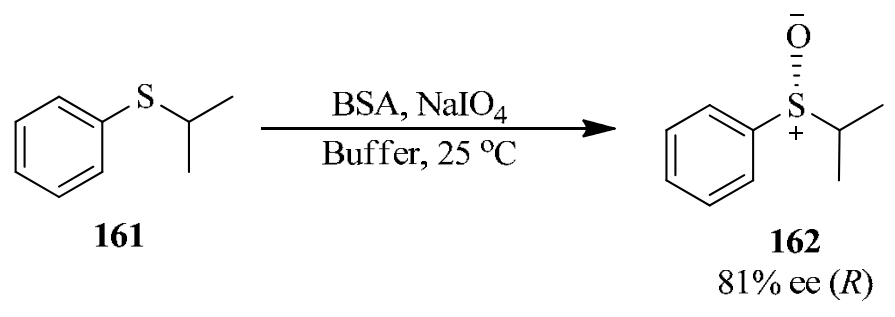

\section{Scheme 66}

Ogura also carried out oxidation in the presence of BSA to obtain the mono sulfoxide of di$p$-tolyl dithioacetal with an optical purity of $60 \% .{ }^{164}$ Colonna used similar conditions to Sugimoto and Ogura to obtain 164 in almost 70\% ee (Scheme 67). ${ }^{165}$

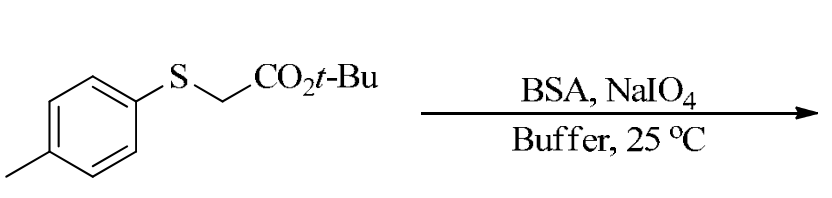

163<smiles>Cc1ccc([Sb]([O-])CC(=O)OC(C)(C)C)cc1</smiles>

164

$69 \%$ ee $(R)$

\section{Scheme 67}

As the results obtained using BSA to induce chirality are highly substrate dependent, the use of BSA in asymmetric sulfide oxidation has received very little attention since these reports.

\subsection{Electrochemical asymmetric sulfide oxidation}

In 1976 Firth and Miller reported limited enantioselectivity in the oxidation of sulfides using electrochemical means. ${ }^{166}$ While the results obtained were poor $(3 \%$ ee) it was the first report of electrochemical asymmetric sulfide oxidation.

A few years later Komori and Nonaka reported a more enantioselective electrochemical oxidation. ${ }^{167}$ Using poly(L-valine)-coated platinum electrodes, phenyl cyclohexyl sulfoxide 165 was obtained in $31 \%$ yield and $54 \%$ ee. Later work by Komori and Nonaka using a variety of poly (amino acid) coated platinum/graphite electrodes established that the best electrode was the L-valine coated electrode. ${ }^{168}$ Using this electrode tert-butyl phenyl sulfoxide 166 was obtained in $45 \%$ yield and $93 \%$ ee. This compared very favorably to the $\operatorname{Kagan}^{18}$ and Modena ${ }^{19}$ oxidation methods which were being published at that time. 

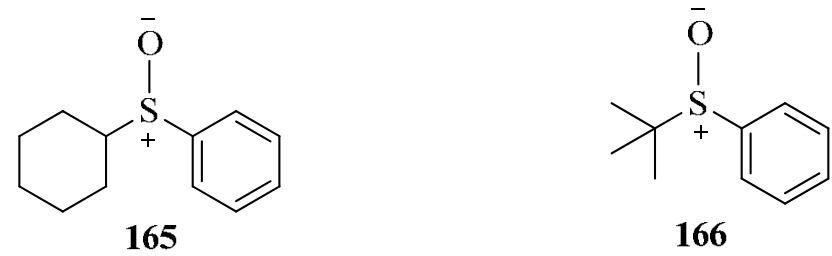

\subsection{Biological asymmetric sulfide oxidation}

Biological asymmetric sulfide oxidation is a less popular method for preparing enantioenriched sulfoxides than chemical asymmetric sulfide oxidation. There are many reasons for this but the principal reason is that since the publication of the Kagan and Modena methods, chemical asymmetric sulfide oxidation has proved itself to be the more practical and efficient method for preparing enantioenriched sulfoxides. Generally, the biological oxidation of sulfides, or biotransformation of sulfides, is carried out using whole cell cultures or isolated enzymes. A number of reviews of this area have appeared. ${ }^{8,169,170}$

2.4.1 Oxidation using whole cells. One of the earliest reports of whole cell cultures capable of oxidising sulfides to sulfoxides was in the 1950s when it was discovered that the addition of biotin to the growth culture of Aspergillus niger resulted in the formation of a new metabolite biotin $S$-oxide. ${ }^{171}$ In 1962 , benzyl phenyl sulfoxide 13 with $18 \%$ optical purity, was successfully prepared by oxidation of the sulfide by fermentation with fungus Aspergillus niger.${ }^{172}$ Later work using Aspergillus niger established that the efficiency of the sulfide oxidation was substrate specific with enantiopure 168 being isolated from the fermentation; for the less sterically demanding substrate 7 , enantioselectivity was considerably lower, Scheme $68 .{ }^{173}$<smiles>[R]Sc1ccc(C)cc1</smiles>

167

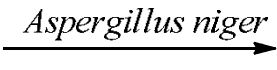

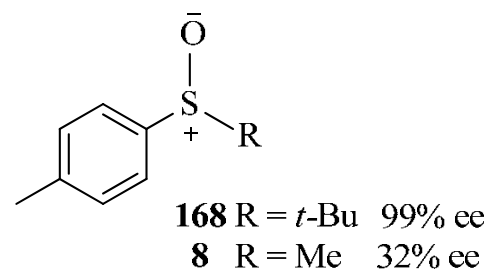

\section{Scheme 68}

The biocatalyst present in the fungus Helminothosporium sp. NRRL 4671 has been used in the asymmetric oxidation of a variety of sulfides with very high enantioselectivity being observed, similarly Mortierella isabellina ATCC 42613 has also been successfully used to prepare highly enantioenriched sulfoxides. ${ }^{174}$

Bacterial cells have proven to be very useful in asymmetric sulfide oxidation. The oxidation of the antibiotics, lincomycin and clindamycin to the sulfoxide by Streptomyces bacteria was the first indication that bacterial cells were capable of oxidising sulfides. ${ }^{175,176}$ Ohta et al. prepared a 
number of aryl alkyl sulfoxides with high enantiopurities using the bacteria, Corynebacterium equi. For example enantiopure $n$-butyl phenyl sulfoxide 169 was obtained using this bacteria. ${ }^{177}$

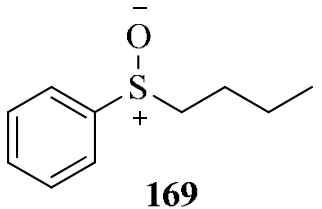

A Micrococcus species was used to prepare the sulfoxide 19 of thioanisole 18 with $>90 \%$ ee. ${ }^{178}$ Pseudomonas putida NCIB 9816-4, which expresses the enzyme naphthalene dioxygenase, was used to prepare a variety of enantioenriched aryl alkyl sulfoxides with up to $98 \%$ ee being reported. $^{179}$

Biocatalytic sulfoxidation using the topsoil bacterium Pseudomonas frederiksbergensis has been reported by Adam et al. ${ }^{180}$ For example 8, was obtained effectively enantiopure ( $>99 \%$ ee) in quantitative yield using Pseudomonas frederiksbergensis to oxidize the sulfide.

Boyd et al. reported the TDO and NDO catalyzed asymmetric oxidation of a range of sulfides. $^{181,182}$ The TDO enzyme system was more reluctant to catalyze oxidation of dialkyl sulfides than aryl alkyl sulfides to the corresponding monosulfoxides.

Yeasts have also been used in asymmetric sulfide oxidation, though to a rather limited extent. Best results were obtained under semi-anaerobic conditions with 8 being obtained with 92-94\% ee. ${ }^{183,184}$ Roberts successfully used bakers' yeast (Saccharomyces cerevisiae NCYC 73) to prepare 8 in high yield and enantiopurity. ${ }^{183}$ Given the ease of protocol and relatively low cost of the bakers' yeast catalyst, this result is very significant.

Kayser et al. prepared enantiopure sulfoxides via biooxidation with engineered yeast (Saccharomyces cerevisiae) and E.coli overexpressing enzyme cyclohexanone monooxygenase (CHMO). It had previously been shown that CHMO-catalyzed oxidations of sulfides required a combination of a large and a small substituent on the sulfur for maximum enantioselectivity. ${ }^{185}$ As a result, this system ${ }^{186}$ was used in the oxidation of 18, producing the sulfoxide 19 in $95 \%$ yield and $99 \%$ ee.

Nagasawa et al. tested over 650 microorganisms in the asymmetric synthesis of the proton pump inhibitor, rabeprazole 4 from the corresponding sulfide. ${ }^{187}$ The microorganisms consisted of 300 molds, 200 bacteria, 100 yeasts, and 50 basidiomycetes. The molds produced the best results, with the highest activity exhibited by the newly isolated strain, Cunninghamella echinulata MK40. The addition of glucose improved product formation. Rabeprazole was produced in enantiopure form $(S)$ and in a $92 \%$ conversion from the sulfide with no sulfone formation. 


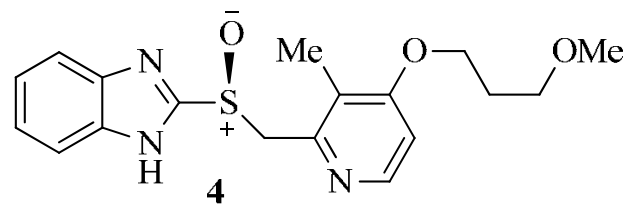

Porto et al. reported that white rot Basidomycetes promoted the asymmetric oxidation of aromatic pro-chiral sulfides, producing sulfoxides in good yields and enantioselectivities, and with a small amount of sulfone production. The oxidation of phenyl propyl sulfide $\mathbf{1 7 0}$ produced the $(S)$-sulfoxide in enantiopure form. ${ }^{188}$<smiles>CCCSc1ccccc1</smiles>

Olivo et al. reported a highly enantioselective oxidation of benzhydrylsulfanyl acetic acid to the corresponding $(S)$-sulfinyl carboxylic acid using the fungus Beauveria bassiana. The sulfoxide 172 was produced in excellent yield (89\%) and enantioselectivity (99\%) (Scheme 69). ${ }^{11}$ The sulfoxide 172 was further amidated using the bacteria Bacillus niger to give $(S)$ Modafinil 5 in $68 \%$ yield.

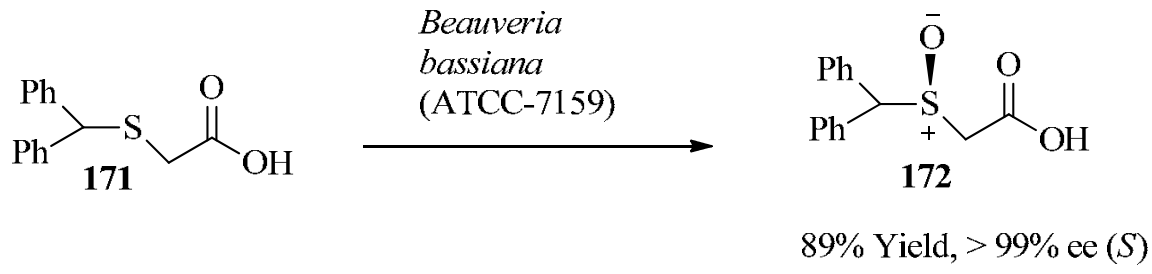

\section{Scheme 69}

Collado et al. reported the enantiomeric oxidation of a series of substituted sulfides using the filamentous fungi Botrytis cinerea, Eutypa lata and Trichoderma viride. In the oxidation of benzyl phenyl sulfide, $T$. viride gave the best result, producing sulfoxide in $60 \%$ yield and $>95 \%$ ee $(R)$. Interestingly, the $(R)$-enantiomer was favored in biotransformations by $T$. viride and $E$. lata while the $(S)$-enantiomer was favored in those by $B$. cinerea. ${ }^{189}$

Chauvin et al. reported the asymmetric oxidation of alkyl aryl and dialkyl sulfides using the microalga, Chlorella sorokiniana. These sulfides were converted to sulfoxides in modest yields (up to $67 \%$ conversion) and enantioselectivities (up to $58 \%$ ee). In the oxidation of alkyl aryl sulfides the formation of the $(R)$-enantiomer was favored while the $(S)$-enantiomer was favored with the dialkyl sulfides. ${ }^{190}$ 
2.4.2 Oxidation using isolated enzymes. While the use of whole cells instead of isolated enzymes for asymmetric sulfide oxidation is advantageous for a number of reasons, obviating the need to isolate the enzymes and to add cofactors to the oxidation, the use of isolated enzymes in asymmetric sulfide oxidation has attracted considerable interest. Most enzymes used in asymmetric sulfide oxidation contain a metal centre, usually iron, which facilitates the oxidation of the sulfide in the presence of an oxidant.

The CHMO enzyme has been used to oxidise a variety of aryl alkyl sulfides with high enantioselectivity. ${ }^{191,192}$ Chen used CHMO isolated from an engineered yeast strain to prepare 19 in $95 \%$ yield and $>99 \%$ ee from its sulfide $18{ }^{193}$

The chloroperoxidase (CPO) enzyme has shown itself to be a very useful enzyme in the asymmetric oxidation of sulfides. ${ }^{194}$ It is the most versatile of the peroxidases. ${ }^{10}$ It can be isolated in quantity from the marine fungus Caldariomyces fumago. Colonna demonstrated that the optimum oxidant for use with CPO is hydrogen peroxide, obtaining sulfoxides in high yield and enantiopurity. ${ }^{195}$ Significant achiral oxidation can occur in these oxidations which is not catalyzed by CPO; this can be avoided by the use of conditions proposed by Sheldon. ${ }^{196,197}$ The first electroenzymatic asymmetric sulfide oxidation was reported using the CPO enzyme from Caldariomyces fumago. ${ }^{198}$ A carbon cathode reduces dissolved oxygen to form hydrogen peroxide which, in the presence of CPO can enantioselectively oxidise sulfides to sulfoxides. Thioanisole 18 was oxidised to form 19 with very high enantioselectivity (99\% ee) using this method. Selective oxygen transfer by heme-peroxidases like CPO has been investigated. ${ }^{199}$ The poor stability of CPO and indeed other peroxidases has limited their use in organic synthesis, however investigations into improving the stability of peroxidases are ongoing. ${ }^{200}$

Leitner and Greiner carried out an enantioselective sulfoxidation by cascade reaction of $\operatorname{Pd}(0)$ catalyzed formation of $\mathrm{H}_{2} \mathrm{O}_{2}$ and enzymatic oxidation using chloroperoxidase (CPO) from Caldariomyces fumago. Supercritical carbon dioxide $\left(\mathrm{sc} \mathrm{CO}_{2}\right)$ was used as medium for in situ generation of $\mathrm{H}_{2} \mathrm{O}_{2}$ from $\mathrm{H}_{2}$ and $\mathrm{O}_{2}$ using $\mathrm{Pd}$ catalysts. The system afforded 19 in $34 \%$ yield and $94 \%$ ee (Scheme 70$){ }^{201}$

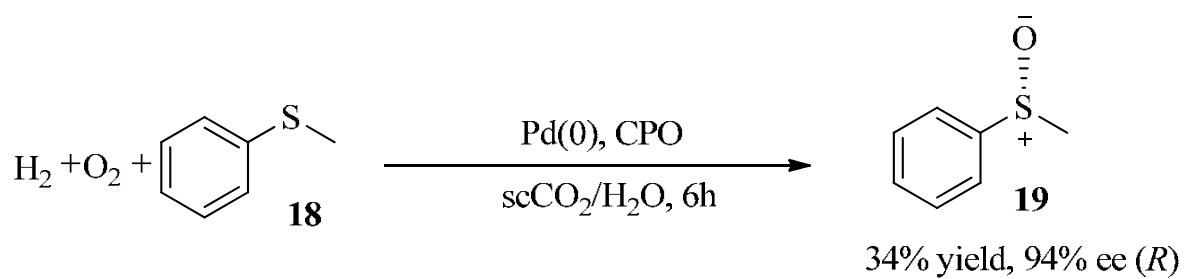

\section{Scheme 70}

Hollmann and Arends also used CPO enzyme to produce 19 in quantitative yield and 99\% ee. This procedure involved light-driven $\mathrm{H}_{2} \mathrm{O}_{2}$ generation, using flavins as photocatalysts and EDTA as sacrificial electron donor. The waste product produced from EDTA oxidation 
(formaldehyde, ethylene diamine) was a major disadvantage with this method. The replacement of EDTA with formate resulted in a decrease in the enantioselectivity to $78 \%{ }^{202}$

Initial investigations using horseradish peroxidase in asymmetric sulfide oxidation were disappointing. ${ }^{203}$ The generation of engineered biocatalysts by replacing one of the amino acids in the enzyme, phenylalanine with leucine, resulted in a major improvement in the performance of the enzyme with $(S)$ sulfoxides being obtained with high enantiopurity. ${ }^{204,205}$ A variety of aryl alkyl sulfoxides were obtained with $>90 \%$ ee. Replacing the amino acid with threonine resulted in a drop in enantioselectivity.

An improvement in the performance of the enzyme, mammalian lactoperoxidase, was observed when the oxidant was added continuously rather than in aliquots, enabling the sulfoxide 19 of thioanisole 18 to be obtained in $85 \%$ yield and $80 \%$ ee. $^{206}$

Flavin-dependent monooxygenase 3 (FMO3) was used to prepare enantioenriched Sulindac 6 from the analogous sulfide in $90 \%$ ee with the $R$ enantiomer predominating. ${ }^{12}$ Sulfides have been asymmetrically oxidised by toluene dioxygenase (TDO) and naphthalene dioxygenase (NDO) with the resulting sulfoxides being isolated in high yield and enantiopurity. ${ }^{207}$

Recombinant 4-hydroxyacetophenone monooxygenase (HAPMO) from Pseudomonas fluorescens ACB was reported as an excellent enzyme for asymmetric sulfide oxidation. ${ }^{208} \mathrm{De}$ Gonzalo et al. used this enzyme to prepare a variety of aryl alkyl sulfoxides in high yield and high enantiopurity, for example 19 was obtained in $99 \%$ ee with $96 \%$ conversion.

Myeloperoxidase mediated asymmetric sulfide oxidation was investigated by Wever ${ }^{203}$ and the results obtained were interesting. At $\mathrm{pH}=5$ maximal sulfoxide yields were reported but optimal enantioselectivity of the oxidation occurred at $\mathrm{pH}=6$. Overall the results were modest with 19 being obtained with a maximum of $32 \%$ ee.

Many enzymes rely on an iron porphyrin system to carry out the oxidation, however the use of non-heme enzymes has also attracted attention. For example manganese peroxidase was successfully used to oxidise 18. ${ }^{203}$ Limited investigations resulted in 19 being isolated in $18 \%$ yield but with $91 \%$ ee.

Vanadium haloperoxidases are probably the most investigated non-heme based peroxidases used in asymmetric sulfide oxidation. Anderssen and Allenmark reported moderate enantioselectivity when oxidising aryl alkyl sulfides using vanadium bromoperoxidase. ${ }^{209}$ ten Brink reported improved enantioselectivity using vanadium bromoperoxidase from Ascophyllum nodosum. ${ }^{210}$ Better enantioselectivity was observed preparing aryl sulfoxides which contained activating substituents at the para position of the aromatic ring. The sulfoxide $\mathbf{1 7 3}$ was obtained in $89 \%$ ee.

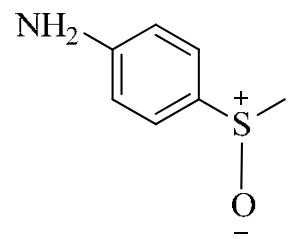


Recently, a cytochrome P450 monooxygenase was successfully cloned from Rhodococcus species ECU0066 and used in asymmetric sulfide oxidations. ${ }^{211}$ A number of aryl methyl sulfides were oxidised to sulfoxides with modest to good conversions and excellent enantioselectivities (Scheme 71).

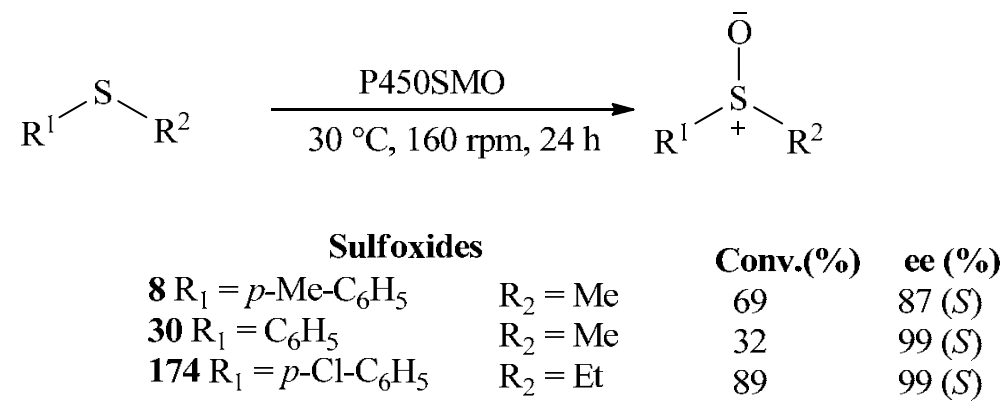

\section{Scheme 71}

Casella et al. reported that mushroom tyrosinase (Agaricus bisporus) could catalyse the asymmetric oxidation of sulfides to sulfoxides in the presence of catechol as substrate. Only the oxy-form of the enzyme was capable of oxidising the sulfide in a two electron process. The yield was low $(\sim 20 \%)$ because L-dopamine, which was used as a reductant, competed with the sulfide in the catalytic reaction. However, the enantioselectivity was high ( $\sim 85 \%$ ee) and could be further increased when excess ascorbic acid is added to the reaction to limit enzyme inactivation by the quinones produced by L-dopa oxidation. ${ }^{212}$

\section{Kinetic Resolution of Sulfoxides}

While asymmetric sulfide oxidation is more attractive as a route to enantiopure sulfoxides, a second strategy involving kinetic resolution in sulfoxide oxidation has also been explored. Kinetic resolution strategies can be categorised as either oxidative or non-oxidative, with the former being the most popular strategy.

\subsection{Oxidative kinetic resolution}

Most kinetic resolution methods involve the preferential oxidation of one sulfoxide enantiomer to the sulfone, leaving the remaining sulfoxide enantioenriched. Asymmetric sulfide oxidation is often accompanied by stereoselective sulfoxide oxidation called kinetic resolution, which often exhibits complementary stereoselectivity to the asymmetric sulfide oxidation step, enhancing the overall enantioselectivity of the oxidation. Most of the reported kinetic resolution methods are in 
fact variations of asymmetric sulfide oxidations, with the principal difference being the substrate used is the sulfoxide rather than the sulfide.

While kinetic resolution of racemic sulfoxides is rarely employed as a route to enantioenriched sulfoxides, as the maximum yield is at best $50 \%$, a number of groups engaged in the enantioselective preparation of sulfoxides have successfully used asymmetric sulfide oxidation in tandem with kinetic resolution to prepare enantioenriched sulfoxides (Scheme 72).

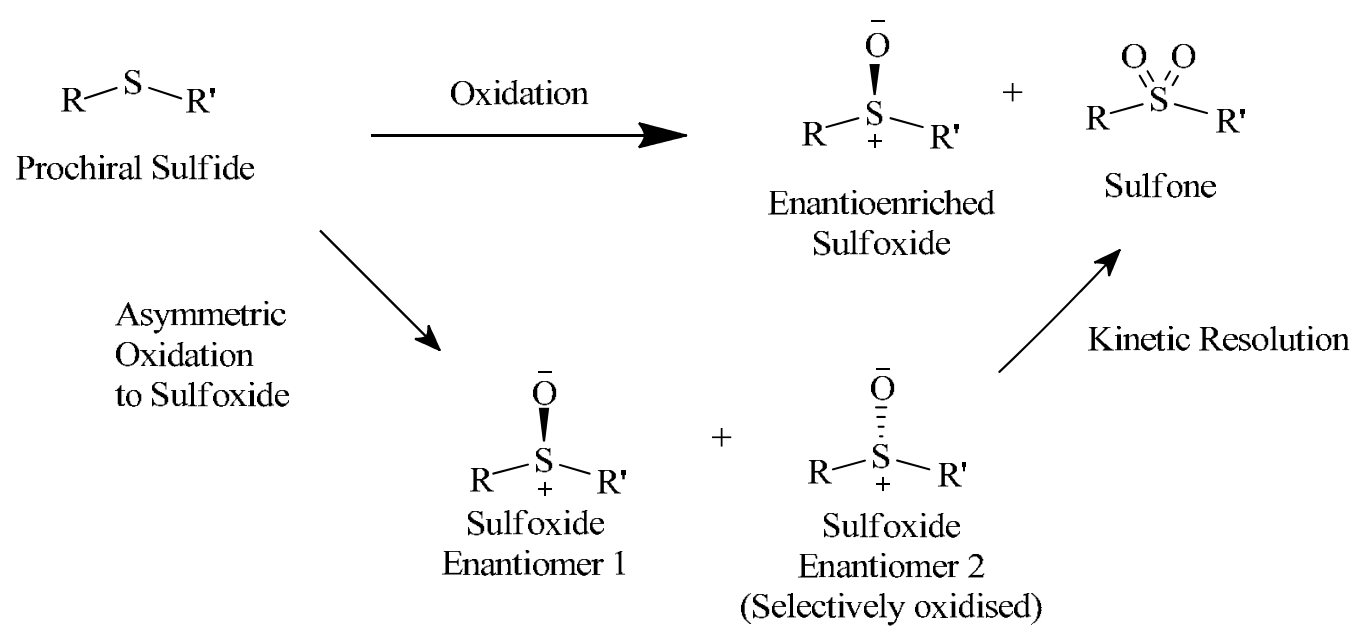

\section{Scheme 72}

Various catalysts and oxidants that have been employed in oxidative kinetic resolutions are discussed below. Most research reports regarding kinetic resolution employ aryl methyl sulfoxides while some reports use aryl benzyl sulfoxides.

3.1.1 Biological methods. Oxidising racemic para-tolyl methyl sulfoxide 8 using an Aspergillus Niger culture, resulted in the unreacted sulfoxide being isolated in $57 \%$ yield and $30 \%$ optical purity. ${ }^{213}$ Sugimoto reported that kinetic resolution took place when oxidising racemic sulfoxide with hydrogen peroxide in the presence of BSA. ${ }^{188}$ The highest enantioselectivity was observed in the kinetic resolution of tert-butyl phenyl sulfoxide 166, which was isolated with $33 \%$ ee after the kinetic resolution experiment. Using a combination of both asymmetric sulfide oxidation and kinetic resolution, Sugimoto obtained phenyl iso-propyl sulfoxide 162 in 93\% ee. ${ }^{214}$

Overall, compared to the number of biological asymmetric sulfide oxidations reported, relatively few biological kinetic resolutions of sulfoxides have been reported.

3.1.2 Chiral oxidants. Peroxy acids. One of the earliest reports of oxidative kinetic resolution was described by Montanari. ${ }^{132}$ A chiral peroxy acid, 2,3,3-trimethylperbutyric acid, preferentially oxidised one enantiomer of a racemate while leaving the other sulfoxide enantiomer enantioenriched. Unoxidised 19 was obtained in 3\% ee while unoxidised tert-butyl 
phenyl sulfoxide 166 was obtained in 5\% ee. Koboyashi described a similar kinetic resolution experiment, using percamphoric acid in the oxidation of racemic benzyl para-tolyl sulfoxide 175; the unoxidised sulfoxide was found to have an optical purity of $3 \%$ ee. $^{215}$

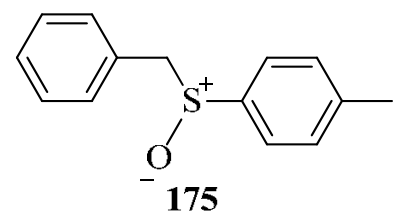

Oxaziridines. Davis has successfully employed oxaziridines in kinetic resolution experiments. ${ }^{216}$ Using chiral 2-sulfonyloxaziridines, such as 176, sulfoxides were isolated in up to $27 \%$ ee, using para-tolyl methyl sulfoxide $\mathbf{8}$ as substrate.

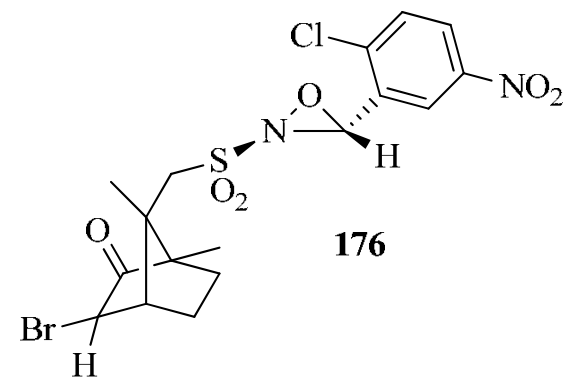

Davis proposed that this oxidative kinetic resolution method could be used in conjunction with asymmetric sulfide oxidation and, through multi-step kinetic resolutions, it would be possible to improve the enantiopurity of the sulfoxide.

Hydroperoxides. TADOOH 135 was used by Seebach and Aoki to asymmetrically oxidise sulfides. ${ }^{134}$ Significant complementary kinetic resolution of the sulfoxide product accompanied the sulfide oxidation, and this was used to improve the overall enantioselectivity of the oxidation. The contribution of kinetic resolution was temperature dependent; virtually no kinetic resolution was observed at $-30{ }^{\circ} \mathrm{C}$, while it was most efficient at room temperature (Scheme 73 ).

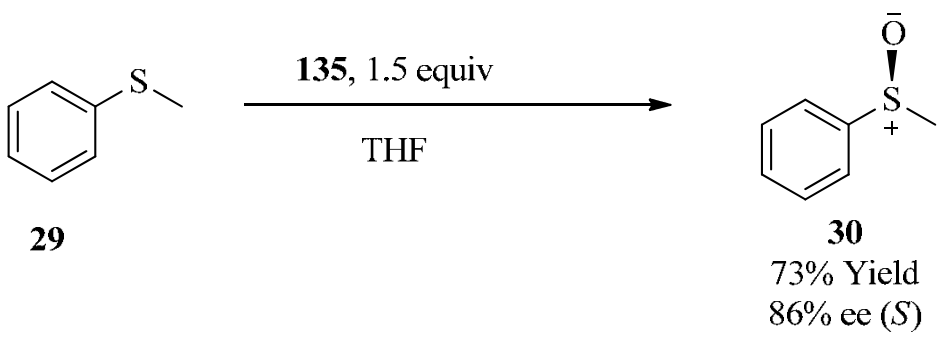

\section{Scheme 73}


3.1.3 Chiral catalysts. Inclusion complexation in the solid state. Toda reported that kinetic resolution occurs when sulfoxides are oxidised in the presence of the optically active host compound, (-)-1,6-di(o-chlorophenyl)-1,6-diphenylhexa-2,4-diyne-1,6-diol, $\quad$ 178. $^{217}$ Racemic sulfoxide 177 was mixed with 178 and kept at room temperature for a day, and then selectively oxidized to the sulfone by mixing with an achiral oxidising agent such as $m$-CPBA or MMPP and leaving for a further day. The sulfoxide recovered was enantioenriched because the optically active host compound selectively binds one sulfoxide enantiomer; the unbound enantiomer is then oxidized to the sulfone. Excellent enantioselectivity was obtained in some cases, albeit at the expense of yield (Scheme 74). The absolute stereochemistry of 177 was not identified.

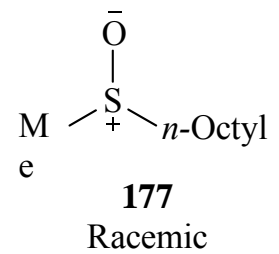

Racemic
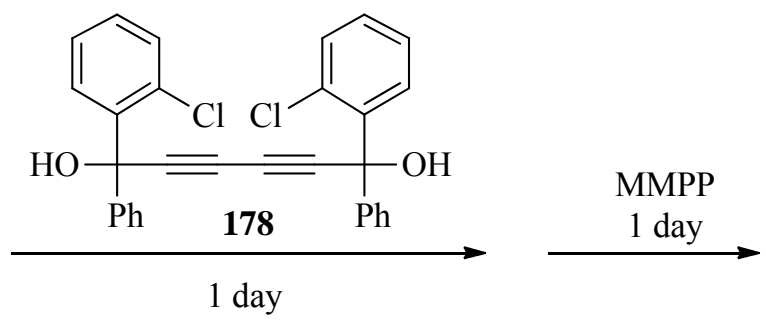<smiles>CS(=O)OO</smiles>

177

$7 \%$ Yield $100 \%$ ee

\section{Scheme 74}

Titanium catalyzed oxidative kinetic resolution. The modified Sharpless reagents developed by Kagan and Modena have both been used in kinetic resolution experiments. Uemura reported a correlation between enantiopurity and sulfone concentration, see section $2.11 .^{218}$ Using a combination of both asymmetric sulfide oxidation and kinetic resolution, 8 was obtained in 99\% ee (Scheme 75). Uemura optimised the conditions for the kinetic resolution which were similar to those used in asymmetric sulfide oxidation. The major difference was that the optimum temperature was found to be $25{ }^{\circ} \mathrm{C}$ for the kinetic resolution compared to $-20{ }^{\circ} \mathrm{C}$ for the asymmetric sulfide oxidation. $^{219}$
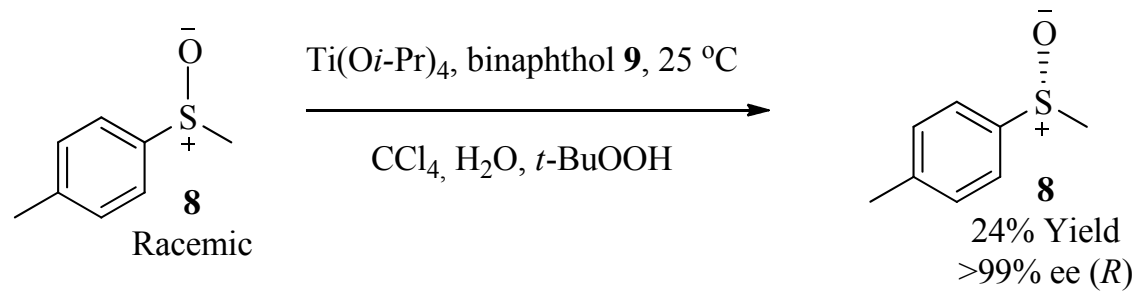

\section{Scheme 75}

Superchi and Rosini reported that $(S, S)$-1,2-diphenylethan-1,2-diol 11 was a suitable ligand for titanium mediated asymmetric sulfide oxidation. ${ }^{30,220}$ The oxidation was accompanied by 
significant sulfone formation due to kinetic resolution. In this case, kinetic resolution did not improve enantioselectivity, and therefore conditions were developed to suppress it. Thus, the reaction time was limited to 2 hours, two equivalents of the oxidant were used and the reaction was carried out at $0{ }^{\circ} \mathrm{C}$. Carrying out at a lower temperature, $-20{ }^{\circ} \mathrm{C}$, would have perhaps reduced or even eliminated kinetic resolution, as has been shown by Uemura. ${ }^{219}$

Licini employed a trialkanolamine ligand $\mathbf{1 2 9}$ and CHP as oxidant in a titanium mediated sulfide oxidation. ${ }^{128}$ Significant sulfone formation was observed, attributable to oxidative kinetic resolution of the sulfoxide (Scheme 76).

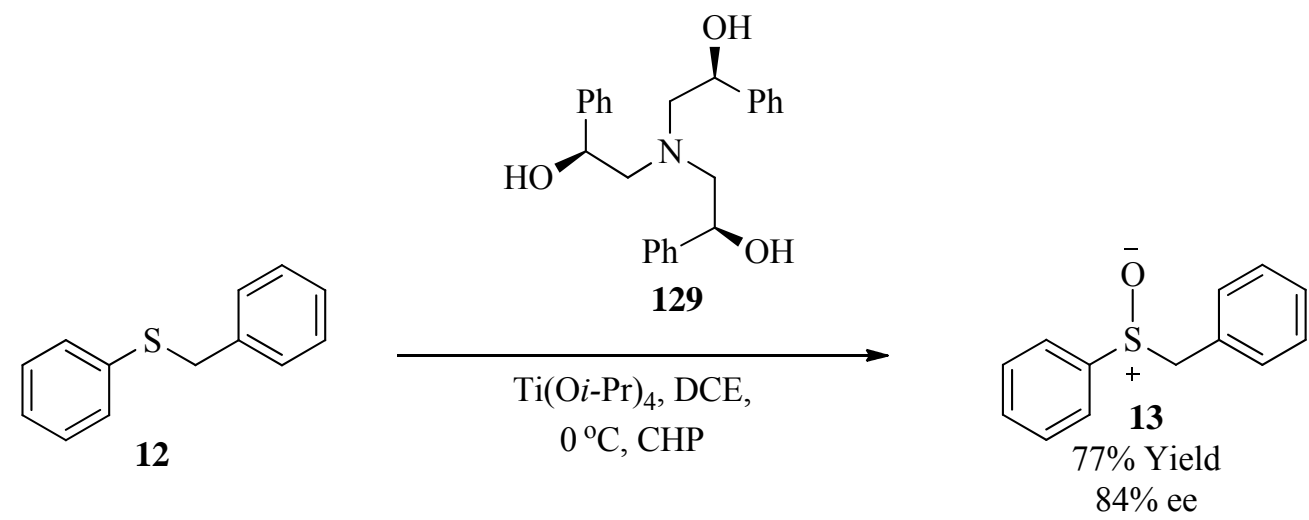

\section{Scheme 76}

Scettri, using the conditions reported by Modena, reported that racemic sulfoxides could be enantioselectively oxidised to the sulfone. ${ }^{41 \mathrm{~b}}$ Using CHP, Scettri obtained para-chlorophenyl methyl sulfoxide 44 in good yield and high enantioselectivity (Scheme 77). Poorer enantioselectivity was observed when TBHP was the oxidant.<smiles></smiles>

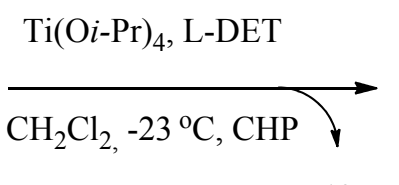

Sulfone

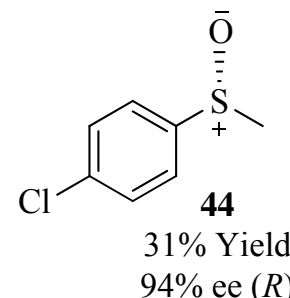

$94 \%$ ee $(R)$

\section{Scheme 77}

In a later report by Scettri, the enantioselectivity of the oxidation was improved using a racemic furyl hydroperoxide $\mathbf{2 4}$ as the oxidant. ${ }^{41 \mathrm{c}}$ The hydroperoxide $\mathbf{2 4}$ had already been successfully used in asymmetric sulfide oxidation, ${ }^{41 \mathrm{a}}$ see section 1.2. The results obtained using the hydroperoxide $\mathbf{2 4}$ were superior to those reported using CHP, with sulfoxides being obtained in higher enantiopurity. The enantioenriched sulfoxide 8 was obtained through a combination of 
asymmetric oxidation and complimentary kinetic resolution (Scheme 78). Kinetic resolution alone produced enantioenriched $\mathbf{8}$ in $>95 \%$ ee but in a $38 \%$ yield, much lower than the $60 \%$ yield obtained through a combination of asymmetric sulfide oxidation and complimentary kinetic resolution.

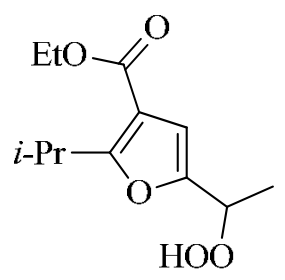

24

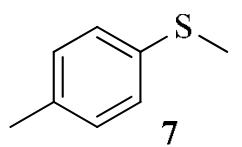

7

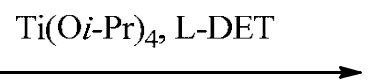

$\mathrm{CH}_{2} \mathrm{Cl}_{2},-20^{\circ} \mathrm{C}, 40 \mathrm{~h}$<smiles>Cc1ccc([Sb](C)=O)cc1</smiles>

$60 \%$ Yield

$>95 \%$ ee $(R)$

\section{Scheme 78}

Steroidal furyl hydroperoxides 25 also proved to be very efficient oxidants in the kinetic resolution of sulfoxides, though not as effective as the furyl hydroperoxide oxidant $\mathbf{2 4}$ discussed previously. ${ }^{41 \mathrm{e}}$ Employing both asymmetric sulfide oxidation and kinetic resolution, sulfoxides were obtained in good yield and high enantiopurity using this oxidant. While the results shown may be inferior in terms of yield and enantioselectivity to those obtained previously by Scettri, the reaction time is considerably shorter (Scheme 79).
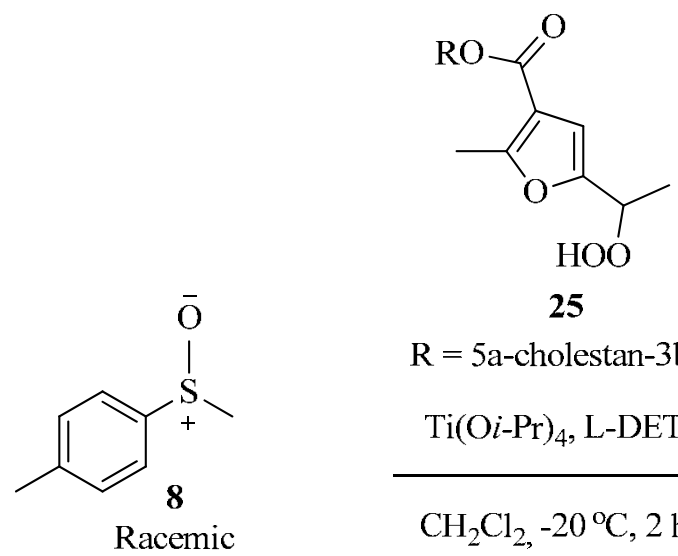

25

$\mathrm{R}=5 \mathrm{a}-$ cholestan-3b-yl
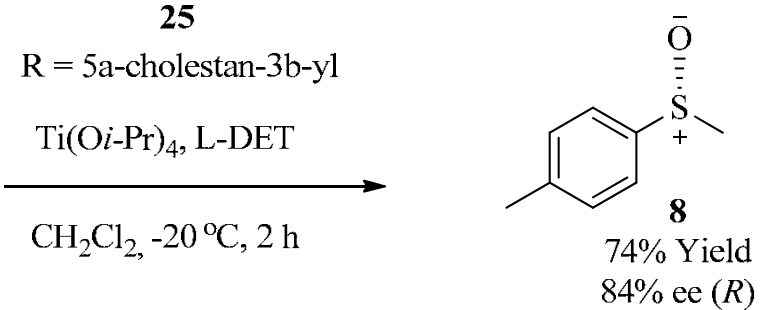

\section{Scheme 79}


Enantiopure chiral camphor derived furyl hydroperoxides, which obviate the need to use a chiral auxiliary in the oxidation, have also been shown to promote the kinetic resolution of sulfoxides. ${ }^{41 \mathrm{~g}}$ For example, the enantiopure chiral camphor derived furyl hydroperoxide $\mathbf{1 7 9}$ was found to catalyse kinetic resolution with moderate enantioselectivity (Scheme 80). ${ }^{43}$

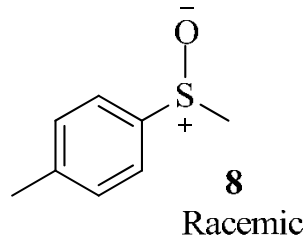

Racemic

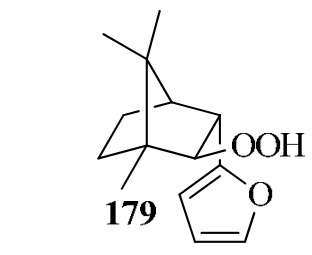

$\mathrm{Ti}(\mathrm{Oi}-\mathrm{Pr})_{4}, 28 \mathrm{~h}$

Toluene, $-20^{\circ} \mathrm{C}$

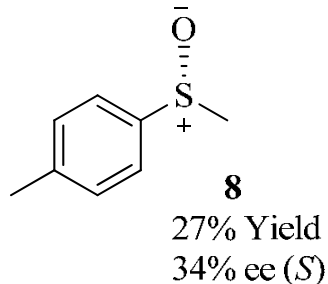

\section{Scheme 80}

Similar results were reported using the optically pure $(S)$-norcamphor derived tertiary furyl hydroperoxides 28 and $\mathbf{1 8 0} .^{42,43 b}$

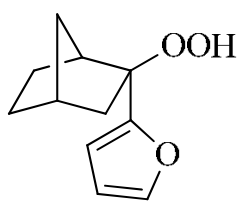

28

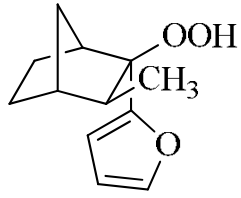

180

Scettri recently used a functionalised $(S)$-norcamphor-based hydroperoxide/titanium(IV) isopropoxide system 182 in the asymmetric oxidation of a range of aryl benzyl and aryl alkyl sulfides. It was observed that the asymmetric oxidation was accompanied by complimentary kinetic resolution (Scheme 81). ${ }^{221}$<smiles>Cc1ccc(SCc2ccccc2)cc1</smiles>
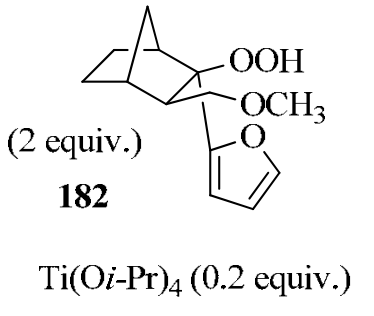

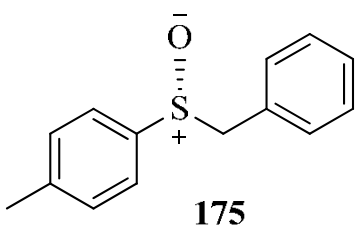

$86 \%$ Yield, $93 \%$ ee $(R)$ 


\section{Scheme 81}

Adam et al. found that titanium mediated asymmetric sulfide oxidation using optically active hydroperoxides as oxidants, was accompanied by the kinetic resolution of the sulfoxide product. $^{40}$ The optimum hydroperoxide was found to be $(S)$-1-phenylethyl hydroperoxide 23 . It was proposed that the enantioselectivity is most likely due to steric effects, as shown in Figure 7, steric hindrance in complex 183a between the hydroperoxide and the aromatic group of the $S$ sulfoxide would be expected, whereas in complex 183b less steric hindrance would be expected, hence preferential oxidation of the $R$ sulfoxide to the sulfone over the $S$ sulfoxide occurs. When the solvent used is iso-propanol, which can coordinate to the titanium centre, no kinetic resolution occurs, supporting Adam's proposal.
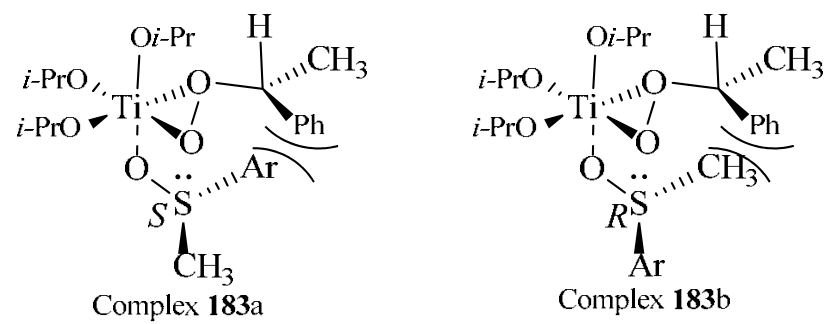

\section{Figure 7}

Chan et al. developed a one pot tandem catalytic oxidation and kinetic resolution process for the enantioselective preparation of sulfoxides. ${ }^{222}$ Using conditions slightly different to those used by Uemura, sulfoxides in high yield and good enantiopurity were obtained. The key difference between the Uemura method and this method was that the oxidant (TBHP) was in a decane solution and not an aqueous solution, affording greater control over the water content of the reaction. The oxidation conditions involved temperature control with the asymmetric oxidation step taking place at $0{ }^{\circ} \mathrm{C}$ and the subsequent kinetic resolution step at $25{ }^{\circ} \mathrm{C}$. The best result was obtained oxidising para-tolyl methyl sulfide 8 (Scheme 82).

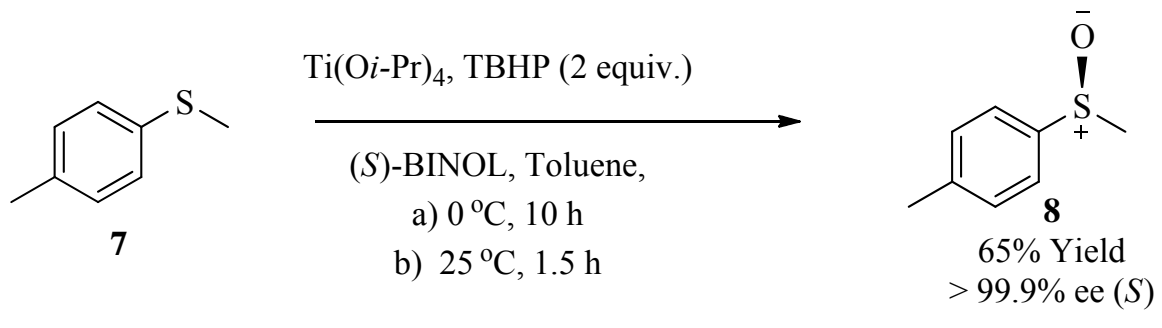

\section{Scheme 82}


Use of the ligand (S)-6,6-dibromobinaphthol 184 was also investigated in this oxidation method and it was found that while enantioselectivity dropped, the rate of sulfur oxidation increased, see section 2.1.2.<smiles>Oc1ccc2cc(Br)ccc2c1-c1c(O)ccc2cc(Br)ccc12</smiles>

Sahoo et al. immobilised a chiral titanium-binol complex onto an ionic liquid modified SBA15 and prepared a variety of enantiopure aryl methyl sulfoxides with complementary kinetic resolution. ${ }^{57}$ When the oxidation was carried out in the presence of 1 equivalent of TBHP, the sulfoxide 19 of thioanisole 18 was obtained in $85 \%$ yield and $75 \%$ ee after 10 hours. Another 0.5 equivalents of TBHP was then added and the oxidation was monitored for another 10 hours producing sulfoxide in $59 \%$ yield and $99 \%$ ee. (Scheme 83 ). ${ }^{57}$

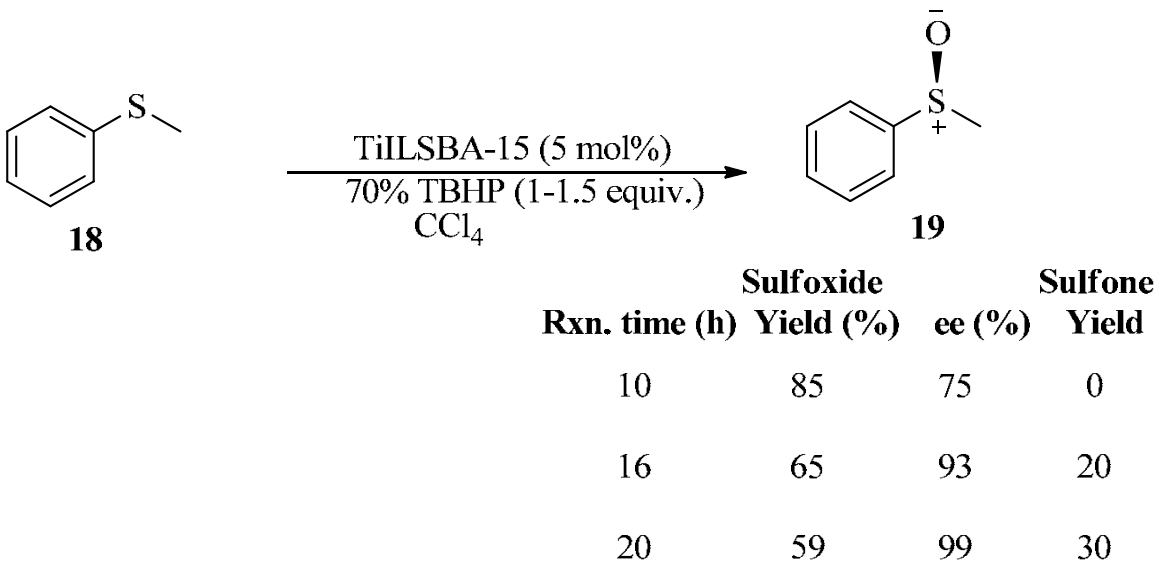

\section{Scheme 83}

Liebscher et al. reported that titanium mediated asymmetric sulfide oxidation, using chiral hydroperoxide moieties, was accompanied by complimentary kinetic resolution (Scheme 84). ${ }^{44}$ Using 1.1 equivalents of $\mathrm{H}_{2} \mathrm{O}_{2}$ the $(R)$-sulfoxide was obtained in a $55 \%$ yield and $23 \%$ ee with some over oxidation to the sulfone. However, the use of 3.3 equivalents of $\mathrm{H}_{2} \mathrm{O}_{2}$ produced the $(R)$-sulfoxide in a $16 \%$ yield and $>99 \%$ ee, with a large amount of over oxidation to the sulfone.

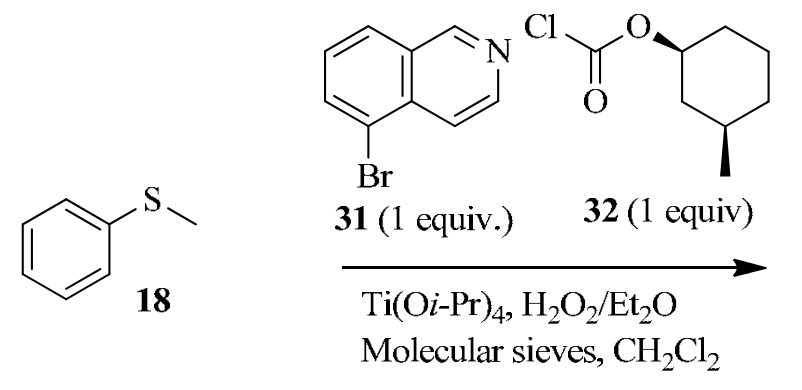




\section{Scheme 84}

Bryliakov and Talsi also observed kinetic resolution in titanium-salen-catalyzed asymmetric oxidation of sulfides. When the amount of oxidant $\left(\mathrm{H}_{2} \mathrm{O}_{2}\right)$ was reduced to just one equivalent the selectivity increased but the enantioselectivity decreased. This indicated that the high enantioselectivity was attained through both asymmetric oxidation and subsequent kinetic resolution. $^{39}$

Zeng et al. reported that the use of a 2,10-camphanediol 47 derived titanium complex, in the asymmetric oxidation of thioanisole 18, was accompanied by complementary kinetic resolution (Scheme 85). ${ }^{35}$ When 2 equivalents of CHP were used the sulfoxide 19 of thioanisole 18 was obtained in $99 \%$ ee but in very poor yield due to the formation of a large amount of sulfone (Scheme 85).

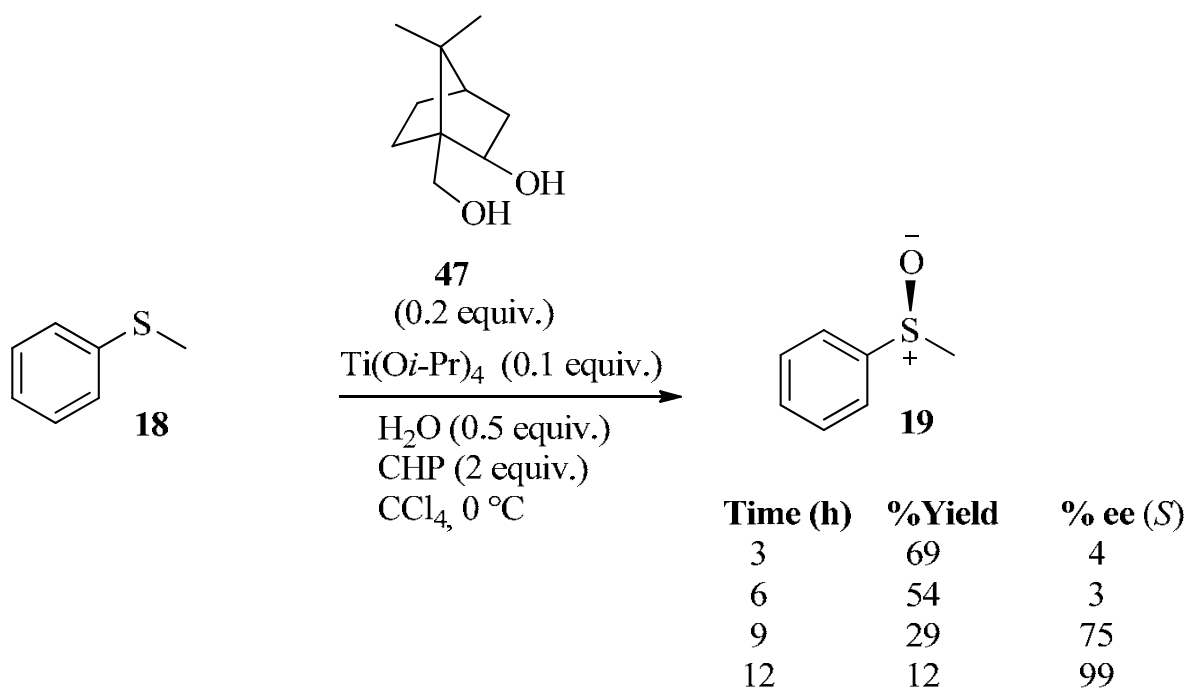

\section{Scheme 85}

Vanadium catalyzed oxidative kinetic resolution. Zhu reported a very efficient kinetic resolution method utilising a vanadium salen catalyst and hydrogen peroxide as the oxidant for the asymmetric oxidation of aryl methyl and aryl benzyl sulfides. ${ }^{99}$ The results obtained using this system compared very favourably with other kinetic resolutions reported. In some cases, the kinetic resolution of the sulfoxide was more enantioselective than the asymmetric sulfide oxidation (Scheme 86). The salen ligand 98 used was the same as that used in the asymmetric sulfide oxidation procedure, see section 2.1.2. Kinetic resolution was found to occur most efficiently using a larger amount of oxidant than that required in asymmetric sulfide oxidation. 
<smiles>c1ccc(CSc2ccccc2)cc1</smiles>

12

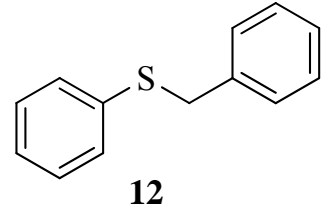

98, $\mathrm{VO}(\text { acac })_{2}$

$\mathrm{CHCl}_{3}, 0{ }^{\circ} \mathrm{C}$<smiles>[O-][Sb](Cc1ccccc1)c1ccccc1</smiles>

$78 \%$ Yield

$72 \%$ ee $(R)$<smiles>O=S(Cc1ccccc1)c1ccccc1</smiles>

$26 \%$ Yield

$93 \%$ ee $(S)$

\section{Scheme 86}

Unusually, the asymmetric sulfide oxidation and kinetic resolution exhibit divergent, hence uncomplementary, stereoselectivity, and any kinetic resolution of the sulfoxide product undermines the enantioselectivity of the asymmetric sulfide oxidation. However, given that the optimal temperature for the kinetic resolution is $25{ }^{\circ} \mathrm{C}$ and $0{ }^{\circ} \mathrm{C}$ for the asymmetric sulfide oxidation, any such effect is likely to be small.

The vanadium catalyst used in an asymmetric sulfide oxidation method reported by Bolm was initially thought not to promote kinetic resolution of sulfoxides. ${ }^{66}$ In the original report of this oxidation, it was deduced that the high enantioselectivity of the oxidation was due exclusively to asymmetric sulfide oxidation. ${ }^{66}$ This was supported by the fact very little sulfone was formed during the oxidation and that the enantiopurity of the sulfoxide product did not change significantly during the reaction. Had kinetic resolution been occurring, it would be expected that enantiopurity of the sulfoxide would decrease or increase relative to increasing sulfone formation. Subsequent reports reinforced the belief that kinetic resolution did not occur using this oxidation method as despite extensive investigation, kinetic resolution was not reported. ${ }^{58}$ The existence of the aqueous soluble achiral diperoxovanadium oxidising species, $\mathbf{8 9}$, which was possibly capable of oxidising sulfoxides to sulfones would have explained the formation of small amounts of sulfone during the reaction.

Zeng et al. was first to report kinetic resolution using this methodology. ${ }^{88}$ Zeng cited considerable sulfone formation $(10 \%)$ in the oxidation of methyl para-nitrophenyl sulfide 109 using the complexes reported by Katsuki, as an indicator of kinetic resolution possibly occuring. ${ }^{72}$ The significance of the sulfone formation was not commented on by Katsuki. The fact that Bolm reported significant sulfone formation in a similar iron catalyzed oxidation coupled with high enantioselectivity that may have been due to kinetic resolution, further 
supported Zeng's suggestion that kinetic resolution could occur during this vanadium catalyzed oxidation. $^{74 \mathrm{c}}$

To establish whether kinetic resolution was taking place Zeng investigated the effects of adding more that one equivalent of the oxidant to the reaction. ${ }^{88}$ Zeng used preformed catalyst in this investigation, which performed better than in situ generated catalyst. ${ }^{88}$ As more oxidant was added, sulfone formation increased and the enantiopurity of the sulfoxide increased, which was attributed to kinetic resolution. The oxidation of the sulfide was modified so that asymmetric sulfide oxidation and concomitant kinetic resolution could take place. The conditions in Scheme 87 were found to be the optimum conditions for the oxidation of thioanisole 18.

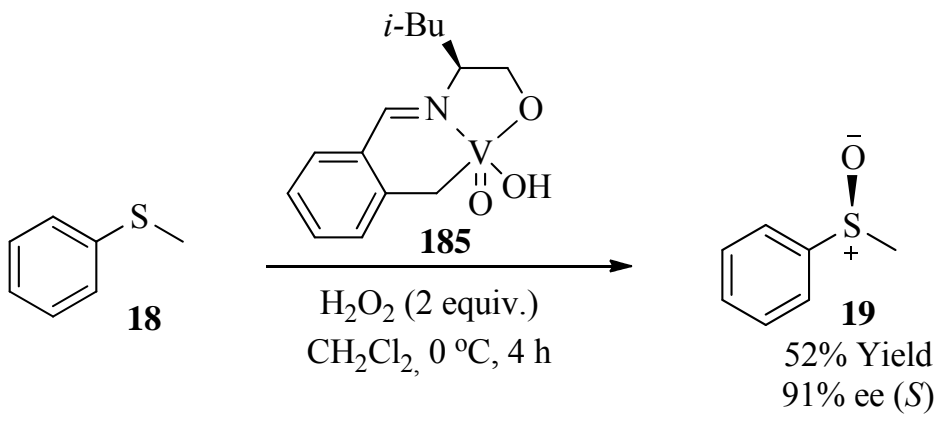

\section{Scheme 87}

At the same time, Jackson independently reported kinetic resolution using this method. ${ }^{93}$ An initial investigation using racemic sulfoxide $\mathbf{1 9}$ as substrate under the conditions in Scheme 88, yielded only limited amounts of sulfone, indicating that kinetic resolution was not a significant factor. Repeating the reaction at room temperature $\left(20{ }^{\circ} \mathrm{C}\right)$ resulted in considerable kinetic resolution being observed.

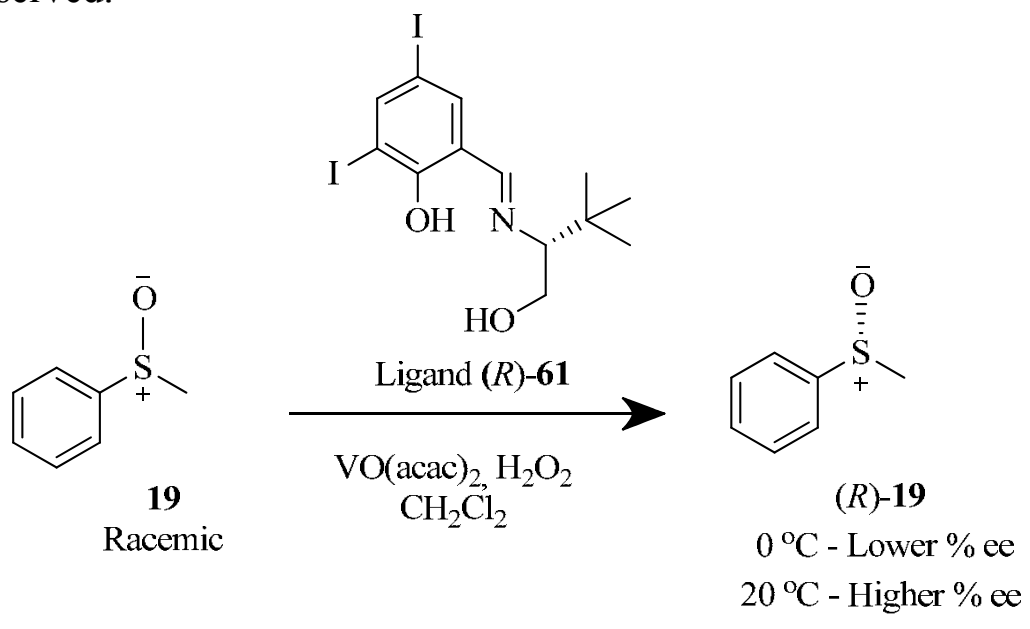

\section{Scheme 88}


Arising out of these observations, a tandem catalytic approach to the oxidative preparation of enantioenriched sulfoxides was developed (Scheme 89). This tandem approach was similar to that used by Chan in a titanium catalyzed oxidation. ${ }^{222}$

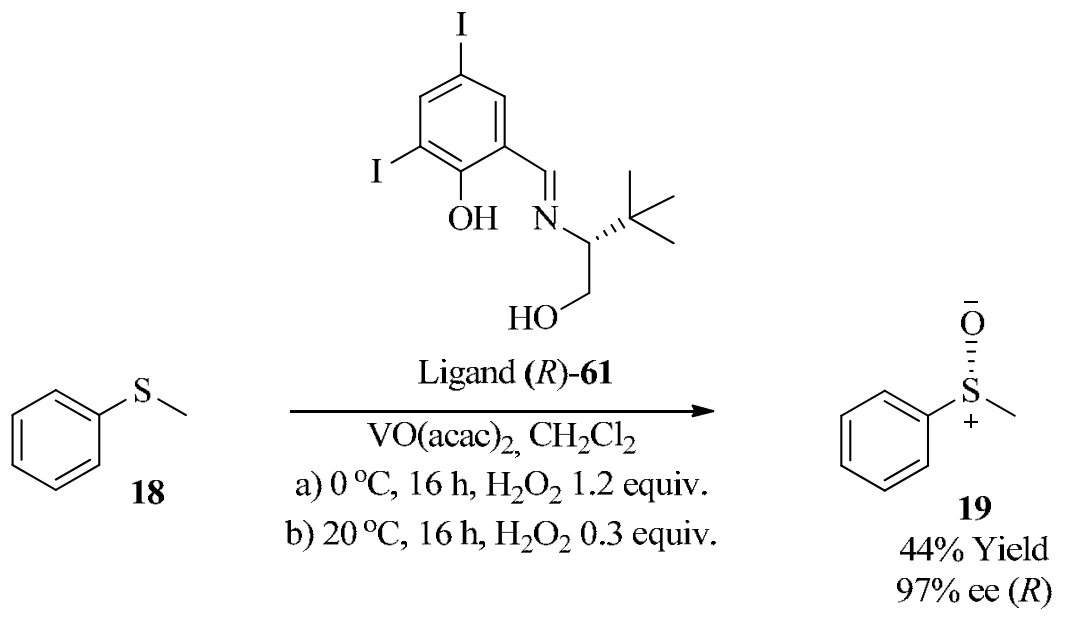

\section{Scheme 89}

Results obtained by Ellman ${ }^{68,69}$ and $\mathrm{Zhu}^{99}$ employing vanadium catalysts in asymmetric oxidation indicated that chloroform was a good solvent for asymmetric sulfide oxidations. Jackson reported that kinetic resolution was enhanced carrying out the reaction in chloroform rather than dichloromethane at $20{ }^{\circ} \mathrm{C}$ and kinetic resolution was improved even further by carrying out the reaction in chloroform at $0{ }^{\circ} \mathrm{C}$ (Scheme 90). ${ }^{93}$
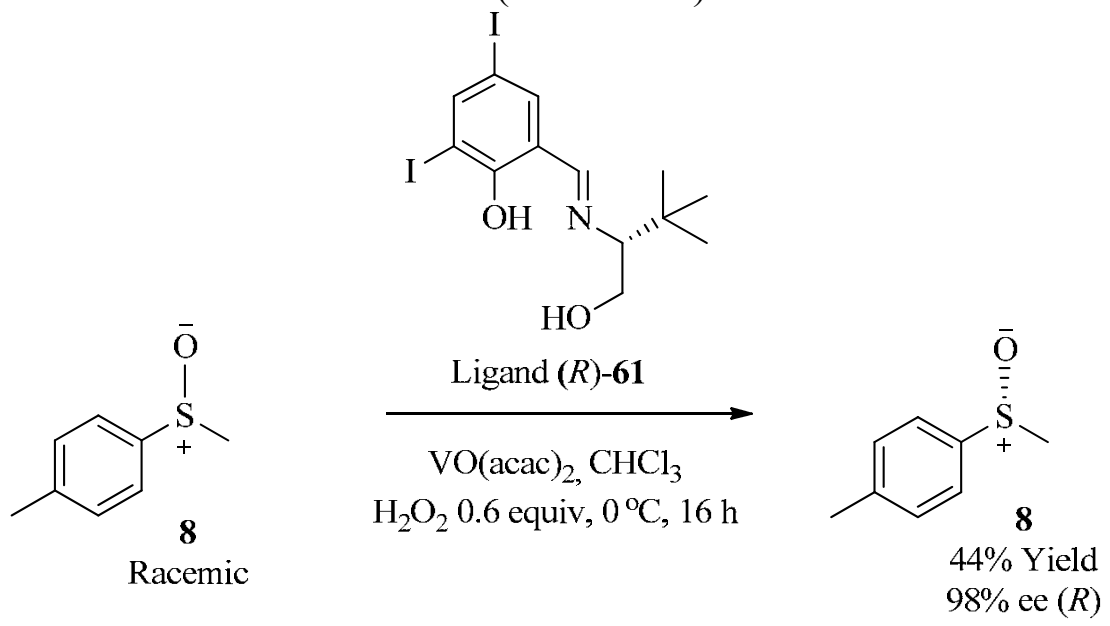

\section{Scheme 90}

Considering the maximum possible yield is $50 \%$, the $44 \%$ yield is exceptional, indicating the high efficiency of the kinetic resolution. Both Ellman and Katsuki carried out asymmetric sulfide oxidations using this catalyst and chloroform as the solvent, in both cases the optimum reaction 
temperature was $0{ }^{\circ} \mathrm{C} .{ }^{68,69,72}$ Jackson proposed that carrying out both the asymmetric sulfide oxidation and subsequent kinetic resolution in chloroform at $0{ }^{\circ} \mathrm{C}$ would be a very efficient route for the enantioselective preparation of sulfoxides. This proved to be the case with a variety of aryl alkyl sulfoxides prepared in good yield and high enantiopurity (Scheme 91). ${ }^{93}$

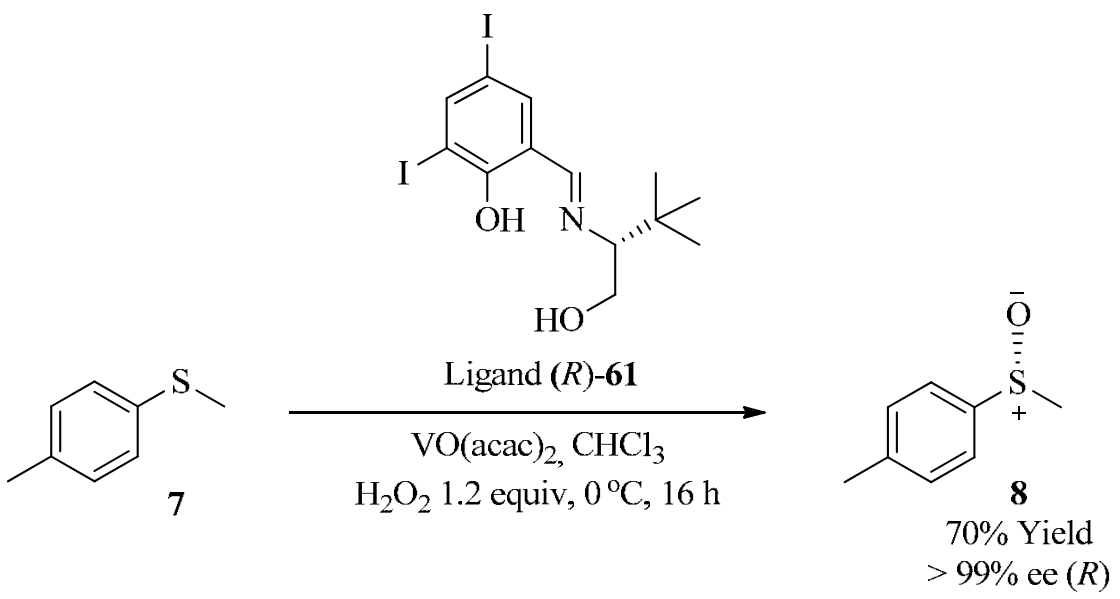

\section{Scheme 91}

This has been undertaken on a large-scale $(60 \mathrm{mmol})$, with $48 \mathrm{hr}$ reaction time. Using parabromophenyl methyl sulfide $\mathbf{1 8 6}$ and $\mathbf{7}$ as substrates, gave slightly lower enantioselectivity than the small-scale reactions, though still very high. Recrystallisation of the product yielded the sulfoxides in high yield effectively enantiopure ( $>99 \%$ ee).

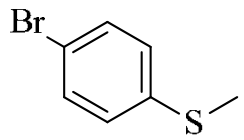

186

Maguire et al. reported kinetic resolution in vanadium catalyzed asymmetric oxidation of aryl benzyl sulfides. ${ }^{75,76}$ A number of ligands were used in these oxidations with ligand $\mathbf{6 1}$ producing the best results. Excellent enantioselectivities were obtained (typically 91-99\% ee) albeit in moderate yields. The kinetic resolution experiments produced the best results when carried out at room temperature. Carrying out the reaction at either higher or lower temperatures (temperature range investigated $-20{ }^{\circ} \mathrm{C}$ to $+30{ }^{\circ} \mathrm{C}$ ) resulted in a decrease in enantiopurity.

Jackson reported the oxidative kinetic resolution of alkyl aryl sulfoxides using a combination of $\mathrm{VO}(\mathrm{acac})_{2}$ and Schiff base ligand $\mathbf{6 1}$ in toluene. ${ }^{223}$ Jackson found that most substrates gave almost racemic products at room temperature but at elevated temperatures $\left(45^{\circ} \mathrm{C}\right)$ high enantioselectivities were obtained (Scheme 92). 

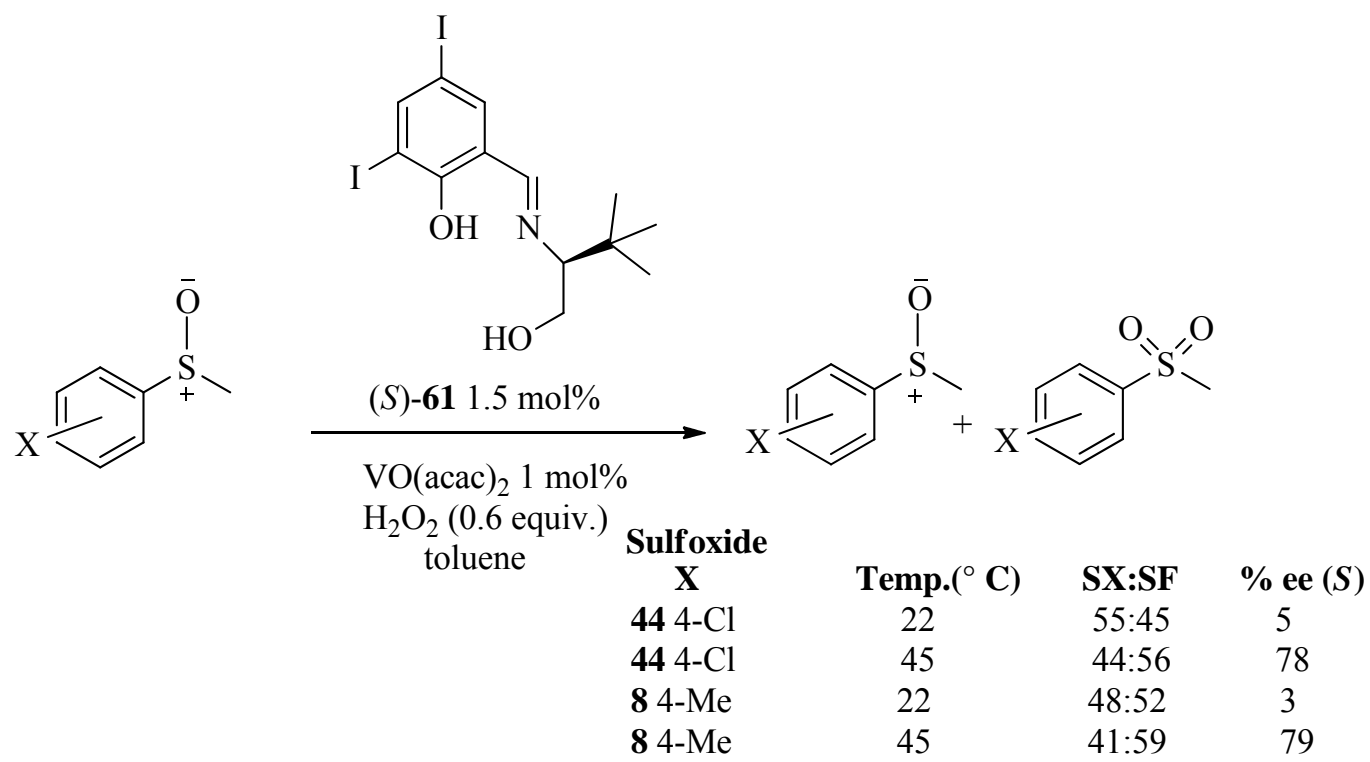

\section{Scheme 92}

Manganese catalyzed oxidative kinetic resolution. The manganese salen catalyst used by Katsuki in asymmetric sulfide oxidation was also found to catalyse kinetic resolution in the oxidation of sulfoxides (section 2.1.4). ${ }^{108}$ However, the resolution was inefficient, with high enantiopurity only being observed when the sulfoxide had been oxidised almost entirely to the sulfone.

Enantioselective aerobic asymmetric oxidation of sulfides using pivalaldehyde in the presence of a catalytic amount of optically active $\beta$-oxo aldiminatomanganese(III) complexes was reported by Nagata. ${ }^{11,114}$ Asymmetric sulfide oxidation was accompanied by kinetic resolution of the sulfoxide product, which enhanced the overall enantioselectivity of the oxidation.

Tungsten catalyzed oxidative kinetic resolution. Similar to Zhu's vanadium salen catalyst, Thakur and Sudalai's tungsten cinchona alkaloid catalyst, see section 2.1.7, was a more effective catalyst for the kinetic resolution of sulfoxides than for asymmetric sulfide oxidation. ${ }^{124}$ The conditions used for the kinetic resolution were identical to those used for the asymmetric sulfide oxidation with the notable exception of temperature. Like many of the oxidative kinetic resolution methods discussed here the optimal temperature was $25{ }^{\circ} \mathrm{C}$. The highest enantioselectivity was observed for the kinetic resolution of racemic para-tolyl benzyl sulfoxide 175 which was obtained in $25 \%$ yield and $9 \%$ ee.

Molybdenum catalyzed oxidative kinetic resolution. Molybdenum catalyzed asymmetric sulfide oxidation reported by Basak was accompanied by kinetic resolution of the sulfoxide product (section 2.1.10). ${ }^{130}$ The effect of the kinetic resolution was complementary to that of the 
asymmetric sulfide oxidation. Using racemic sulfoxide as the substrate under the same conditions as the asymmetric sulfide oxidation resulted in the isolation of enantioenriched sulfoxide (Scheme 93). Kinetic resolution also occurred efficiently when CHP was used as the oxidising agent.

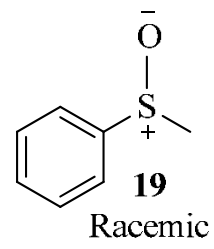

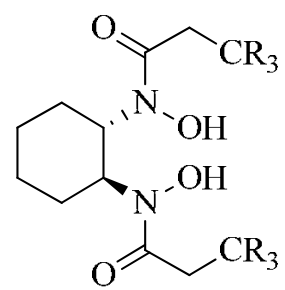

$$
\frac{\mathrm{R}=\text { 4-isopropylphenyl }}{\mathrm{Mo(acac})_{2}, \mathrm{THP}, \mathrm{CH}_{2} \mathrm{Cl}_{2}, 0^{\circ} \mathrm{C}}
$$

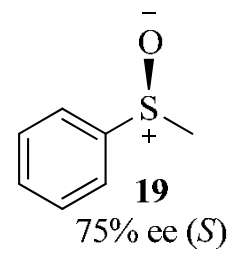

\section{Scheme 93}

Using asymmetric sulfide oxidation in combination with kinetic resolution resulted in the isolation of sulfoxides in good yield and high enantiopurity. Again the results obtained using CHP as the oxidant were better than those obtained using THP (Scheme 94).

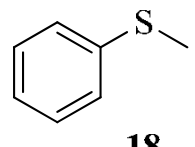

18

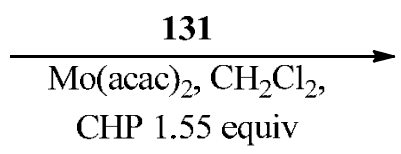

a) $-40^{\circ} \mathrm{C}, 19 \mathrm{~h}$

b) $0{ }^{\circ} \mathrm{C}, 24 \mathrm{~h}$<smiles>C[Sb]([O-])c1ccccc1</smiles>

$96 \%$ ee $(S)$

$43 \%$ Yield

\section{Scheme 94}

Zirconium catalyzed sulfoxide oxidation. Bonchio et al. reported in 1999 a highly stereoselective sulfide oxidation using a chiral zirconium(IV) catalyst. ${ }^{126,127}$ A significant amount of the sulfone formed during the oxidation. Using less oxidant (CHP) overcomes this problem but the resulting sulfoxide is effectively racemic. This, while not commented on by Bonchio, would seem to indicate that kinetic resolution of the sulfoxide was possibly taking place. The fact that using less oxidant resulted in only racemic sulfoxide being formed would suggest that the kinetic resolution, if it is taking place, is more stereoselective than the asymmetric sulfide oxidation.

\subsection{Non-oxidative kinetic resolution}


Besides enantioselective oxidation to the sulfone, it is possible to carry out kinetic resolution using other types of methodology.

3.2.1 Chemical methods. Another approach to enantiopure sulfoxides involves the preferential reduction of one of the sulfoxide enantiomers to the sulfide, leaving the other enantiomer enriched. Mikołajczyk, using ortho-ethyl phosphonothioic acid or ortho-iso-propyl methylphosphonothioic acid as the reducing agent, prepared enantioenriched sulfoxides from racemic sulfoxide. ${ }^{224}$ The enantioselectivity of the reduction was moderate with the highest enantioselectivity being observed in the reduction of $n$-butyl methyl sulfoxides with the remaining sulfoxide having $6 \%$ ee. The reducing reagent used was ortho-iso-propyl methylphosphonothioic acid. Mikołajczyk also reported the asymmetric reduction of chiral sulfoxides by optically active lithium aluminium hydride complexes with alcohols, but again low enantiopurities were obtained. $^{225}$

Drabowicz reported the partial kinetic resolution of racemic sulfoxides by reduction using a formamidinesulfinic acid-optically active amine reducing agent. Drabowicz noted that steric hindrance influenced the optical purity of the resolved sulfoxides but only modest enantiopurities were achieved overall. $^{226}$

Montanari reported very high enantioselectivity in the reduction of mesityl para-tolyl sulfoxide 187 using chiral poly[N-(1-phenylethyl)iminoalanes] obtaining 187 in $78 \%$ ee in a

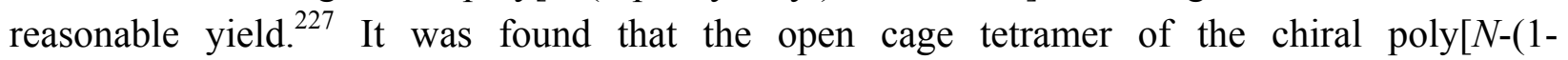
phenylethyl)iminoalanes] 188 was responsible for the enantioselectivity of the reduction.

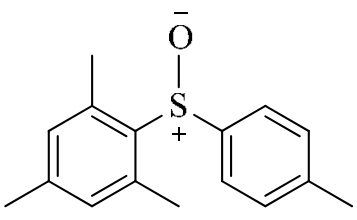

187

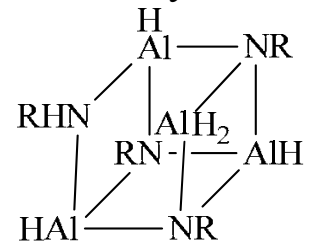

188

$\mathrm{R}=\mathrm{PhCHMe}$

Naso resolved sulfoxides using a selective elimination reaction. ${ }^{228}$ Racemic $\beta$-halosulfoxides 189 were reacted with a chiral base to form a vinyl sulfoxide $\mathbf{1 9 0}$. When the sulfoxide was reacted with insufficient base the remaining sulfoxide was enantioenriched, indicating one sulfoxide enantiomer was less reactive than the other. Highest enantioenrichment was observed when the para-tolyl $\beta$-fluoroethyl sulfoxide was used as substrate. The remaining unreacted 189 had $24 \%$ ee while the product 190 had $23 \%$ ee (Scheme 95 ). The configuration of the sulfoxide is dependent upon the base used. 


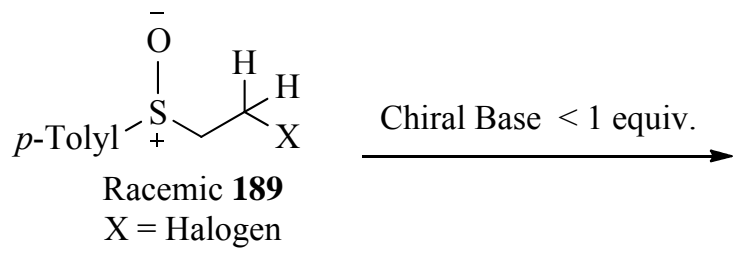<smiles></smiles>

189

$\mathrm{X}=\mathrm{F}, 24 \%$ ee

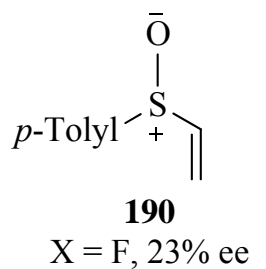

\section{Scheme 95}

Similar methodology was used to prepare enantioenriched sulfoxide. ${ }^{229}$ Reacting the $\alpha$ sulfinyl carbanion 191 with a menthyl carboxylate 194, resulted in the formation of enantioenriched $\beta$-ketosulfoxide and the remaining unreacted $\mathbf{8}$ was also enantioenriched (Scheme 96).
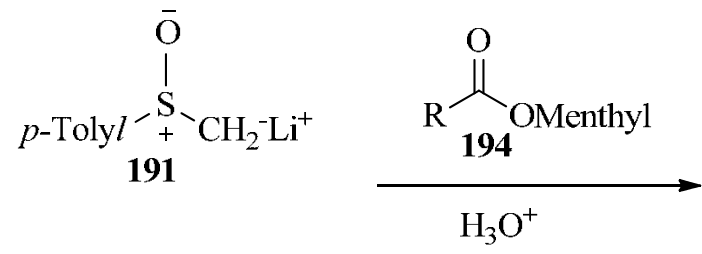

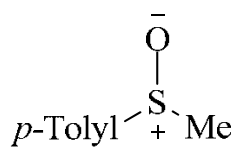

$8,13 \%$ ee

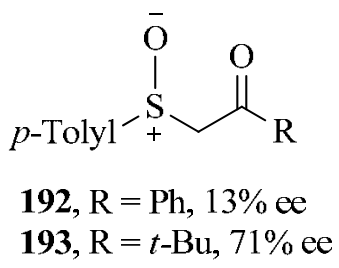

\section{Scheme 96}

Conditions were optimised and it was found that the reaction was most efficient when 0.5 equivalents of 194 was used. The results obtained when $\mathrm{R}=$ methyl were very poor with very little enantioselectivity in the reaction. When $\mathrm{R}=$ tert-butyl, there was a significant improvement in enantioselectivity with the product 193 having 71\% ee. The highest reported enantiopurity for unreacted starting material was $13 \%$ ee when $\mathrm{R}=$ phenyl. This methodology was developed from a method used to prepare bissulfoxides, where a menthyl sulfinate ester was used instead of a menthyl carboxylate. ${ }^{230}$

Ohta reported very high enantioselectivity in an enzymatic kinetic resolution. ${ }^{231}$ Hydrolysing methyl benzenesulfinylacetate using Corynebacterium equi, it was noticed that there was a substantial drop in the rate of the reaction once half the sulfoxide was hydrolysed. This was attributed to the fact that one sulfoxide enantiomer was preferentially hydrolysed by the bacteria. 
The sulfoxides were recovered in a very high yield for a kinetic resolution reaction, between 30 43\% with the maximum possible yield being $50 \%$. Enantioselectivity was excellent with 195 obtained in $97 \%$ ee. However, this method seems to be limited to certain substrates since when the lipophilic ester 196 was the substrate, enantioselectivity observed was either poor or absent.

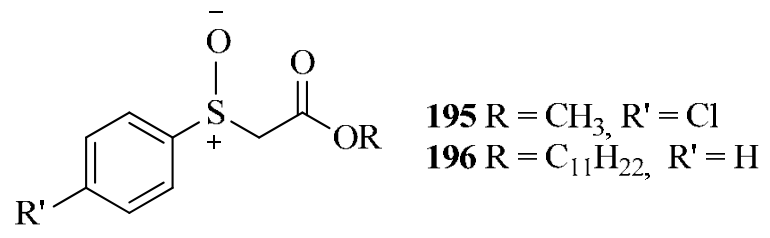

Sulfoxide enantiomers effectively do not interconvert at room temperature; they only do so at an appreciable rate at high temperatures. Pirkle observed that heating sulfoxides at low concentrations with cholesteryl esters in degassed sealed vessels resulted in a change in the ratio of sulfoxide enantiomers present. ${ }^{232}$ The change in the ratio of enantiomers was very small, for example, 1-naphthyl methyl sulfoxide $\mathbf{7 4}$ was obtained in $9 \%$ ee, using cholesteryl paranitrobenzoate. As the sulfoxides isolated are not obtained in quantitative yield, it is unclear whether the enantioenrichment is due to enantiomer interconversion or otherwise. ${ }^{233}$

3.2.2 Biological methods. While enantioselective oxidation of sulfides to sulfoxides using biological approaches has been explored extensively, see section 2.4, the reverse reaction involving the asymmetric reduction of racemic sulfoxides has received much less attention. There have been a number of reports of DMSO reductase enzymes, which can effect kinetic resolution of racemic sulfoxides/substrates. ${ }^{234}$ Sulfoxide 8 has been obtained with enantioselectivities from 32 to $>98 \%$ ee using a range of biocatalysts in asymmetric reductions of racemic 8 . $^{235}$

\section{Nucleophilic Displacement}

Nucleophilic displacement at the sulfur atom is one of the most popular and efficient methods for the preparation of enantiopure sulfoxides. ${ }^{8}$ It was first reported by Andersen ${ }^{236}$ and the methodology used in this first nucleophilic displacement is now commonly referred to as the Andersen method.

\subsection{Single nucleophilic substitution of an enantiomerically pure chiral precursor}

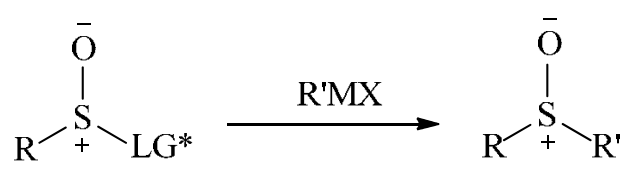

\section{Scheme 97}


The Andersen method for the preparation of enantiopure sulfoxides employs the use of a enantiomerically pure menthyl sulfinate ester. Nucleophilic attack by a Grignard reagent upon diastereomerically pure sulfinate displaces the O-menthyl leaving group to form the enantiopure sulfoxide in good yield. The reaction proceeds with complete inversion of configuration at sulfur (Scheme 97 and 98). ${ }^{237}$<smiles>O=S([Al])O[Na]</smiles>

197

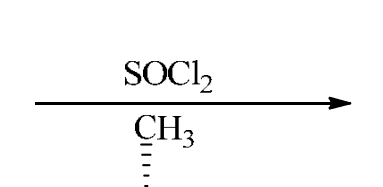<smiles>CC(C)C1CCCC[C@H]1O</smiles><smiles>C[As](C)([O-])O[Al]</smiles>

(R)-199<smiles>C[Sb](=O)([O-])O[Na]</smiles>

(S)-199 + Menthol

201

\section{Scheme 98}

The procedure described above is the method of choice for the large-scale preparation of non-racemic sulfoxides. Both diastereomers of 199 are commercially available. A significant drawback with this procedure is the preparation of the menthyl sulfinate esters. The sulfinate diastereomers require multiple recrystallisations to achieve the high degree of diastereomeric purity necessary for asymmetric synthesis of sulfoxides using the Andersen procedure. Utilising an equilibration technique discovered by Herbrandson (Scheme 99), which substantially increased the yields of $(S)-\mathbf{1 9 9}$, resolved this problem to an extent. ${ }^{238}$ The Andersen method is suitable for the preparation of alkyl aryl or diaryl sulfoxides, however dialkyl sulfoxides could not be produced using this method, as the required menthyl sulfinate could not be prepared in enantiomerically pure form at the sulfur. Investigations by Drabowicz et al. established that benzene is the best solvent for the Andersen procedure. ${ }^{239}$

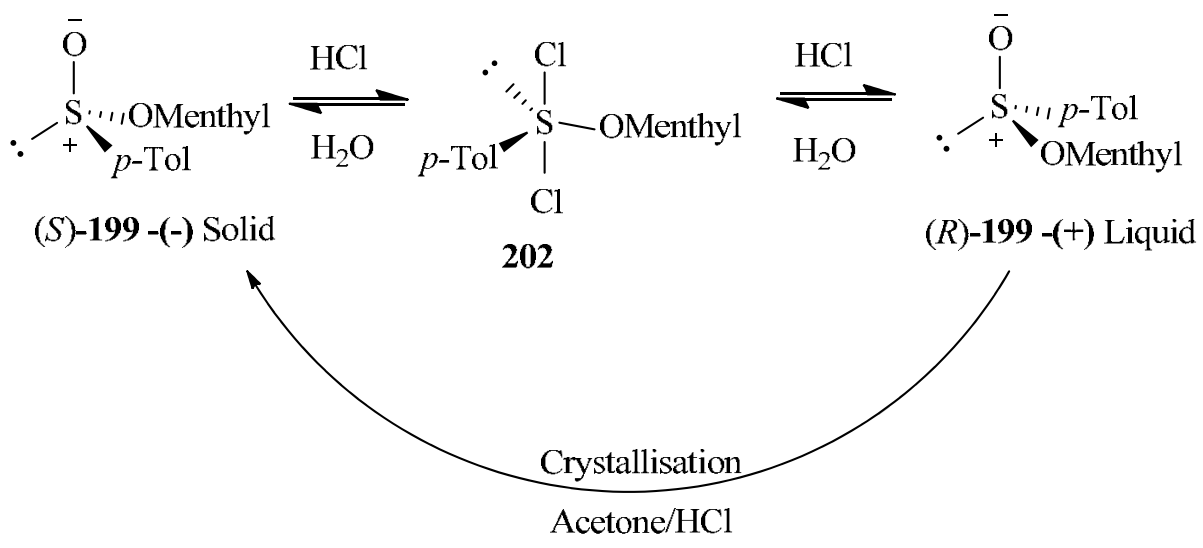




\section{Scheme 99}

Recently, Dorta et al. prepared four stereoisomers of bis-sulfoxide binaphthyl or biphenyl derivatives 203 and 204 in 34-60\% yield. ${ }^{240}$ These new chiral sulfoxide ligands were prepared from racemic 2,2'-dibromo substituted precursors using either $(+)$ or (-)-menthyl paratoluenesulfinate (Scheme 100). The resulting diastereomeric pairs were separated chromatographically. ${ }^{240,241}$

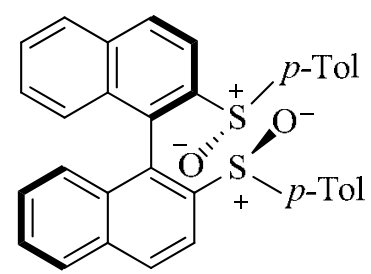

$\left(M, S_{S}, S_{S}\right)-\mathbf{2 0 3}$

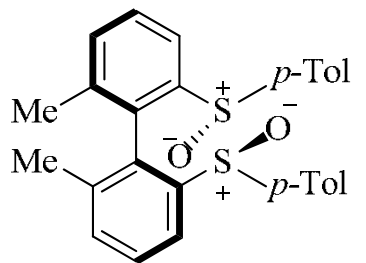

$\left(\mathrm{P}, \mathrm{S}_{\mathrm{S}}, \mathrm{S}_{\mathrm{S}},\right)^{-204}$<smiles>Brc1ccc2ccccc2c1-c1c(Br)ccc2ccccc12</smiles>

205
(1) Li Base; $-78^{\circ} \mathrm{C}$

(2) (1R or $1 S)$-Menthyl ( $S$ or $R$ )-para-toluenesulfinate, $-78^{\circ} \mathrm{C}-\mathrm{R} . \mathrm{T}$.

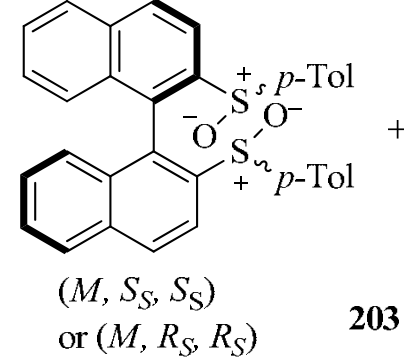

203

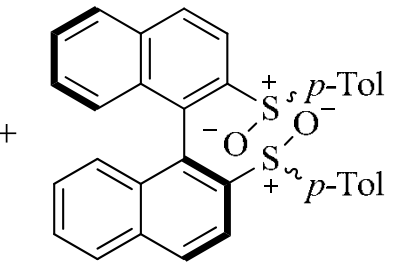

$\left(P, S_{S}, S_{\mathrm{S}}\right)$

or $\left(P, R_{S}, R_{S}\right)$

\section{Scheme 100}

Since the original Andersen procedure was published in the 1960s, a number of groups have proposed adaptations to the procedure. Most of this research has focussed on the development of new sulfinate esters. ${ }^{8}$

Andersen et al. published a procedure for the synthesis of pure methyl alkyl sulfoxides using cholesterol as the leaving group instead of menthol. ${ }^{242}$ Using cholesterol allowed preparation of the epimeric mixture of enantiomerically pure methyl sulfinate esters 207 suitable for nucleophilic substitution (Scheme 101). Dialkyl sulfoxides with high enantiomeric purity were obtained, generally in excess of $80 \%$ ee, albeit with poor yields; typically less than $50 \%$. 

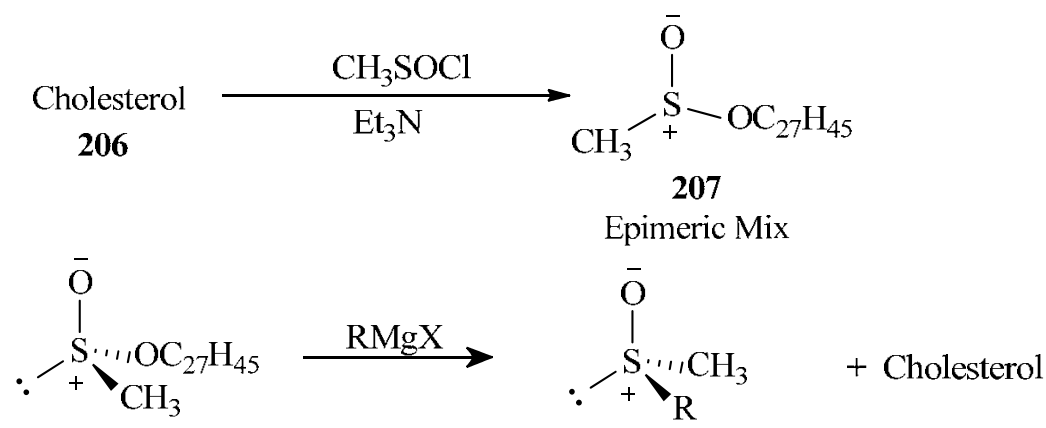

$(S)-\mathbf{2 0 7}$

8, $\mathrm{R}=p$-tolyl

\section{Scheme 101}

Whitesell et al. investigated the use of trans-2-phenylcyclohexanol $\mathbf{2 0 8}$ as the leaving group in the sulfinate ester (Scheme 102). ${ }^{243,244}$ Using 208 in the preparation of the sulfinate ester proved to be more practical than menthol, albeit at higher cost. The two cyclohexanol sulfinate diastereomers 209 formed could be separated by crystallisation or chromatography. Chromatography could not be used to separate the menthyl sulfinate diastereomers.

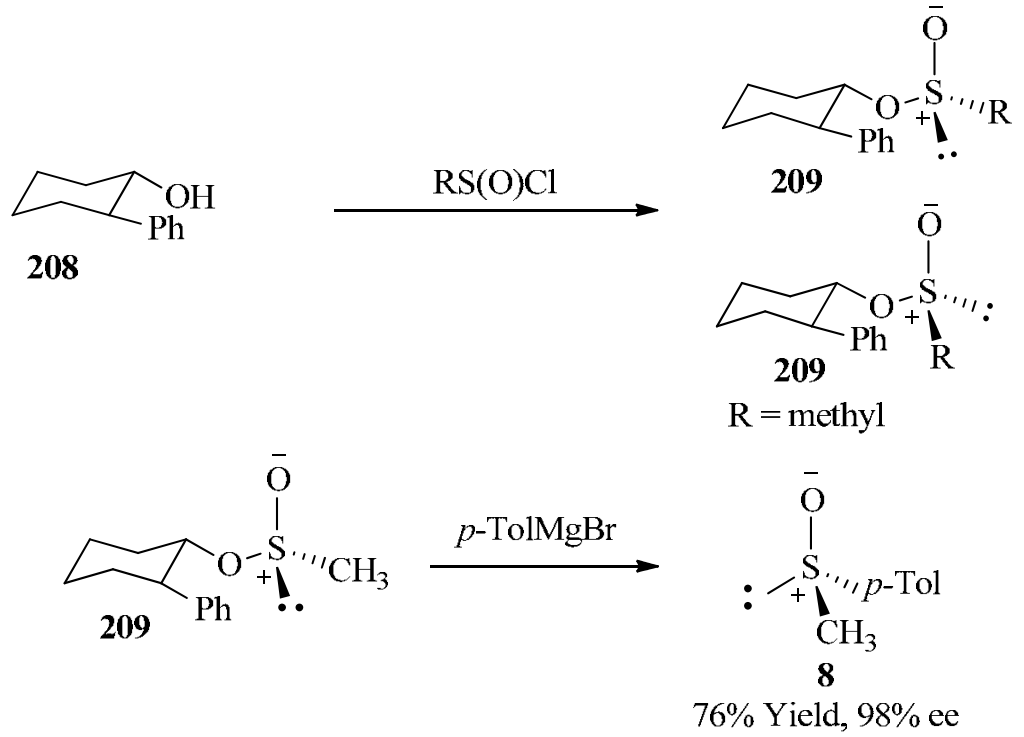

\section{Scheme 102}

Diacetone-D-glucose (DAG) 211 was also successfully used as an alternative to menthol in the preparation of the sulfinate ester 210. ${ }^{245}$ Using different bases in the preparation of the 
sulfinate, it was possible to obtain either of the two diastereomers of $\mathbf{2 1 0}$ with high diastereoselectivity (Scheme 103).

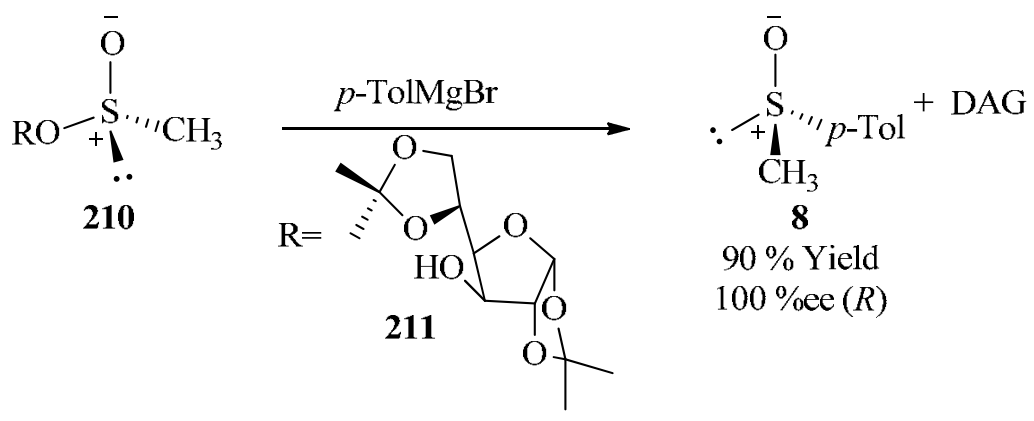

\section{Scheme 103}

In 1999, Drabowicz reported a method of asymmetric sulfoxide synthesis, which employed the amino alcohol $N$-methylephedrine 213 as the leaving group (Scheme 104). ${ }^{246}$ The sulfinates 214a and 214b were prepared using 213 and could be separated using flash chromatography. High enantioselectivity was observed.<smiles>[R12]S(=O)Cl</smiles>
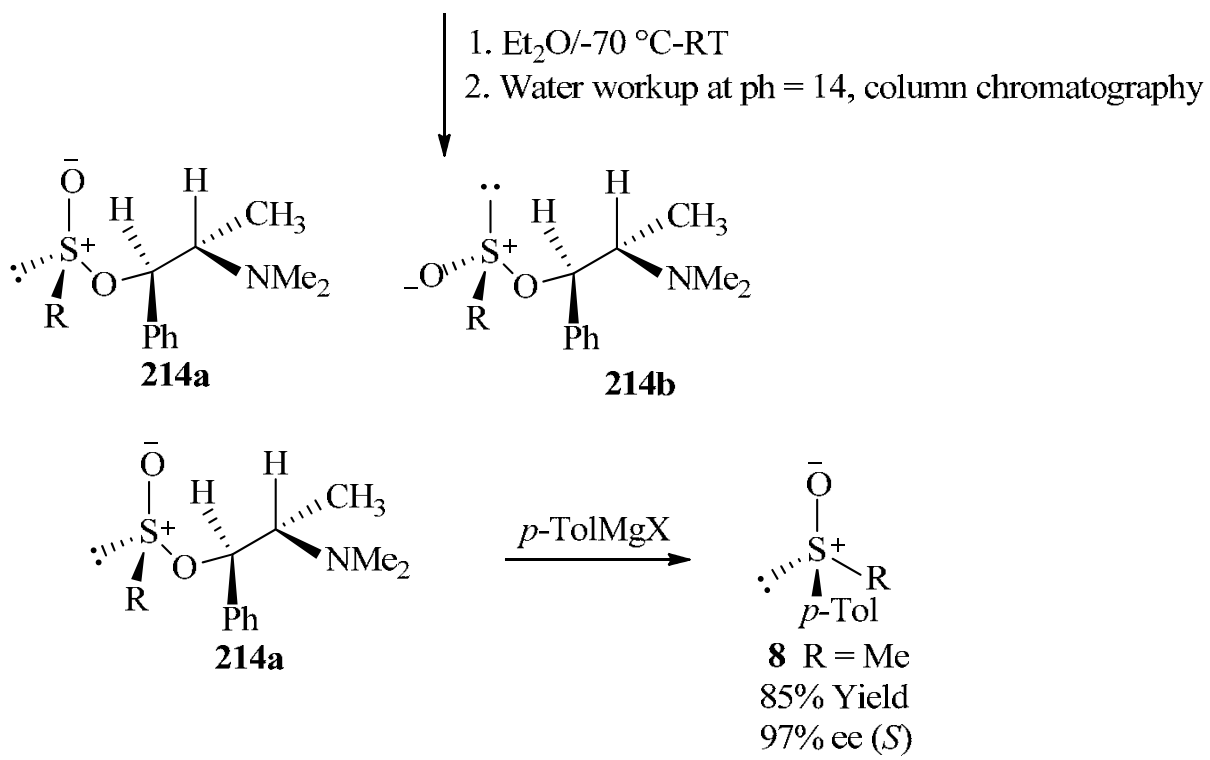


\section{Scheme 104}

Harpp employed organocopper reagents instead of Grignard reagents using the Andersen procedure. $^{247}$ The sulfoxide 215 was obtained in 59\% yield and $100 \%$ ee using this method (Scheme 105).<smiles>C[As](C)(=O)O[Mg]</smiles>

$(S)-199$<smiles>CCCCCC(C)OCC</smiles>

(R)-215 $59 \%$ Yield $100 \%$ ee

\section{Scheme 105}

Chiral sulfinamides have also been successfully used as the chiral auxiliaries in nucleophilic substitutions. Jacobus and Mislow reported that the reaction of benzenesulfinyl chloride with $(S)$ (+)-deoxyephredine 216 yielded a 3:1 mixture of sulfinamide diastereomers, 217a and 217b, which could be separated by fractional crystallisation (Scheme 106). ${ }^{248}$ By reacting the appropriate diastereomer with methyl lithium, sulfoxides with up to $92 \%$ optical purity could be isolated. Attempts to form the sulfoxides using Grignard reagents instead of lithium reagents proved unsuccessful.<smiles>CN[C@@H](C)c1ccccc1</smiles>

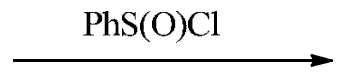<smiles>C[C@H](Cc1ccccc1)N(C)[S@](C)(=O)[18OH]</smiles>

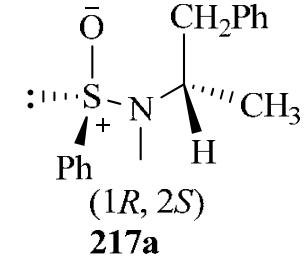<smiles>C[C@H](Cc1ccccc1)N(I)S(C)(=O)=O</smiles>

$(1 S, 2 S)$ 217b<smiles>C[Sb](C)(=O)OC#N</smiles>

Scheme 106 
$N$-Sulfinylsultam 218 has been successfully used by Oppolzer to prepare enantioenriched sulfoxides and sulfinimines. ${ }^{249} \mathbf{2 1 8}$ was formed through the 4-dimethylaminopyridine (DMAP) assisted sulfinylation of sultam. Treating 218 with an organometallic reagent in THF at low temperatures resulted in the formation of the sulfoxides, which were obtained in good yield and excellent enantiopurity (Scheme 107).

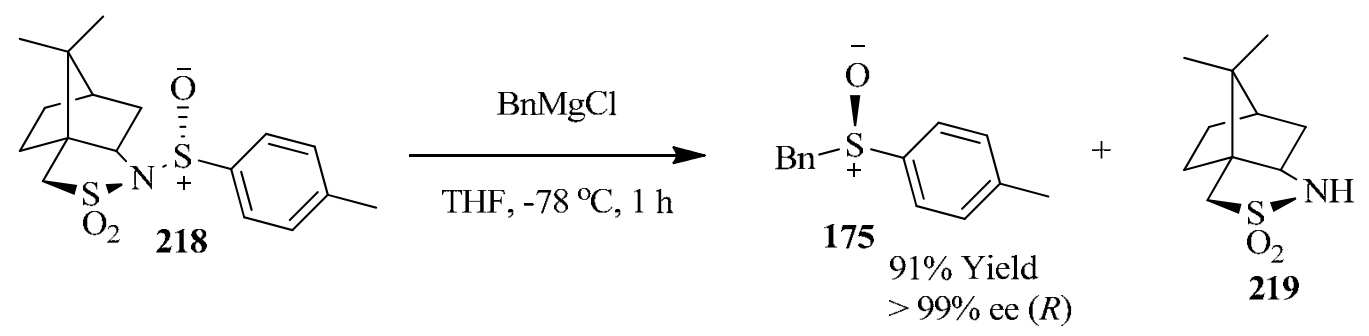

\section{Scheme 107}

Evans et al. used chiral $N$-sulfinyl oxazolidinones 220 in the preparation of enantiopure sulfoxides (Scheme 108). Here a number of dialkyl and alkyl aryl sulfoxides were synthesised with very high enantioselectivities. ${ }^{250}$

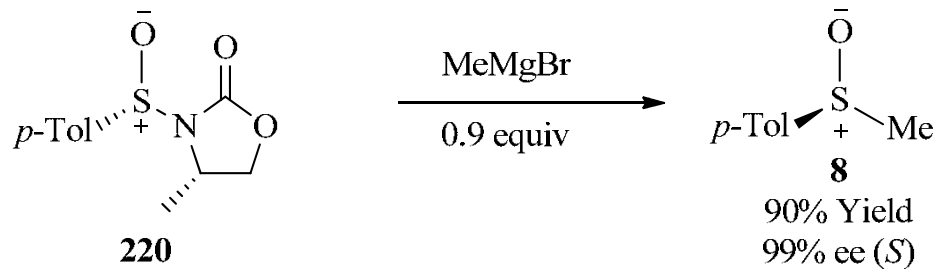

\section{Scheme 108}

Sulfinate esters and sulfinamides are not the only chiral auxiliaries that have been successfully used in nucleophilic substitution reactions. Johnson reported a general method for the preparation of dialkyl sulfoxides, similar to that proposed by Andersen, with a sulfoxide as the chiral precursor. ${ }^{251}$ Alkyllithium or alkyl sodium reagents are used to displace an aryl group from the sulfoxide chiral precursor to produce the unsymmetrical enantiopure dialkyl sulfoxide. The chiral sulfoxide precursor could be prepared using the Andersen synthesis.

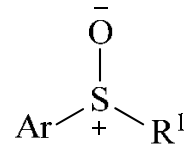

221

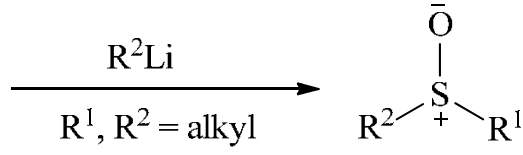

222

\section{Scheme 109}


Ellman prepared a limited number of enantiopure tert-butyl sulfoxides using an enantiopure tert-butanesulfinate ester $\mathbf{5 6}$ as the chiral auxiliary. ${ }^{69}$ Enantiopure $\mathbf{5 6}$ could be prepared by asymmetric sulfide oxidation of the disulfide. Treating $\mathbf{5 6}$ with an organolithium reagent resulted in the formation of the sulfoxide with inversion of stereochemistry. Furthermore, by reacting $\mathbf{5 6}$ initially with lithiated piperidine, it was possible to obtain the other sulfoxide enantiomer. Other dialkyl sulfoxides were prepared using this method in good yield and high enantiopurity. tertButanesulfinamides could also be prepared using this method.<smiles>[13CH3]SSS([13CH3])=O</smiles>

56

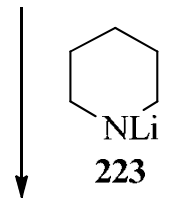

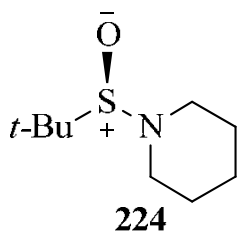

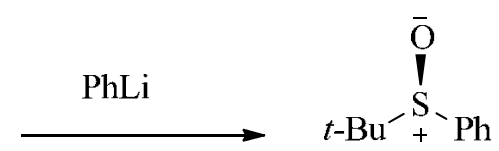

(S)-166

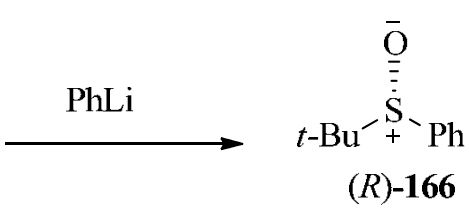

\section{Scheme 110}

Liao et al. synthesised a series of enantiomerically pure mono- and bis-aryl tert-butyl sulfoxides to promote the enantioselective allylation of aldehydes with allyltrichlorosilane. $(R)-$ Thiosulfinate 56 was used for the synthesis of monomeric 225 and dimeric aryl tert-butyl sulfoxides 226 from the corresponding aryl bromides 227 in yields of 24-92\% (Scheme 111). ${ }^{252}$ 
<smiles>[R20]c1ccc(S(=O)[18CH2][13CH3])c([R])c1</smiles><smiles>CC(C)C[As]([O-])c1ccccc1O[Ga]Oc1ccccc1S(=O)O</smiles><smiles>[R]c1ccc(Br)c([R2])c1</smiles><smiles>[2H][S@](=[V])(SC(C)(C)C)C(C)(C)C</smiles><smiles>[R]O[R10](=O)OC</smiles>

\section{Scheme 111}

Similar to Johnson's report, ${ }^{251}$ work by Cardellicchio with chiral halovinyl sulfoxides and organometallic reagents confirmed that the formation of enantiopure sulfoxides through the displacement of a carbon leaving group was a practical route to sulfoxides. ${ }^{253}$ Cardellicchio successfully prepared a variety of sulfoxides with very high enantiopurity through the displacement of methyl dimethylphosphonate using Grignard reagents (Scheme 112). ${ }^{254}$

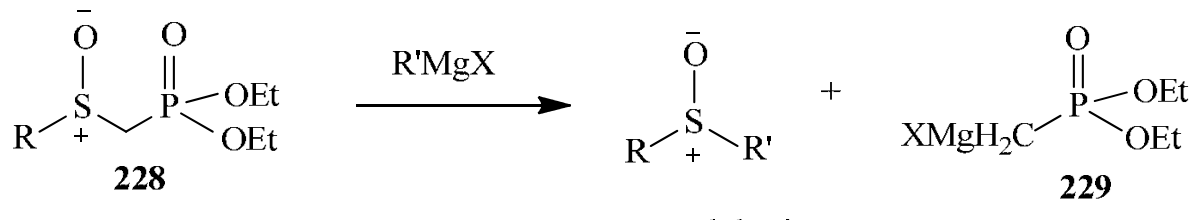

\section{Scheme 112}

Later investigations focussed on preparing different enantiopure chiral auxiliaries for this route to sulfoxides. ${ }^{255,256}$ Using a titanium mediated oxidation it was possible to prepare 228 in high enantiopurity from the corresponding sulfide 230 (Scheme 113). 

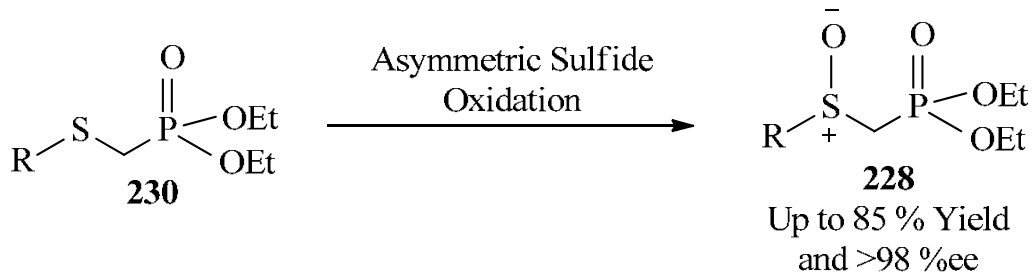

\section{Scheme 113}

Similar to Johnson's report, ${ }^{251}$ Cardellicchio prepared enantiopure sulfoxides through the displacement of the aryl group in appropriately substituted aryl methyl sulfoxides using organometallic reagents. ${ }^{257}$ para-Bromophenyl methyl sulfoxide $\mathbf{8 8}$ was identified as the best sulfoxide precursor for this reaction. Enantiopure $\mathbf{8 8}$ could be prepared by asymmetric sulfide oxidation followed by recrystallisation. This method worked very well for the preparation of long chain alkyl methyl sulfoxides (Scheme 114).<smiles>C[As](=O)c1ccc(Br)cc1</smiles>

(R)-88

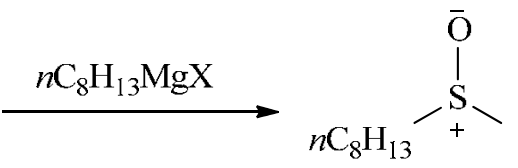

(S)-231

$>98 \%$ ee

\section{Scheme 114}

A number of other research groups have reported the enantioselective preparation of sulfoxides through the displacement of carbon leaving groups from sulfinyl chiral auxiliaries. ${ }^{258}$

\subsection{Double nucleophilic substitution of an enantiomerically pure sulfinyl precursor}

The nucleophilic substitution methods previously discussed involve only one nucleophilic displacement. Using these methods means that the resulting sulfoxide will contain a substituent from the chiral precursor used. This limits the scope of this route to sulfoxides. This fundamental limitation has curtailed the widespread use of single nucleophilic substitution for the preparation of enantiopure sulfoxides. This limitation could be obviated if the chiral precursor could undergo two sequential nucleophilic displacement reactions to yield the desired sulfoxides in high enantioselectivity and yield. For this to occur the chiral precursor needs to possess two leaving groups of different leaving ability. Cyclic sulfites are the most commonly used chiral precursors that meet this criterion. 


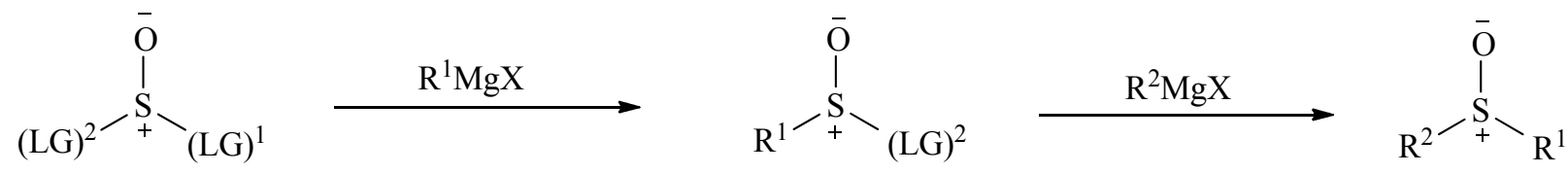

$\mathrm{LG}=$ carbionic leaving group

\section{Scheme 115}

Wudl and Lee were the first to develop a synthesis where the starting reagent possessed two groups of different leaving ability and underwent successive nucleophilic attack from two different nucleophiles (Scheme 116). ${ }^{259,260}$ Here ephedrine 232 was reacted with thionyl chloride to form two diastereomers 233a and 233b, which could be separated. The appropriate diastereomer was reacted with an organometallic reagent to yield a chiral hydroxysulfinamide 234, which underwent subsequent reaction with another organometallic reagent to yield ephedrine and the sulfoxide. High selectivity was observed when Grignard reagents were used for the final nucleophilic displacement, however low yields were reported. Using organolithium reagents, higher yields were reported but with lower selectivity due to racemisation occurring during the breaking of the S-N bond. The problem of the formation of symmetrical sulfoxides after the first nucleophilic displacement was overcome by the addition of a small amount of tetramethylethylenediamine (TMEDA). The best result obtained was $100 \%$ ee $(R)-\mathbf{8}$ in $25 \%$ yield. 
<smiles>CN[C@@H](C)C(O)c1ccccc1</smiles>

232

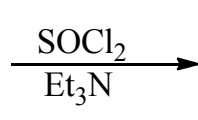

$\mathrm{R}^{1} \mathrm{M}, \mathrm{H}_{3} \mathrm{O}^{+}$<smiles>[2H][S@@]1([O])=[N+](C)[C@H](C)[C@H](c2ccccc2)O1</smiles>

233a<smiles>C[C@@H]1[C@H](c2ccccc2)O[S@@](C)(=O)N1C</smiles>

233a<smiles>C[C@@H]1[C@H](c2ccccc2)O[S@@](C)(=O)[N+]1C</smiles>

233b<smiles>[Z4]C(C(O)c1ccccc1)N(C)[As]([R])([2H])[O-]</smiles>

234

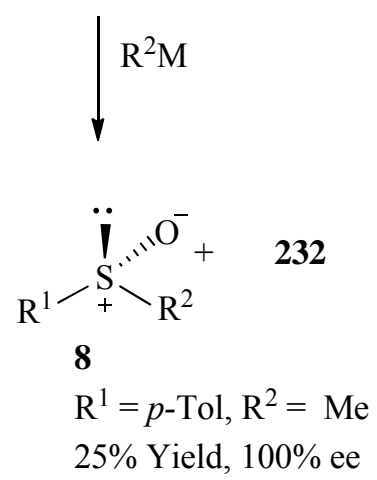

\section{Scheme 116}

Work by Snyder and Benson improved the method developed by Wudl and Lee. ${ }^{261}$ Improvements were made in the preparation of the oxathiazolidine- $S$-oxide, 233a and 233b, which resulted in higher yields. The problems with selectivity and yield reported by Wudl and Lee when carrying out the second displacement were solved by the use of an additive. Addition of trimethylaluminium prior to the displacement reaction, resulted in improvements in both the yield and enantioselectivity of the reaction (Scheme 117). It was proposed that the intermediate 235 was formed in the presence of the trimethylaluminium, which facilitated the formation of the sulfoxide. The sulfoxide 19 of thioanisole 18 was prepared in a yield of $71 \%$ and $>99 \%$ ee $(S)$ while iso-propyl phenyl sulfoxide was also prepared in a yield of $82 \%$ and $>99 \%$ ee $(S)$ using this method. Both aryl alkyl and dialkyl sulfoxides were prepared using this method. Diaryl sulfoxides were not accessible using this method. 


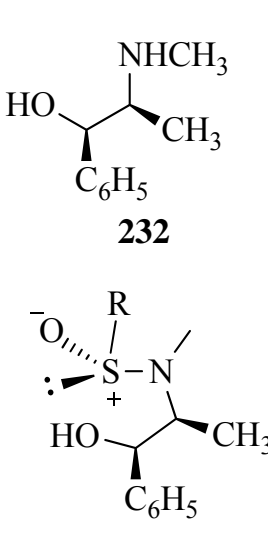

234

$\mathrm{AlMe}_{3}, \mathrm{RT}$

$\mathrm{CH}_{2} \mathrm{Cl}_{2}, 30 \min \left(-\mathrm{CH}_{4}\right)$

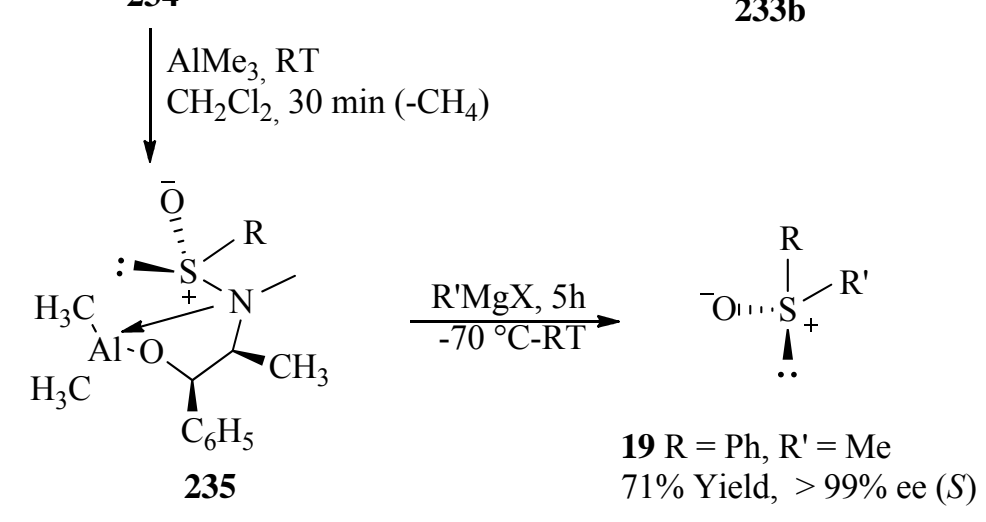

$\mathrm{SOCl}_{2}$ (1.2 equiv.)

$\underset{\mathrm{CH}_{2} \mathrm{Cl}_{2}, 0^{\circ} \mathrm{C}, 24 \mathrm{~h}}{\stackrel{\mathrm{Et}_{3} \mathrm{~N} \text { (2.4 equiv.) }}{\longrightarrow}}$

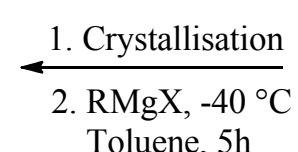

Toluene, $5 \mathrm{~h}$

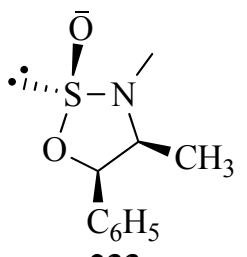

233a

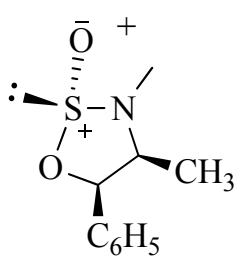

233b

\section{Scheme 117}

Senanayake et al. further improved the Wudl and Lee method. ${ }^{262}$ Ephedrine 232, which had been used by Wudl and Lee was replaced by $(1 R, 2 S)-(+)$-cis-amino-2-indanol, 236. Following the procedure outlined in (Scheme 118), high enantioselectivity and high yields were reported for the preparation of sulfinamides. 
<smiles>[R6]OS(=O)(=O)N[C@H]1c2ccccc2C[C@H]1O</smiles>

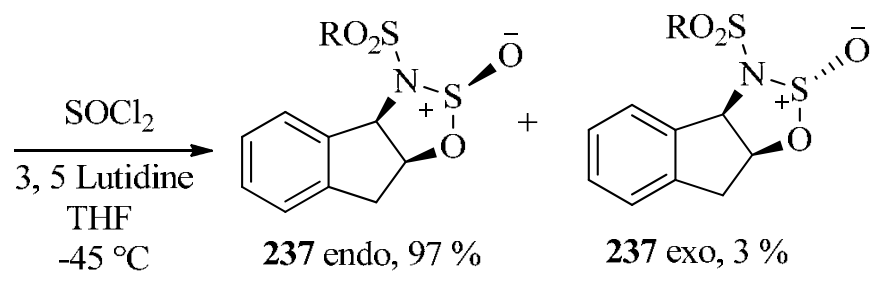

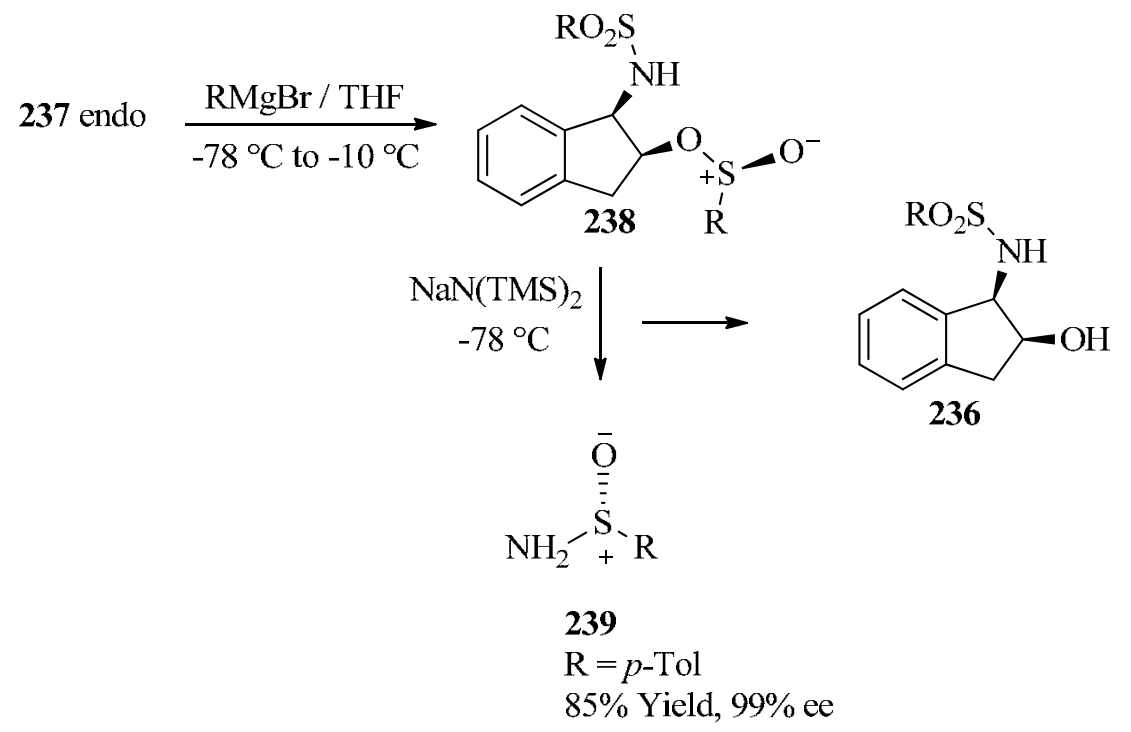

\section{Scheme 118}

Subsequent work by Senanayake et al. resulted in the development of a one pot synthetic route to sulfoxides. ${ }^{262-263}$ The method is very similar to that used to prepare sulfinamides shown in Scheme 118. Senanayake initially synthesised sulfoxides using $N$-sulfonyl-1,2,3oxathiazolidine-2-oxide 237 endo and 237 exo where $\mathrm{R}$ = para-tolyl or 2,4,6-mesityl (Scheme 119). Investigations into the preparation of 237 established that employing different bases could induce high selectivity towards 237 endo or 237 exo. With this information it was possible to isolate enantiomerically pure 237. The first nucleophilic displacement was carried out at low temperature in THF and the second displacement was carried out at a lower temperature in THF. The results obtained using this method were generally good with high yields and high enantioselectivity. 


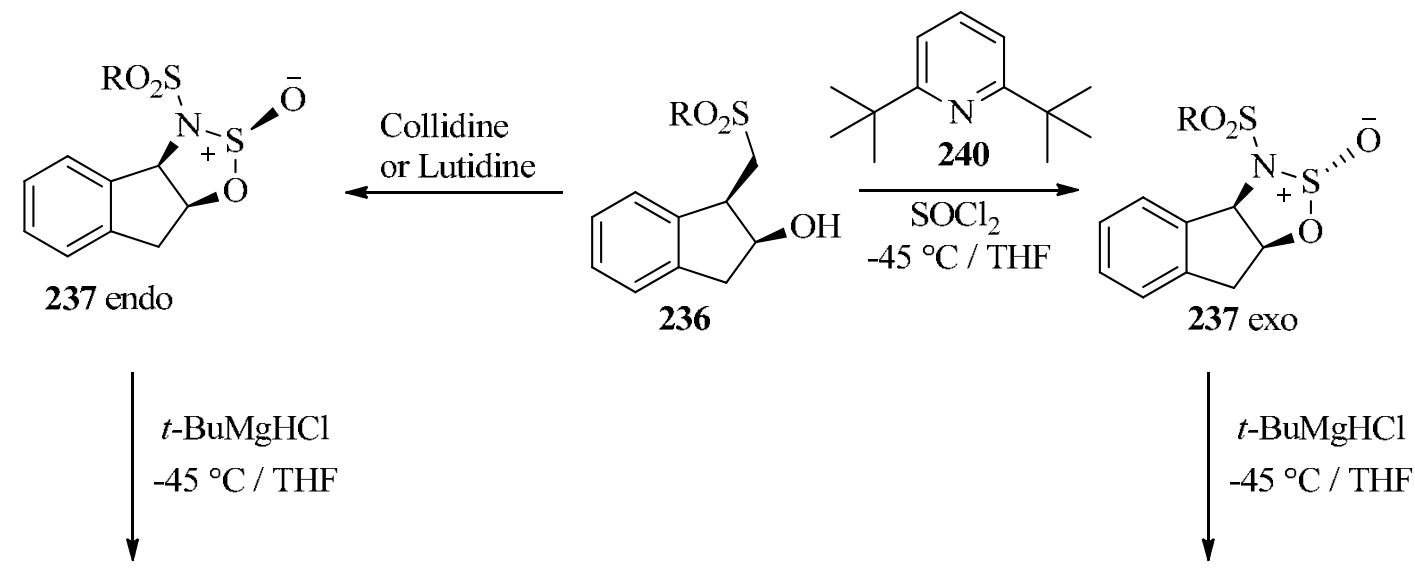<smiles>[Y16][C@H]1Cc2ccccc2[C@H]1O[S@](=O)C(C)(C)C</smiles>

\section{$i-\mathrm{PrMgCl}$}

$-78^{\circ} \mathrm{C} / \mathrm{THF}$

236
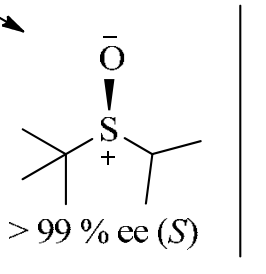

242

\section{Scheme 119}

The method shown in Scheme 119 involves the use of expensive $N$-sulfonyl-1,2,3oxathiazolidine-2-oxide 236. Senanayake investigated this method using a more readily available and less expensive amino alcohol, norephedrine 243. Senanayake identified $N$-tosyl-1,2,3oxathiazolidine-2-oxide 244 as the most suitable derivative of 232 for the preparation of enantiopure sulfoxides. This template 244 could be used to prepare sulfoxides using a one-pot synthesis. The template could also be isolated from the final reaction mixture and recycled. Overall, the enantioselectivities and yields reported were very high (Scheme 120). 

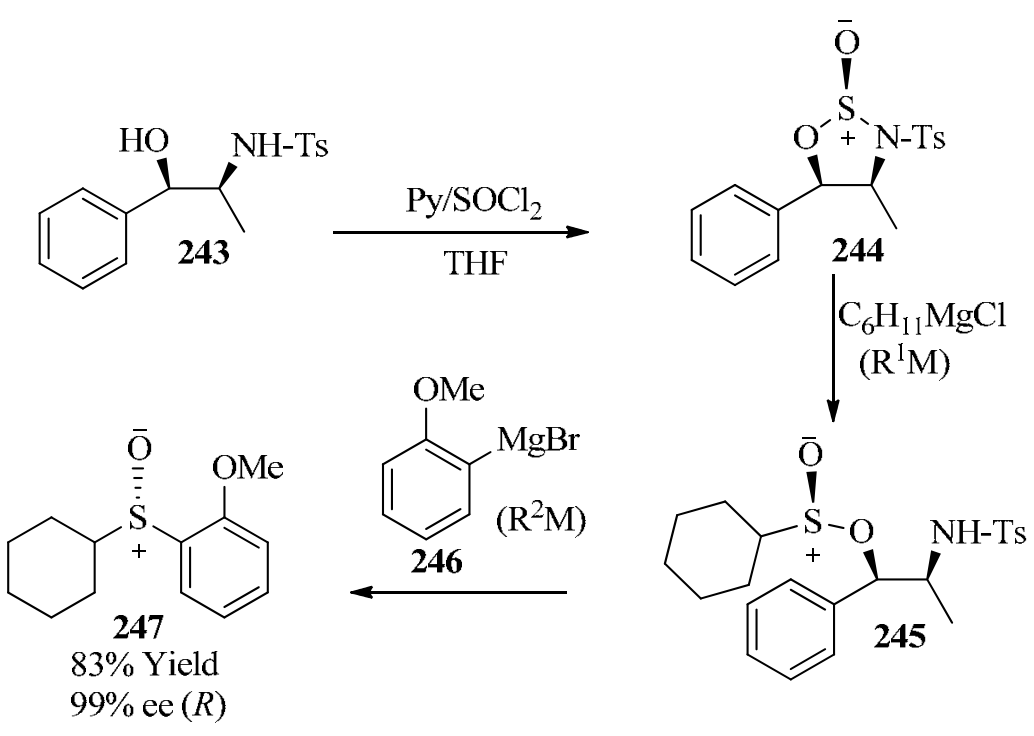

\section{Scheme 120}

García Ruano et al. reported a one-pot synthesis of sulfoxides using 24 . $^{264} \mathrm{~N}$ Benzyloxycarbonylsulfamidite $\mathbf{2 4 9}$ was prepared from 248. By varying the conditions used to prepare 249 the ratio of the resulting diastereomers could be altered so that the preferential formation of one diastereomer would take place. The first displacement was carried out at low temperature in dichloromethane. The addition of $\mathrm{HBF}_{4}$ to the reaction prior to the second displacement reduced racemisation. The second displacement was also carried out at low temperature in dichloromethane. Overall, the results using this method were quite good, with high enantioselectivity often in excess of $90 \%$ ee being reported. García Ruano recommended this one pot synthesis, outlined in Scheme 121 for the synthesis of dialkyl, diaryl, aryl vinyl, aryl alkyl sulfoxides. Qin and Jiang used a similar method to prepare sulfinamides. ${ }^{265}$

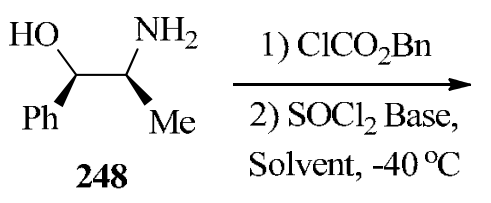

248

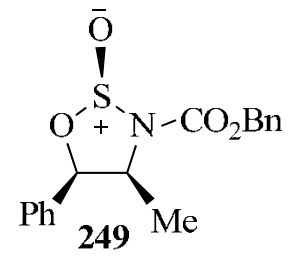

$\mathbf{R}$
30 Ph
$\mathbf{1 3 8}$ Mesityl
$\mathbf{1 8 7}$ Mesityl

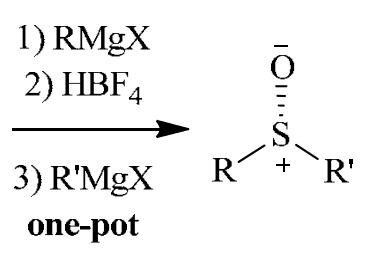

\begin{tabular}{lcl}
\multicolumn{1}{c}{$\mathbf{R}^{\prime}$} & Yield (\%) & ee $(\%)$ \\
$\mathrm{Me}$ & 54 & $93(R)$ \\
$\mathrm{Me}$ & 78 & $98(S)$ \\
para-Tolyl & 71 & $97(R)$
\end{tabular}

\section{Scheme 121}

$\mathrm{Lu}$ and Senanayake reported another method for the preparation of enantiopure sulfoxides. ${ }^{266}$ This method utilised the cinchona alkaloid, quinine $\mathbf{2 5 0}$ to form the chiral precursor $\mathbf{2 5 1}$. The S- 
$\mathrm{N}$ bond in $\mathbf{2 5 2}$ is a non-covalent bond. The advantage of this is that nucleophilic displacement of the S-O bond is less likely to occur so only one product will form as a result of the first nucleophilic substitution.
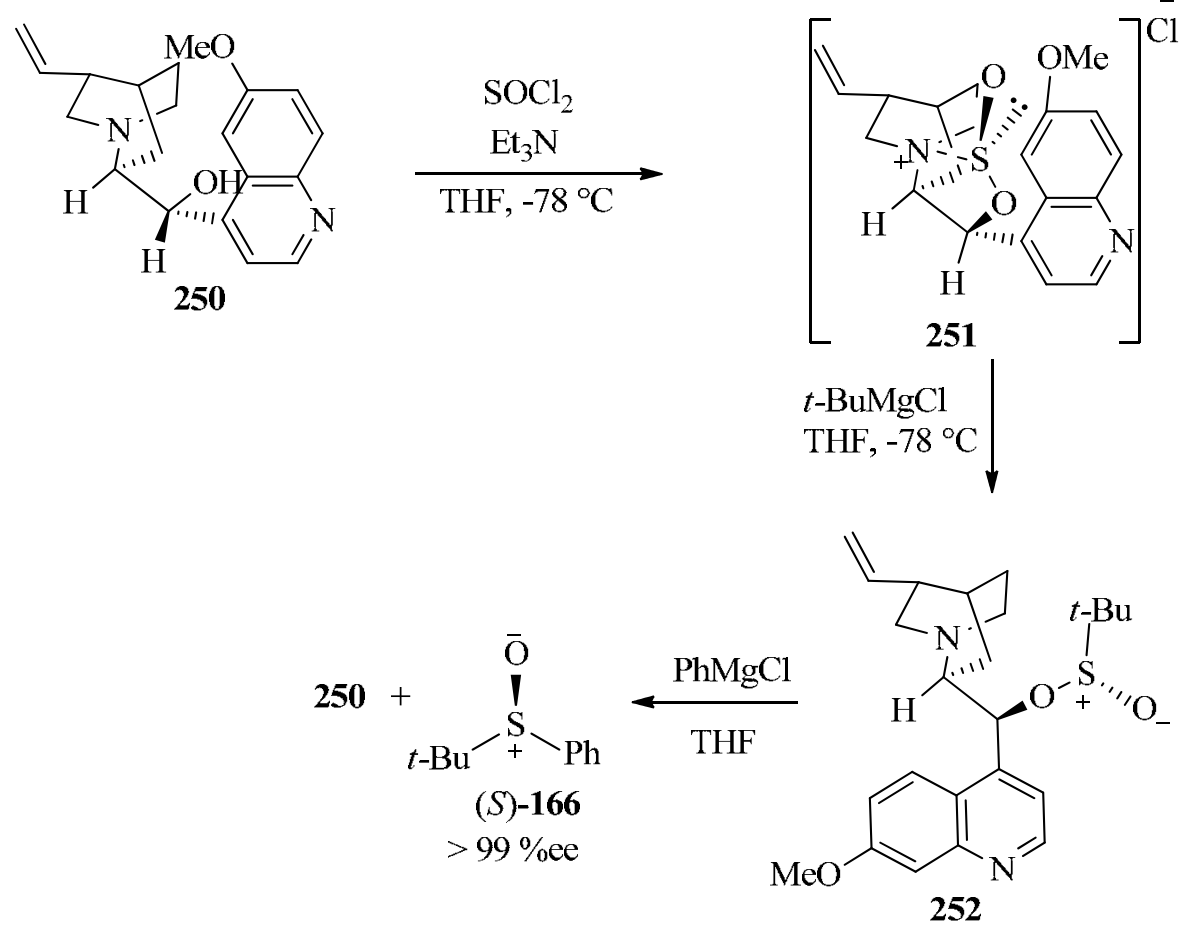

\section{Scheme 122}

Using a para-tolyl Grignard reagent for the first displacement resulted in formation of the ditolyl sulfoxide. This problem was overcome by using a different organometallic reagent, paratolyldiethylaluminum, which was prepared in situ using diethylaluminum chloride and paratolylmagnesium bromide. This methodology was also used for the preparation of sulfinamides.

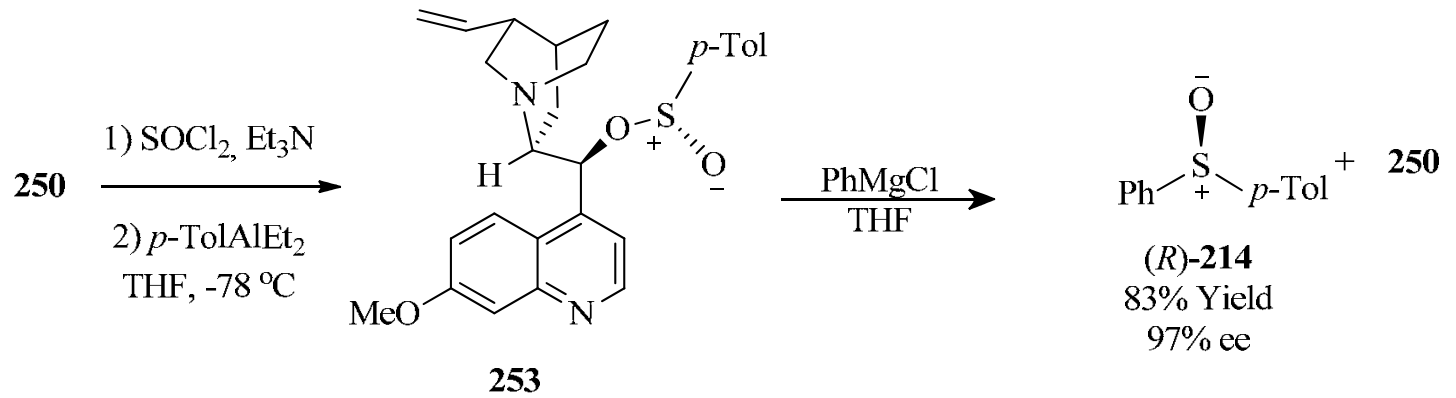

\section{Scheme 123}


In the early 1990s Kagan developed a route to chiral sulfoxides, shown in Scheme 124, involving a double nucleophilic displacement. ${ }^{267}$ The route was similar to that used by Wudl and Lee. Here a diol 254 was reacted with thionyl chloride to yield cyclic sulfite diastereomers 255. The diastereomers could be separated by crystallisation and then reacted with suitable organometallic reagents in THF to form sulfinates 256 and 257. The formation of symmetrical sulfoxide side products was not observed when Grignard reagents were used. An interesting observation was that 256 was preferred when $\mathrm{R}^{1}$ was small and if $\mathrm{R}^{1}$ was bulky 257 was preferred. The route was found to be especially suitable for the chiral tert-butyl sulfoxides. Unusually, unlike previous chiral precursors discussed, which involved the displacement of an S$\mathrm{N}$ bond followed by the displacement of an S-O bond or vice versa, the sequential breaking of two S-O bonds occurs using this sulfite.

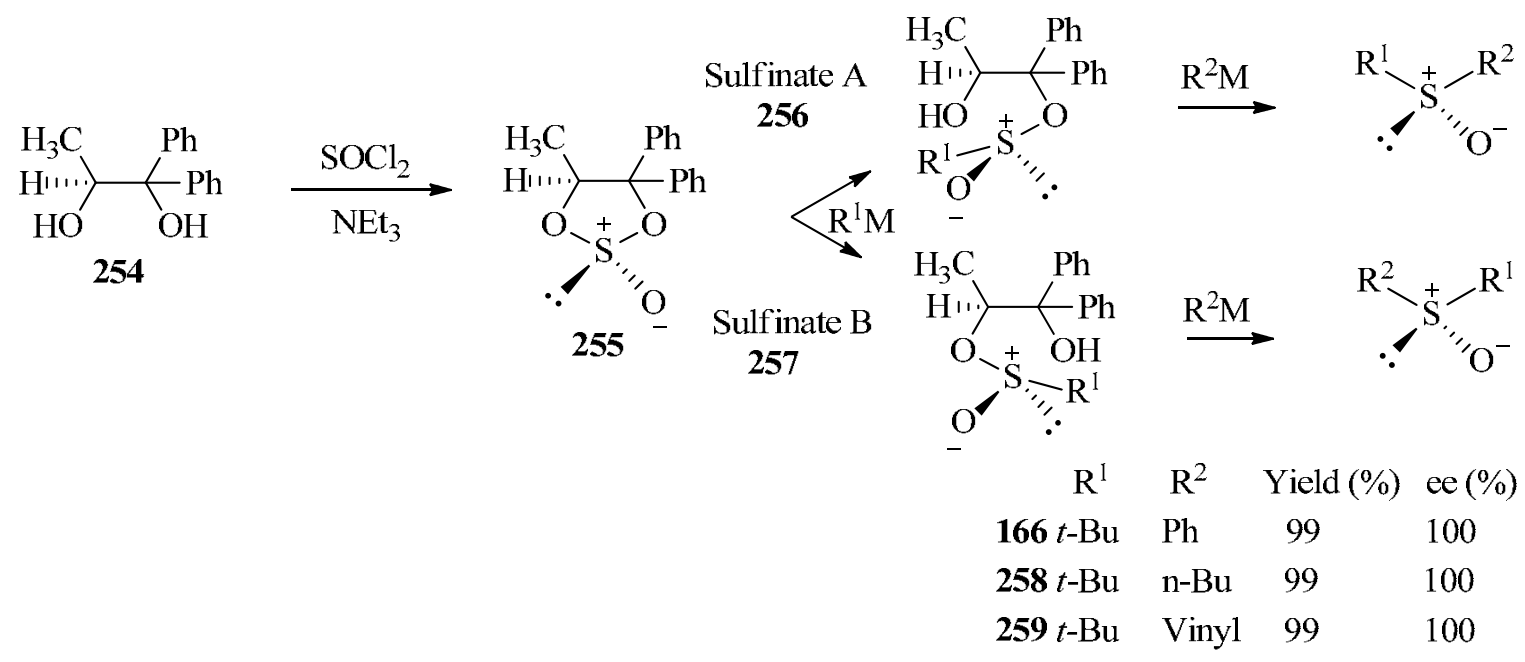

\section{Scheme 124}

The preparation of the above chiral precursors used in double nucleophilic substitution is quite challenging. This has had the effect of limiting the use of these methods to prepare sulfoxides.

Cardellicchio proposed a novel method for the preparation of dialkyl sulfoxides, using an easily prepared acyclic chiral auxiliary. Cardellicchio made use of both the Andersen method, ${ }^{236}$ and the fact that substituted aryl groups can be displaced from sulfoxides using Grignard reagents, ${ }^{257}$ to prepare menthyl para-bromobenzenesulfinate 260, a menthyl sulfinate ester that could undergo sequential nucleophilic substitution. The sequential substitution of $\mathbf{2 6 0}$ is possible due to the different leaving abilities of the O-menthyl group and para-bromobenzene group. 


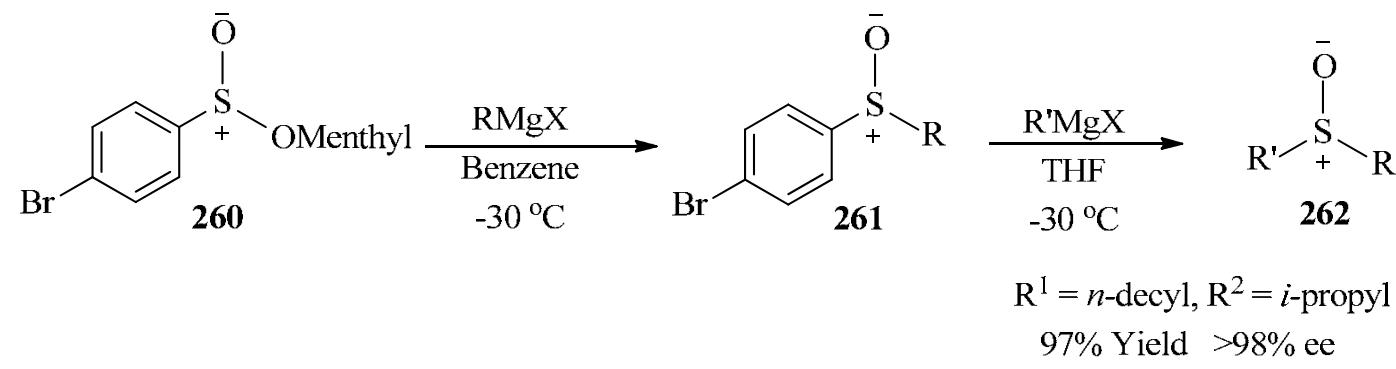

\section{Scheme 125}

The sulfinate ester 260 can be prepared in good yield using existing methodology, ${ }^{268}$ however this method still required the diastereomers of $\mathbf{2 6 0}$ to be separated. Cardellicchio proposed a new chiral precursor to overcome this problem. Thus, benzyl para-bromophenyl sulfoxide 263, which contains two substituents of different leaving abilities and is readily obtainable from the corresponding sulfide using a titanium mediated oxidation method, ${ }^{269}$ has been used for the preparation of dialkyl sulfoxides. For example, $n$-dodecyl iso-propyl sulfoxide 265 was prepared in $91 \%$ yield and $>98 \%$ ee (Scheme 126).<smiles>O=S(Br)c1ccc(Br)cc1</smiles>

$(R)-\mathbf{2 6 3}$

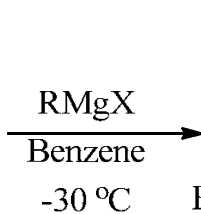

$-30^{\circ} \mathrm{C}$

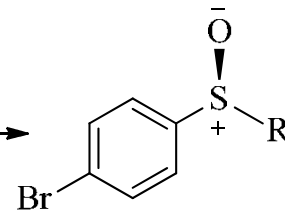

$(S)-264$

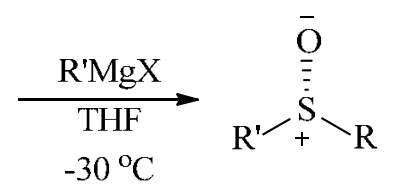

$$
\text { (R)-265 R }=n \text {-dodecyl, } \mathrm{R}^{\prime}=i \text {-propyl }
$$$$
91 \% \text { Yield, }>98 \% \text { ee }
$$

\section{Scheme 126}

Despite the very high enantioselectivity and yields of these reactions, this approach developed by Cardellicchio has received little attention. This is primarily due to the limited number of sulfoxides, mainly dialkyl sulfoxides, that can be prepared using these precursors. ${ }^{270}$ The development of new carbanionic leaving groups may extend the scope of this methodology.

\section{Conclusions}

Clearly, significant progress has been made over the past three decades in developing routes to enantioenriched sulfoxides using a combination of metal catalyzed processes, biocatalysis and use of chiral auxiliaries. As this manuscript neared completion a related review was published; ${ }^{271}$ while many of the same areas are described, this present review provides more detail in some aspects, for example the area of kinetic resolution. 


\section{References}

1. Solladie, G. Asymmetric Synthesis 1983, 2, 157.

2. Sklute, G.; Amsallem, D.; Shabli, A.; Varghese, J. P.; Marek, I. J. Am. Chem. Soc. 2003, 125, 11776.

3. Carreno, M. C.; García Ruano, J. L.; Martin, A. M.; Pedregal, C.; Rodriguez, J. H.; Rubio, A.; Sanchez, J.; Solladie, G. J. Org. Chem. 1990, 55, 2120.

4. (a) Ruano García J. L.; de la Plata, B. C. Top. Curr. Chem. 1999, 204, 1. (b) Lee, A. W. M.; Chan, W. H. Top. Curr. Chem. 1997, 190, 103. (c) Arai, Y.; Koizumi, T. Sulfur Rep. 1993, 15, 41.

5. Renaud, P.; Gerster, M. Angew. Chem., Int. Ed. 1998, 37, 2562.

6. Toru, T.; Watanabe, Y.; Mase, N.; Tsusaka, M.; Hayakawa, T.; Ueno, Y. Pure Appl. Chem. 1996, 68, 711.

7. Fernández, I.; Valdivia, V.; Pernia Leal, M.; Khiar, N. Org. Lett. 2007, 9, 2215.

8. Fernández, I.; Khiar, N. Chem. Rev. 2003, 103, 3651.

9. (a) Carreno, M. C.; Hernandez-Torres, G.; Ribagorda, M.; Urbano, A. Chem. Commun. 2009, 6129. (b) Hanquet, G.; Colobert, F.; Lanners, S.; Solladie, G. Arkivoc 2003, (vii), 328. (c) Pellissier, H. Tetrahedron 2006, 62, 5559 (d) Senanayake, C. H.; Krishnamurthy, D.; Lu, Z.-H.; Han, Z.; Gallou, I. Aldrichimica Acta 2005, 38, 93. (e) Mikołajczyk, M., Drabowicz, J.; Kiełbasiński, P. Chiral Sulfur Reagents: Applications in Asymmetric and Stereoselective Synthesis, CRC Press: Boca Raton, USA, 1998, pp 1-274.

10. Agranat, I.; Caner, H. Drug Discovery Today 1999, 4, 313.

11. Olivo, H. F.; Osorio-Lozada, A.; Peeples, T. L. Tetrahedron: Asymmetry 2005, 16, 3507.

12. Hamman, M. A.; Haehner-Daniels, B. D.; Wrighton, S. A.; Rettie, A. E.; Hall, S. D. Biochem. Pharmacol. 2000, 60, 7.

13. (a) Legros, J.; Dehli, J. R.; Bolm, C. Adv. Synth. Catal. 2005, 347, 19. (b) Volcho, K. P.; Salakhutdinov, N. F. Russ. Chem. Rev. 2009, 78, 457.

14. (a) Collins, S. G.; Maguire, A. R. Sci. Synth. 2007, 31a, 907. (b) Mikołajczyk, M. Drabowicz, J.; Kiełbasiński, P.; Topics in Stereochemistry, vol. 13, Allinger, M. L.; Eliel, E. L.; Eds. Interscience New York 1982, 333-468. (c) Drabowicz, J.; Kiełbasiński, P.; Mikołajczyk, M.; Synthesis of Sulfones, Sulfoxides and Cyclic Sulfides, Eds. Patai, S.; Rappaport, Z.; Wiley, Chichester, 1994 , 109-254.

15. (a) Maccioni, A.; Montanari, F.; Secci, M.; Tramontini, M. Tetrahedron Lett. 1961, 2, 607

(b) Balenovic, K.; Bregant, N.; Francetic, D. Tetrahedron Lett. 1960, 1, 20.

16. (a) Madesclaire, M. Tetrahedron 1986, 42, 5459. (b) Baird, C. P.; Rayner, C. M. J. Chem. Soc., Perkin Trans. 1 1998, 1973. (c) Bryliakov, K. P.; Talsi, E. P. Curr. Org. Chem. 2008, 12, 386. (d) Kagan, H. B.; Luukas, T. O. Transition Metals for Organic Synthesis: Beller, M.; Bolm, C. Eds.; $2^{\text {nd }}$ Edn; Wiley: Weinheim. 2004; 30613. (e) Procter, D. J. J. Chem. Soc., Perkin Trans. 1 2001, 335.

17. Pitchen, P.; Kagan, H. B. Tetrahedron Lett. 1984, 25, 1049. 
18. Pitchen, P.; Dunach, E.; Deshmukh, M. N.; Kagan, H. B. J. Am. Chem. Soc. 1984, 106, 8188.

19. Di Furia, F.; Modena, G.; Seraglia, R. Synthesis 1984, 325.

20. Katsuki, T.; Sharpless, K. B. J. Am. Chem. Soc. 1980, 102, 5974.

21. Sharpless, K. B. Chem. Br. 1986, 22, 38.

22. Ramon, D. J.; Yus, M. Chem. Rev. 2006, 106, 2126.

23. Bonchio, M.; Licini, G.; Modena, G.; Moro, S.; Bortolini, O.; Traldi, P.; Nugent, W. Chem. Commun. 1997, 869.

24. Potvin, P. G.; Fieldhouse, B. G. Tetrahedron: Asymmetry 1999, 10, 1661.

25. Zhao, S. H.; Samuel, O.; Kagan, H. B. Tetrahedron 1987, 43, 5135.

26. Hanson, R. M.; Sharpless, K. B. J. Org. Chem. 1986, 51, 1922.

27. Komatsu, N.; Nishibayashi, Y.; Sugita, T.; Uemura, S. Tetrahedron Lett. 1992, 33, 5391.

28. Yamanoi, Y.; Imamoto, T. J. Org. Chem. 1997, 62, 8560.

29. Takeda, T.; Imamoto, T. Tetrahedron: Asymmetry 1999, 10, 3209.

30. Superchi, S.; Rosini, C. Tetrahedron: Asymmetry 1997, 8, 349.

31. Superchi, S.; Scafato, P.; Restaino, L.; Rosini, C. Chirality 2008, 20, 592.

32. Bolm, C.; Dabard, O. A. G. Synlett 1999, 360.

33. Martyn, L. J. P.; Pandiaraju, S.; Yudin, A. K. J. Organomet. Chem. 2000, 603, 98.

34. Chen, Y.; Yekta, S.; Martyn, L. J. P.; Zheng, J.; Yudin, A. K. Org. Lett. 2000, 2, 3433.

35. Zeng, Q.-L.; Tang, H.-Y.; Zhang, S.; Liu, J.-C. Chin. J. Chem. 2008, 26, 1435.

36. Sun, J.; Yang, M.; Dai, Z.; Zhu, C.; Hu, H. Synthesis 2008, 2513.

37. (a) Matsugi, M.; Fukuda, N.; Minamikawa, J.-i.; Otsuka, S. Tetrahedron Lett. 1998, 39, 5591. (b) Matsugi, M.; Fukuda, N.; Muguruma, Y.; Yamaguchi, T.; Minamikawa, J.-i.; Otsuka, S. Tetrahedron 2001, 57, 2739. (c) Matsugi, M.; Shimada, R.; Ohata, S.; Nojima, M.; Fukuda, N.; Minamikawa, J.-i.; Kita, Y. Chem. Pharm. Bull. 2002, 50, 1511.

38. Bryliakov, K. P.; Talsi, E. P. J. Mol. Catal. A: Chem. 2007, 264, 280.

39. Bryliakov, K. P.; Talsi, E. P. Eur. J. Org. Chem. 2008, 3369.

40. Adam, W.; Korb, M. N.; Roschmann, K. J.; Saha-Moeller, C. R. J. Org. Chem. 1998, 63, 3423.

41. (a) Scettri, A.; Bonadies, F.; Lattanzi, A. Tetrahedron: Asymmetry 1996, 7, 629. (b) Scettri, A.; Bonadies, F.; Lattanzi, A.; Senatore, A.; Soriente, A. Tetrahedron: Asymmetry 1996, 7, 657. (c) Lattanzi, A.; Bonadies, F.; Senatore, A.; Soriente, A.; Scettri, A. Tetrahedron: Asymmetry 1997, 8, 2473. (d) Lattanzi, A.; Bonadies, F.; Scettri, A. Tetrahedron: Asymmetry 1997, 8, 2141. (e) Palombi, L.; Bonadies, F.; Pazienza, A.; Scettri, A. Tetrahedron: Asymmetry 1998, 9, 1817. (f) Lattanzi, A.; Bonadies, F.; Schiavo, A.; Scettri, A. Tetrahedron: Asymmetry 1998, 9, 2619. (g) Lattanzi, A.; Scettri, A. J. Organomet. Chem. 2006, 691, 2072.

42. Lattanzi, A.; Iannece, P.; Scettri, A. Tetrahedron: Asymmetry 2004, 15, 1779.

43. (a) Lattanzi, A.; Iannece, P.; Scettri, A. Tetrahedron: Asymmetry 2004, 15, 413. (b) Lattanzi, A.; Piccirillo, S.; Scettri, A. Eur. J. Org. Chem. 2006, 713. 
44. Blumenthal, H.; Liebscher, J. Arkivoc 2009, (xi), 204.

45. Cotton, H.; Elebring, T.; Larsson, M.; Li, L.; Sörensen, H.; von Unge, S. Tetrahedron: Asymmetry 2000, 11, 3819.

46. Khomenko, T. M.; Volcho, K. P.; Komarova, N. I.; Salakhutdinov, N. F. Russ. J. Org. Chem. 2008, 44, 124.

47. Jiang, B.; Zhao, X.-L.; Dong, J.-J.; Wang, W.-J. Eur. J. Org. Chem. 2009, 987.

48. Delamare, M.; Belot, S.; Caille, J.-C.; Martinet, F.; Kagan, H. B.; Henryon, V. Tetrahedron Lett. 2009, 50, 1702.

49. Maguire, A. R.; Papot, S.; Ford, A.; Touhey, S.; O'Connor, R.; Clynes, M. Synlett 2001, 41.

50. Naso, F.; Cardellicchio, C.; Affortunato, F.; Capozzi, M. A. M. Tetrahedron: Asymmetry 2006, 17, 3226.

51. Naso, F.; Capozzi, M. A. M.; Bottoni, A.; Calvaresi, M.; Bertolasi, V.; Capitelli, F.; Cardellicchio, C. Chem.--Eur. J. 2009, 15, 13417.

52. Massa, A.; Mazza, V.; Scettri, A. Tetrahedron: Asymmetry 2005, 16, 2271.

53. Ding, K.; Wang, Z.; Wang, X.; Liang, Y.; Wang, X. Chem. Eur. J. 2006, 12, 5188.

54. Iwamoto, M.; Tanaka, Y.; Hirosumi, J.; Kita, N.; Triwahyono, S. Microporous Mesoporous Mater. 2001, 48, 271.

55. Gao, J.; Guo, H.; Liu, S.; Wang, M. Tetrahedron Lett. 2007, 48, 8453.

56. Yuan, X.-y.; Wang, X.-t. J. Chongqing Univ. (Engl. Ed.) 2008, 7, 179.

57. Sahoo, S.; Kumar, P.; Lefebvre, F.; Halligudi, S. B. J. Catal. 2009, 262, 111.

58. Bolm, C. Coord. Chem. Rev. 2003, 237, 245.

59. Curci, R.; Di Furia, F.; Testi, R.; Modena, G. J. Chem. Soc., Perkin Trans. 2 1974, 752.

60. Nakajima, K.; Kojima, M.; Fujita, J. Chem. Lett. 1986, 1483.

61. Nakajima, K.; Kojima, K.; Kojima, M.; Fujita, J. Bull. Chem. Soc. Jpn. 1990, 63, 2620.

62. Nakajima, K.; Sasaki, C.; Kojima, M.; Aoyama, T.; Ohba, S.; Saito, Y.; Fujita, J. Chem. Lett. 1987, 2189.

63. Sasaki, C.; Nakajima, K.; Kojima, M.; Fujita, J. Bull. Chem. Soc. Jpn. 1991, 64, 1318.

64. Nakajima, K.; Kojima, M.; Toriumi, K.; Saito, K.; Fujita, J. Bull. Chem. Soc. Jpn. 1989, 62,760 .

65. Colonna, S.; Manfredi, A.; Spadoni, M.; Casella, L.; Gullotti, M. J. Chem. Soc., Perkin Trans. 1 1987, 71.

66. Bolm, C.; Bienewald, F. Angew. Chem., Int. Ed. Engl. 1995, 34, 2640.

67. Khiar, N.; Mallouk, S.; Valdivia, V.; Bougrin, K.; Soufiaoui, M.; Fernández, I. Org. Lett. 2007, 9, 1255.

68. Liu, G.; Cogan, D. A.; Ellman, J. A. J. Am. Chem. Soc. 1997, 119, 9913.

69. Cogan, D. A.; Liu, G.; Kim, K.; Backes, B. J.; Ellman, J. A. J. Am. Chem. Soc. 1998, 120, 8011.

70. Balcells, D.; Maseras, F.; Ujaque, G. J. Am. Chem. Soc. 2005, 127, 3624.

71. Vetter, A. H.; Berkessel, A. Tetrahedron Lett. 1998, 39, 1741. 
72. Ohta, C.; Shimizu, H.; Kondo, A.; Katsuki, T. Synlett 2002, 161.

73. (a) Green, S. D.; Monti, C.; Jackson, R. F. W.; Anson, M. S.; MacDonald, S. J. F. Chem. Commun. 2001, 2594. (b) Pelotier, B.; Anson, M. S.; Campbell, I. B.; MacDonald, S. J. F.; Priem, G.; Jackson, R. F. W. Synlett 2002, 1055.

74. (a) Korte, A.; Legros, J.; Bolm, C. Synlett 2004, 2397. (b) Legros, J.; Bolm, C. Angew. Chem., Int. Ed. 2003, 42, 5487. (c) Legros, J.; Bolm, C. Angew. Chem., Int. Ed. 2004, 43, 4225 (d) Legros, J.; Bolm, C. Chem.--Eur. J. 2005, 11, 1086.

75. Kelly, P.; Lawrence, S. E.; Maguire, A. R. Synlett 2006, 1569.

76. Kelly, P.; Lawrence, S. E.; Maguire, A. R. Eur. J. Org. Chem. 2006, 4500.

77. Jeong, Y.-C.; Choi, S.; Hwang, Y. D.; Ahn, K.-H. Tetrahedron Lett. 2004, 45, 9249.

78. Jeong, Y.-C.; Huang, Y. D.; Choi, S.; Ahn, K.-H. Tetrahedron: Asymmetry 2005, 16, 3497.

79. Gao, A.; Wang, M.; Wang, D.; Zhang, L.; Liu, H.; Tian, W.; Sun, L. Chinese J. Catal. 2006, 27, 743.

80. Liu, H.; Wang, M.; Wang, Y.; Yin, R.; Tian, W.; Sun, L. Appl. Organomet. Chem. 2008, 22, 253.

81. Liu, H.-B.; Wang, M.; Wang, Y.; Wang, Y.; Sun, H.; Sun, L.-C. Catal. Commun. 2009, 11, 294.

82. Wu, Y.; Liu, J.; Li, X.; Chan, A. S. C. Eur. J. Org. Chem. 2009, 2607.

83. Suresh, P.; Srimurugan, S.; Babu, B.; Pati, H. N. Tetrahedron: Asymmetry 2007, 18, 2820.

84. Koneva, E. A.; Volcho, K. P.; Korchagina, D. V.; Komarova, N. I.; Kochnev, A. I.; Salakhutdinov, N. F.; Tolstikov, A. G. Russ. Chem. Bull. 2008, 57, 108.

85. Koneva, E. A.; Volcho, K. P.; Korchagina, D. V.; Salakhutdinov, N. F.; Tolstikov, A. G. Russ. J. Org. Chem. 2009, 45, 815.

86. Barbarini, A.; Maggi, R.; Muratori, M.; Sartori, G.; Sartorio, R. Tetrahedron: Asymmetry 2004, 15, 2467.

87. Zeng, Q.; Wang, H.; Weng, W.; Lin, W.; Gao, Y.; Huang, X.; Zhao, Y. New J. Chem. 2005, 29, 1125.

88. Zeng, Q.; Wang, H.; Wang, T.; Cai, Y.; Weng, W.; Zhao, Y. Adv. Synth. Catal. 2005, 347, 1933.

89. Hsieh, S.-H.; Kuo, Y.-P.; Gau, H.-M. J. Chem. Soc., Dalton Trans. 2007, 97.

90. Lippold, I.; Becher, J.; Klemm, D.; Plass, W. J. Mol. Catal. A: Chem. 2009, 299, 12.

91. Kwiatkowski, E.; Romanowski, G.; Nowicki, W.; Kwiatkowski, M.; Suwinska, K. Polyhedron 2007, 26, 2559.

92. Romanowski, G.; Kwiatkowski, E.; Nowicki, W.; Kwiatkowski, M.; Lis, T. Polyhedron 2008, 27, 1601.

93. Drago, C.; Caggiano, L.; Jackson, R. F. W. Angew. Chem., Int. Ed. 2005, 44, 7221.

94. Karpyshev, N. N.; Yakovleva, O. D.; Talsi, E. P.; Bryliakov, K. P.; Tolstikova, O. V.; Tolstikov, A. G. J. Mol. Catal. A: Chem. 2000, 157, 91.

95. Conte, V.; Di Furia, F.; Moro, S. J. Mol. Catal. A: Chem. 1997, 117, 139. 
96. Blum, S. A.; Bergman, R. G.; Ellman, J. A. J. Org. Chem. 2002, 68, 150.

97. Bolm, C.; Bienewald, F. Synlett 1998, 1327.

98. Bryliakov, K. P.; Karpyshev, N. N.; Fominsky, S. A.; Tolstikov, A. G.; Talsi, E. P. J. Mol. Catal. A: Chem. 2001, 171, 73.

99. Sun, J.; Zhu, C.; Dai, Z.; Yang, M.; Pan, Y.; Hu, H. J. of Org. Chem. 2004, 69, 8500.

100. Groves, J. T.; Viski, P. J. Org. Chem. 1990, 55, 3628.

101. Naruta, Y.; Tani, F.; Maruyama, K. J. Chem. Soc., Chem. Commun. 1990, 1378.

102. Naruta, Y.; Tani, F.; Maruyama, K. Tetrahedron: Asymmetry 1991, 2, 533.

103. Chiang, L. C.; Konishi, K.; Aida, T.; Inoue, S. J. Chem. Soc., Chem. Commun. 1992, 254.

104. Bryliakov, K. P.; Talsi, E. P. Angew. Chem., Int. Ed. 2004, 43, 5228.

105. (a) Egami, H.; Katsuki, T. J. Am. Chem. Soc. 2007, 129, 8940 (b) Egami, H.; Katsuki, T. Synlett 2008, 1543 (c) Katsuki, T. Coord. Chem. Rev. 1995, 140, 189.

106. Palucki, M.; Hanson, P.; Jacobsen, E. N. Tetrahedron Lett. 1992, 33, 7111.

107. Noda, K.; Hosoya, N.; Yanai, K.; Irie, R.; Katsuki, T. Tetrahedron Lett. 1994, 35, 1887.

108. Noda, K.; Hosoya, N.; Irie, R.; Yamashita, Y.; Katsuki, T. Tetrahedron 1994, 50, 9609.

109. Kokubo, C.; Katsuki, T. Tetrahedron 1996, 52, 13895.

110. Irie, R.; Ito, Y.; Katsuki, T. Synlett 1991, 265.

111. Choi, J. Y.; Hwang, G.-S.; Senapati, B. K.; Ryu, D. H. Bull. Korean Chem. Soc. 2008, 29, 1879.

112. Schoumacker, S.; Hamelin, O.; Pecaut, J.; Fontecave, M. Inorg. Chem. 2003, 42, 8110.

113. Imagawa, K.; Nagata, T.; Yamada, Y.; Mukaiyama, T. Chem. Lett. 1995, 335.

114. Nagata, T.; Imagawa, K.; Yamada, T.; Mukaiyama, T. Bull. Chem. Soc. Jpn. 1995, 68, 3241.

115. Alcon, M. J.; Corma, A.; Iglesias, M.; Sanchez, F. J. Mol. Catal. A: Chem. 2002, 178, 253.

116. Gao, A.; Wang, M.; Shi, J.; Wang, D.; Tian, W.; Sun, L. Appl. Organomet. Chem. 2006, 20,830 .

117. Wang, D.; Wang, M.; Wang, X.; Chen, Y.; Gao, A.; Sun, L. J. Catal. 2006, 237, 248.

118. Hirotsu, M.; Ohno, N.; Nakajima, T.; Kushibe, C.; Ueno, K.; Kinoshita, I. Dalton Trans. 2010, 39, 139.

119. Bunce, S.; Cross, R. J.; Farrugia, L. J.; Kunchandy, S.; Meason, L. L.; Muir, K. W.; O'Donnell, M.; Peacock, R. D.; Stirling, D.; Teat, S. J. Polyhedron 1998, 17, 4179.

120. Zhu, H.-B.; Dai, Z.-Y.; Huang, W.; Cui, K.; Gou, S.-H.; Zhu, C.-J. Polyhedron 2004, 23, 1131.

121. Plitt, P.; Pritzkow, H.; Oeser, T.; Kraemer, R. J. Inorg. Biochem. 2005, 99, 1230.

122. Ayala, V.; Corma, A.; Iglesias, M.; Sanchez, F. J. Mol. Catal. A: Chem. 2004, 221, 201.

123. (a) Kelly, P.; Lawrence, S. E.; Maguire, A. R. Synlett 2007, 1501 (b) Miyazaki, T.; Katsuki, T. Synlett 2003, 1046.

124. Thakur, V. V.; Sudalai, A. Tetrahedron: Asymmetry 2003, 14, 407.

125. Kantam, M. L.; Prakash, B. V.; Bharathi, B.; Reddy, C. V. J. Mol. Catal. A: Chem. 2005, $226,119$. 
126. Bonchio, M.; Licini, G.; Di Furia, F.; Mantovani, S.; Modena, G.; Nugent, W. A. J. Org. Chem. 1999, 64, 1326.

127. Licini, G.; Bonchio, M.; Modena, G.; Nugent, W. A. Pure Appl. Chem. 1999, 71, 463.

128. Di, Furia, F.; Licini, G.; Modena, G.; Motterle, R.; Nugent, W. A. J. Org. Chem. 1996, 61, 5175.

129. Bonchio, M.; Carofiglio, T.; Di Furia, F.; Fornasier, R. J. Org. Chem. 1995, 60, 5986.

130. Basak, A.; Barlan, A. U.; Yamamoto, H. Tetrahedron: Asymmetry 2006, 17, 508.

131. Matsumoto, K.; Yamaguchi, T.; Fujisaki, J.; Saito, B.; Katsuki, T. Chem.--Asian J. 2008, 3,351 .

132. Folli, U.; Iarossi, D.; Montanari, F.; Torre, G. J. Chem. Soc., C: Organic 1968, 1317.

133. Pirkle, W. H.; Rinaldi, P. L. J. Org. Chem. 1977, 42, 2080.

134. Aoki, M.; Seebach, D. Helv. Chim. Acta 2001, 84, 187.

135. Davis, F. A.; Jenkins, R., Jr.; Yocklovich, S. G. Tetrahedron Lett. 1978, 5171.

136. Davis, F. A.; Jenkins, R., Jr.; Rizvi, S. Q. A.; Panunto, T. W. J. Chem. Soc., Chem. Commun. 1979, 600.

137. Davis, F. A.; Jenkins, R. H., Jr.; Awad, S. B.; Stringer, O. D.; Watson, W. H.; Galloy, J. J. Am. Chem. Soc. 1982, 104, 5412.

138. Davis, F. A.; McCauley, J. P., Jr.; Harakal, M. E. J. Org. Chem. 1984, 49, 1465.

139. Davis, F. A.; McCauley, J. P., Jr.; Chattopadhyay, S.; Harakal, M. E.; Towson, J. C.; Watson, W. H.; Tavanaiepour, I. J. Am. Chem. Soc. 1987, 109, 3370.

140. Davis, F. A.; Towson, J. C.; Weismiller, M. C.; Lal, S.; Carroll, P. J. J. Am. Chem. Soc. 1988, $110,8477$.

141. Davis, F. A.; ThimmaReddy, R.; Weismiller, M. C. J. Am. Chem. Soc. 1989, 111, 5964.

142. Davis, F. A.; Reddy, R. T.; Han, W.; Carroll, P. J. J. Am. Chem. Soc. 1992, 114, 1428.

143. Meladinis, V.; Verfurth, U.; Herrmann, R. Z. Naturforsch., B: Chem. Sci. 1990, 45, 1689.

144. Davis, F. A.; Reddy, R. T.; McCauley, J. P., Jr.; Przeslawski, R. M.; Harakal, M. E.; Carroll, P. J. J. Org. Chem. 1991, 56, 809.

145. Schwan, A. L.; Pippert, M. F. Tetrahedron: Asymmetry 1995, 6, 131.

146. Davis, F. A.; Lal, S. G.; Durst, H. D. J. Org. Chem. 1988, 53, 5004.

147. Page, P. C. B.; Heer, J. P.; Bethell, D.; Collington, E. W.; Andrews, D. M. Tetrahedron Lett. 1994, 35, 9629.

148. Page, P. C. B.; Heer, J. P.; Bethell, D.; Collington, E. W.; Andrews, D. M. Synlett 1995, 773.

149. Page, P. C. B.; Heer, J. P.; Bethell, D.; Collington, E. W.; Andrews, D. M. Tetrahedron: Asymmetry 1995, 6, 2911.

150. Bethell, D.; Page, P. C. B.; Vahedi, H. J. Org. Chem. 2000, 65, 6756.

151. Hanquet, G.; Lusinchi, X.; Milliet, P. Tetrahedron Lett. 1988, 29, 2817.

152. Bohé, L.; Lusinchi, M.; Lusinchi, X. Tetrahedron 1999, 55, 155.

153. Schoumacker, S.; Hamelin, O.; Téti, S.; Pécaut, J.; Fontecave, M. J. Org. Chem. 2004, 70, 301. 
154. Jennings, W. B.; Kochanewycz, M. J.; Lovely, C. J.; Boyd, D. R. J. Chem. Soc., Chem. Commun. 1994, 2569.

155. del Rio. R. E.; Wang, B.; Achab, S.; Bohé, L. Org. Lett. 2007, 9, 2265.

156. Akhatou, A.; Rahimi, M.; Cheboub, K.; Ghosez, L.; Hanquet, G. Tetrahedron 2007, 63, 6232.

157. (a) Ladziata, U.; Zhdankin, V. V. Synlett 2007, 527 (b) Zhdankin, V. V.; Smart, J. T.; Zhao, P.; Kiprof, P. Tetrahedron Lett. 2000, 41, 5299 (c) Ladziata, U.; Carlson, J.; Zhdankin, V. V. Tetrahedron Lett. 2006, 47, 6301.

158. Higuchi, T.; Pitman, I. H.; Gensch, K. H. J. Am. Chem. Soc. 1966, 88, 5676.

159. Surendra, K.; Krishnaveni, N. S.; Kumar, V. P.; Sridhar, R.; Rao, K. R. Tetrahedron Lett. 2005, 46, 4581.

160. Rossi, L. I.; de Rossi, R. H. Appl. Catal., A: Gen 2004, 267, 267.

161. Czarnik, A. W. J. Org. Chem. 1984, 49, 924.

162. Drabowicz, J.; Mikołajczyk, M. Phosphorus Sulfur 1984, 21, 245.

163. Sugimoto, T.; Kokubo, T.; Miyazaki, J.; Tanimoto, S.; Okano, M. J. Chem. Soc., Chem. Commun. 1979, 402.

164. Ogura, K.; Fujita, M.; Iida, H. Tetrahedron Lett. 1980, 21, 2233.

165. Colonna, S.; Banfi, S.; Fontana, F.; Sommaruga, M. J. Org. Chem. 1985, 50, 769.

166. Firth, B. E.; Miller, L. L. J. Am. Chem. Soc. 1976, 98, 8272.

167. Komori, T.; Nonaka, T. J. Am. Chem. Soc. 1983, 105, 5690.

168. Komori, T.; Nonaka, T. J. Am. Chem. Soc. 1984, 106, 2656.

169. Holland, H. L. Chem. Rev. 1988, 88, 473.

170. Holland, H. L. Nat. Prod. Rep. 2001, 18, 171.

171. Wright, L. D.; Cresson, E. L.; Valiant, J.; Wolf, D. E.; Folkers, K. J. Am. Chem. Soc. 1954, $76,4163$.

172. Dodson, R. M.; Newman, N.; Tsuchiya, H. M. J. Org. Chem. 1962, 27, 2707.

173. Auret, B. J.; Boyd, D. R.; Henbest, H. B.; Ross, S. J. Chem. Soc., C 1968, 2371.

174. (a) Holland, H. L.; Brown, F. M.; Larsen, B. G. Bioorg. Med. Chem. 1994, 2, 647. (b) Holland, H. L.; Brown, F. M.; Larsen, B. G. Tetrahedron: Asymmetry 1994, 5, 1241. (c) Holland, H. L.; Brown, F. M.; Larsen, B. G. Tetrahedron: Asymmetry 1995, 6, 1561. (d) Holland, H. L.; Brown, F. M.; Larsen, B. G.; Zabic, M. Tetrahedron: Asymmetry 1995, 6, 1569. (e) Holland, H. L.; Bornmann, M. J.; Lakshmaiah, G. J. Mol. Catal. B: Enzym. 1996, 1, 97. (f) Holland, H. L.; Brown, F. M.; Lakshmaiah, G.; Larsen, B. G.; Patel, M. Tetrahedron: Asymmetry 1997, 8, 683. (g) Holland, H. L.; Brown, F. M.; Kerridge, A.; Turner, C. D. J. Mol. Catal. B: Enzym. 1999, 6, 463. (h) Holland, H. L.; Gu, J.-X.; Kerridge, A.; Willetts, A. Biocatal. Biotransform. 1999, 17, 305.

175. Argoudelis, A. D.; Mason, D. J. J. Antibiot. 1969, 22, 289.

176. Argoudelis, A. D.; Coats, J. H.; Mason, D. J.; Sebek, O. K. J. Antibiot. 1969, $22,309$. 
177. (a) Ohta, H.; Okamoto, Y.; Tsuchihashi, G. Chem. Lett. 1984, 205 (b) Ohta, H.; Okamoto, Y.; Tsuchihashi, G. Agric. Biol. Chem. 1985, 49, 671 (c) Ohta, H.; Okamoto, Y.; Tsuchihashi, G. Agric. Biol. Chem. 1985, 49, 2229.

178. Mahmoudian, M.; Michael, A. J. Biotechnol. 1993, 27, 173.

179. Lee, K.; Brand, J. M.; Gibson, D. T. Biochem Biophys Res Commun 1995, 212, 9.

180. Adam, W.; Heckel, F.; Saha-Möller, C. R.; Taupp, M.; Schreier, P. Tetrahedron: Asymmetry 2004, 15, 983.

181. Boyd, D. R.; Sharma, N. D.; Haughey, S. A.; Malone, J. F.; King, A. W. T.; McMurray, B. T.; Alves-Areias, A.; Allen, C. C. R.; Holt, R.; Dalton, H. J. Chem. Soc., Perkin Trans. 1 2001, 3288.

182. Boyd, D. R.; Sharma, N. D.; Ljubez, V.; Byrne, B. E.; Shepherd, S. D.; Allen, C. C. R.; Kulakov, L. A.; Larkin, M. J.; Dalton, H. Chem. Commun. 2002, 1914.

183. Tang, J.; Brackenridge, I.; Roberts, S. M.; Beecher, J.; Willetts, A. J. Tetrahedron 1995, $51,13217$.

184. Beecher, J.; Richardson, P.; Roberts, S.; Willetts, A. Biotechnol. Lett. 1995, 17, 1069.

185. Carrea, G.; Redigolo, B.; Riva, S.; Colonna, S.; Gaggero, N.; Battistel, E.; Bianchi, D. Tetrahedron: Asymmetry 1992, 3, 1063.

186. Zhao, H.; Kayser, M. M.; Wang, Y.; Palkovits, R.; Schueth, F. Microporous Mesoporous Mater. 2008, 116, 196.

187. Yoshida, T.; Kito, M.; Tsujii, M.; Nagasawa, T. Biotechnol. Lett. 2001, 23, 1217.

188. Ricci, L. C.; Comasseto, J. V.; Andrade, L. H.; Capelari, M.; Cass, Q. B.; Porto, A. L. M. Enzyme Microb. Technol. 2005, 36, 937.

189. Pinedo-Rivilla, C.; Aleu, J.; Collado, I. G. J. Mol. Catal. B: Enzym. 2007, 49, 18.

190. Daligault, F.; Nugier-Chauvin, C.; Patin, H. Org. Biomol. Chem. 2006, 4, 1474.

191. Ottolina, G.; Pasta, P.; Carrea, G.; Colonna, S.; Dallavalle, S.; Holland, H. L. Tetrahedron: Asymmetry 1995, 6, 1375.

192. Colonna, S.; Gaggero, N.; Carrea, G.; Pasta, P. Chem. Commun. 1997, 439.

193. Chen, G.; Kayser, M. M.; Mihovilovic, M. D.; Mrstik, M. E.; Martinez, C. A.; Stewart, J. D. New J. Chem. 1999, 23, 827.

194. Colonna, S.; Del Sordo, S.; Gaggero, N.; Carrea, G.; Pasta, P. Heteroat. Chem. 2002, 13, 467.

195. Colonna, S.; Gaggero, N.; Casella, L.; Carrea, G.; Pasta, P. Tetrahedron: Asymmetry 1992, 3,95 .

196. van Deurzen, M. P. J.; Remkes, I. J.; van Rantwijk, F.; Sheldon, R. A. J. Mol. Catal. A: Chem. 1997, 117, 329.

197. van Deurzen, M. P. J.; van Rantwijk, F.; Sheldon, R. A. Tetrahedron 1997, 53, 13183.

198. Lutz, S.; Steckhan, E.; Liese, A. Electrochem. Commun. 2004, 6, 583.

199. van Rantwijk, F.; Sheldon, R. A. Curr. Opin. Biotechnol. 2000, 11, 554.

200. van de Velde, F.; van Rantwijk, F.; Sheldon, R. A. Trends Biotechnol. 2001, 19, 73. 
201. Karmee, S. K.; Roosen, C.; Kohlmann, C.; Luetz, S.; Greiner, L.; Leitner, W. Green Chem. 2009, 11, 1052.

202. Perez, D. I.; Grau, M. M.; Arends, I. W. C. E.; Hollmann, F. Chem. Commun. 2009, 6848.

203. Tuynman, A.; Schoemaker, H. E.; Wever, R. Monatsh. Chem. 2000, 131, 687.

204. Ozaki, S.-I.; Ortiz de Montellano, P. R. J. Am. Chem. Soc. 1994, 116, 4487.

205. Ozaki, S.-i.; Ortiz de Montellano, P. R. J. Am. Chem. Soc. 1995, 117, 7056.

206. Tuynman, A.; Vink, M. K. S.; Dekker, H. L.; Schoemaker, H. E.; Wever, R. Eur. J. Biochem. 1998, 258, 906.

207. Boyd, D. R.; Sharma, N. D.; Haughey, S. A.; Kennedy, M. A.; McMurray, B. T.; Sheldrake, G. N.; Allen, C. C. R.; Dalton, H.; Sproule, K. J. Chem. Soc., Perkin Trans. 1 1998, 1929.

208. de Gonzalo, G.; Torres Pazmiño, D. E.; Ottolina, G.; Fraaije, M. W.; Carrea, G. Tetrahedron: Asymmetry 2006, 17, 130.

209. Andersson, M. A.; Allenmark, S. G. Tetrahedron 1998, 54, 15293.

210. ten Brink, H. B.; Holland, H. L.; Schoemaker, H. E.; van Lingen, H.; Wever, R. Tetrahedron: Asymmetry 1999, 10, 4563.

211. Zhang, J.-D.; Li, A.-T.; Yang, Y.; Xu, J.-H. Appl. Microbiol. Biotechnol. 2010, 85, 615.

212. Pievo, R.; Gullotti, M.; Monzani, E.; Casella, L. Biochemistry 2008, 47, 3493.

213. Auret, B. J.; Boyd, D. R.; Henbest, H. B. J. Chem. Soc., C 1968, 2374.

214. Sugimoto, T.; Kokubo, T.; Miyazaki, J.; Tanimoto, S.; Okano, M. Bioorg. Chem. 1981, 10, 311.

215. Kobayashi, M.; Yabe, A. Bull. Chem. Soc. Jpn. 1967, 40, 224.

216. Davis, F. A.; Billmers, J. M. J. Org. Chem. 1983, 48, 2672.

217. Toda, F.; Mori, K.; Matsuura, Y.; Akai, H. J. Chem. Soc., Chem. Commun. 1990, 1591.

218. Komatsu, N.; Hashizume, M.; Sugita, T.; Uemura, S. J. Org. Chem. 1993, 58, 4529.

219. Komatsu, N.; Hashizume, M.; Sugita, T.; Uemura, S. J. Org. Chem. 1993, 58, 7624.

220. Donnoli, M. I.; Superchi, S.; Rosini, C. J. Org. Chem. 1998, 63, 9392.

221. Lattanzi, A.; Piccirillo, S.; Scettri, A. Adv. Synth. Catal. 2007, 349, 357.

222. Jia, X.; Li, X.; Xu, L.; Li, Y.; Shi, Q.; Au-Yeung, T. T. L.; Yip, C. W.; Yao, X.; Chan, A. S. C. Adv. Synth. Catal. 2004, 346, 723.

223. Mohammadpoor-Baltork, I.; Hill, M.; Caggiano, L.; Jackson, R. F. W. Synlett 2006, 3540.

224. Mikołajczyk, M.; Para, M. J. Chem. Soc. D 1969, 1192.

225. Mikołajczyk, M.; Drabowicz, J. Phosphorus Sulfur 1976, 1, 301.

226. Drabowicz, J.; Pacholczyk, M. Phosphorus Sulfur 1981, 10, 233.

227. Annunziata, R.; Borgogno, G.; Montanari, F.; Quici, S.; Cucinella, S. J. Chem. Soc., Perkin Trans. 1 1981, 113.

228. Marchese, G.; Naso, F.; Ronzini, L. J. Chem. Soc., Chem. Commun. 1974, 830.

229. Kunieda, N.; Motoki, H.; Kinoshita, M. Chem. Lett. 1978, 713.

230. Kunieda, N.; Nokami, J.; Kinoshita, M. Bull. Chem. Soc. Jpn. 1976, 49, 256.

231. Ohta, H.; Kato, Y.; Tsuchihashi, G. Chem. Lett. 1986, 217. 
232. Pirkle, W. H.; Rinaldi, P. L. J. Am. Chem. Soc. 1977, 99, 3510.

233. Eskenazi, C.; Nicoud, J. F.; Kagan, H. B. J. Org. Chem. 1979, 44, 995.

234. (a) Abo, M.; Tachibana, M.; Okubo, A.; Yamazaki, S. Biosci., Biotechnol., Biochem. 1994, 58, 596. (b) Abo, M.; Tachibana, M.; Okubo, A.; Yamazaki, S. Bioorg. Med. Chem. 1995, 3, 109. (c) Hanlon, S. P.; Graham, D. L.; Hogan, P. J.; Holt, R. A.; Reeve, C. D.; Shaw, A. L.; McEwan, A. G. Microbiology 1998, 144 ( Pt 8), 2247.

235. Boyd, D. R.; Sharma, N. D.; Byrne, B. E.; Haughey, S. A.; Kennedy, M. A.; Allen, C. C. R. Org. Biomol. Chem. 2004, 2, 2530.

236. Andersen, K. K. Tetrahedron Lett. 1962, 3, 93.

237. (a) Andersen, K. K. J. Org. Chem. 1964, 29, 1953. (b) Andersen, K. K.; Gaffield, W.; Papanikolaou, N. E.; Foley, J. W.; Perkins, R. I. J. Am. Chem. Soc. 1964, 86, 5637. (c) Hope, H.; De, 1. C. U.; Homer, G. D.; Messing, A. W.; Sommer, L. H. Angew. Chem., Int. Ed. Engl. 1969, 8, 612. (d) Axelrod, M.; Bickart, P.; Jacobus, J.; Green, M. M.; Mislow, K. J. Amer. Chem. Soc. 1968, 90, 4835.

238. Herbrandson, H. F.; Dickerson, R. T., Jr.; Weinstein, J. J. Am. Chem. Soc. 1956, 78, 2576.

239. Drabowicz, J.; Bujnicki, B.; Mikołajczyk, M. J. Org. Chem. 1982, 47, 3325.

240. Mariz, R.; Luan, X.; Gatti, M.; Linden, A.; Dorta, R. J Am Chem Soc 2008, 130, 2172.

241. Burgi, J. J.; Mariz, R.; Gatti, M.; Drinkel, E.; Luan, X.; Blumentritt, S.; Linden, A.; Dorta, R. Angew. Chem. Int. Ed. 2009, 48, 2768.

242. Andersen, K. K.; Bujnicki, B.; Drabowicz, J.; Mikołajczyk, M.; O'Brien, J. B. J. Org. Chem. 1984, 49, 4070.

243. Whitesell, J. K.; Wong, M. S. J. Org. Chem. 1991, 56, 4552.

244. Whitesell, J. K.; Wong, M.-S. J. Org. Chem. 1994, 59, 597.

245. (a) Ridley, D. D.; Smal, M. A. J. Chem. Soc., Chem. Commun. 1981, 505 (b) Fernández, I.; Khiar, N.; Llera, J. M.; Alcudia, F. J. Org. Chem. 1992, 57, 6789 (c) Khiar, N.; Fernández, I.; Alcudia, F. Tetrahedron Lett. 1994, 35, 5719 (d) Ridley, D. D.; Smal, M. A. Aust. J. Chem. 1982, 35, 495 (e) Alcudia, F. K., N.; Fernández, I.; Tetrahedron Lett. 1991, 32, 7299.

246. Drabowicz, J.; Bujnicki, B.; Biscarini, P.; Mikołajczyk, M. Tetrahedron: Asymmetry 1999, $10,3177$.

247. Harpp, D. N.; Vines, S. M.; Montillier, J. P.; Chan, T. H. J. Org. Chem. 1976, 41, 3987.

248. Jacobus, J.; Mislow, K. Chem. Commun. 1968, 253.

249. Oppolzer, W.; Froelich, O.; Wiaux-Zamar, C.; Bernardinelli, G. Tetrahedron Lett. 1997, 38, 2825.

250. Evans, D. A.; Faul, M. M.; Colombo, L.; Bisaha, J. J.; Clardy, J.; Cherry, D. J. Am. Chem. Soc. 1992, 114, 5977.

251. Lockard, J. P.; Schroeck, C. W.; Johnson, C. R. Synthesis 1973, 485.

252. Wang, P.; Chen, J.; Cun, L.; Deng, J.; Zhu, J.; Liao, J. Org. Biomol. Chem. 2009, 7, 3741.

253. Cardellicchio, C.; Fiandanese, V.; Naso, F.; Scilimati, A. Tetrahedron Lett. 1992, 33, 5121. 
254. Cardellicchio, C.; Iacuone, A.; Naso, F.; Tortorella, P. Tetrahedron Lett. 1996, 37, 6017.

255. Capozzi, M. A. M.; Cardellicchio, C.; Fracchiolla, G.; Naso, F.; Tortorella, P. J. Am. Chem. Soc. 1999, 121, 4708.

256. Cardellicchio, C.; Fracchiolla, G.; Naso, F.; Tortorella, P. Tetrahedron 1999, 55, 525.

257. Capozzi, M. A. M.; Cardellicchio, C.; Naso, F.; Tortorella, P. J. Org. Chem. 2000, 65, 2843.

258. (a) Durst, T.; LeBelle, M. J.; Van, d. E. R.; Tin, K. C. Can. J. Chem. 1974, 52, 761 (b) Hojo, M.; Masuda, R.; Saeki, T.; Fujimori, K.; Tsutsumi, S. Synthesis 1977, 789 (c) Furukawa, N.; Ogawa, S.; Matsumura, K.; Fujihara, H. J. Org. Chem. 1991, 56, 6341.

259. Wudl, F.; Lee, T. B. K. J. Chem. Soc., Chem. Commun. 1972, 61.

260. Wudl, F.; Lee, T. B. K. J. Am. Chem. Soc. 1973, 95, 6349.

261. Benson, S. C.; Snyder, J. K. Tetrahedron Lett. 1991, 32, 5885.

262. Han, Z.; Krishnamurthy, D.; Grover, P.; Fang, Q. K.; Senanayake, C. H. J. Am. Chem. Soc. 2002, 124, 7880 .

263. (a) Han, Z.; Krishnamurthy, D.; Grover, P.; Wilkinson, H. S.; Fang, Q. K.; Su, X.; Lu, Z.H.; Magiera, D.; Senanayake, C. H. Angew. Chem., Int. Ed. 2003, 42, 2032. (b) Han, Z.; Krishnamurthy, D.; Grover, P.; Fang, Q. K.; Su, X.; Wilkinson, H. S.; Lu, Z.-H.; Magiera, D.; Senanayake, C. H. Tetrahedron 2005, 61, 6386.

264. Garcia, R. J. L.; Alemparte, C.; Aranda, M. T.; Zarzuelo, M. M. Org. Lett. 2003, 5, 75.

265. Qin, Y.; Wang, C.; Huang, Z.; Xiao, X.; Jiang, Y. J. Org. Chem. 2004, 69, 8533.

266. Lu, B. Z.; Jin, F.; Zhang, Y.; Wu, X.; Wald, S. A.; Senanayake, C. H. Org. Lett. 2005, 7, 1465.

267. (a) Rebiere, F.; Kagan, H. B. Tetrahedron Lett. 1989, 30, 3659 (b) Kagan, H. B.; Rebiere, F. Synlett 1990, 643. (c) Rebiere, F.; Samuel, O.; Ricard, L.; Kagan, H. B. J. Org. Chem. 1991, 56, 5991.

268. Capozzi, M. A. M.; Cardellicchio, C.; Naso, F.; Spina, G.; Tortorella, P. J. Org. Chem. 2001, 66, 5933.

269. Capozzi, M. A. M.; Cardellicchio, C.; Naso, F.; Rosito, V. J. Org. Chem. 2002, 67, 7289.

270. Capozzi, M. A. M.; Cardellicchio, C.; Naso, F. Eur. J. Org. Chem. 2004, 1855.

271. Wojaczynska, E.; Wojaczynski, J. Chem. Rev. 2010, 110, 4303. 


\section{Authors' Biographies}

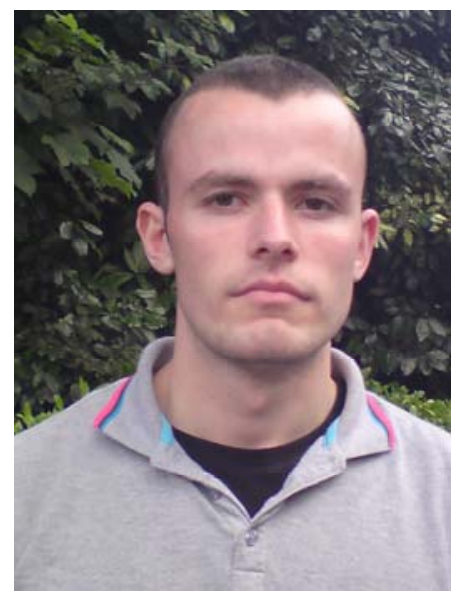

Graham O’Mahony, University College Cork.

Graham O'Mahony received his B.Sc in Chemistry from University College Cork in 2008. He is currently undertaking a Ph.D under the supervision of Professor Anita Maguire. His research focuses on copper catalyzed asymmetric sulfide oxidation.

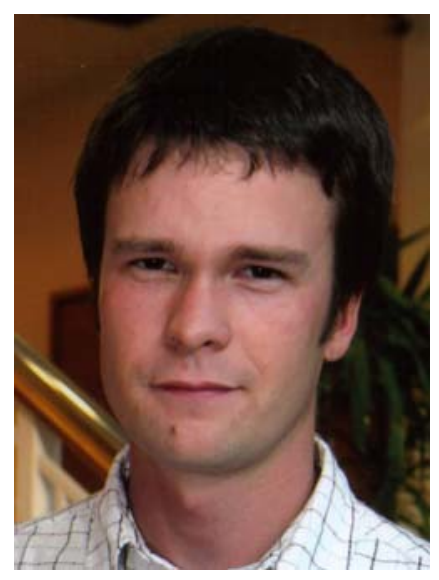

Padraig Kelly, University College Cork.

Padraig Kelly received his B.Sc in the Chemistry of Pharmaceutical Compounds from University College Cork in 2001. He received his Ph.D. from University College Cork for research under the supervision of Professor Anita Maguire and Dr. Simon Lawrence in the area of enantioselective transition metal catalyzed oxidation of sulfides. 


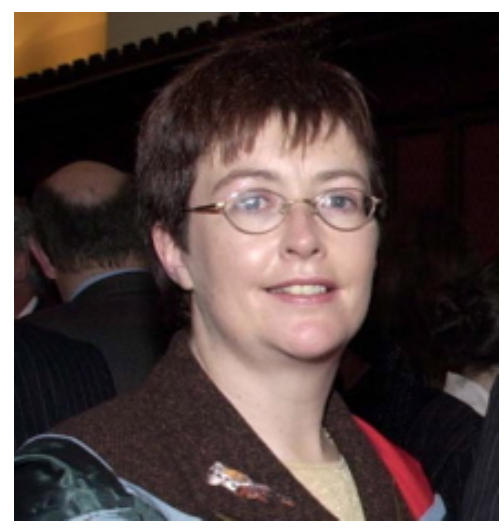

Prof. Anita Maguire, University College Cork.

Anita Maguire undertook undergraduate and postgraduate studies at University College Cork (B.Sc. 1985, Ph.D. 1989), focusing during her Ph.D on asymmetric catalysis in reactions of $\alpha-$ diazoketones. Following postdoctoral research in the Facultes Universitaires, Namur, Belgium and subsequently at the University of Exeter, she returned to Cork in 1991. Her research interests include development of new synthetic methodology including organosulfur chemistry, asymmetric synthesis including biocatalysis, and the design and synthesis of bioactive compounds with pharmaceutical applications.

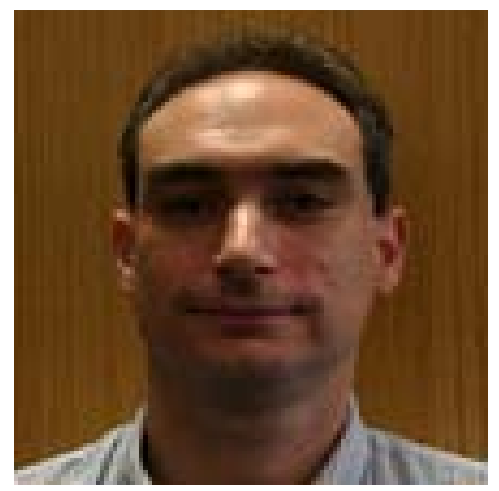

Dr. Simon Lawrence, University College Cork.

Simon Lawrence undertook undergraduate and postgraduate studies at University of Durham (B.Sc. 1991, Ph.D. 1995) in the area of sulfur-nitrogen heterocycles. Following postdoctoral research in the Imperial College, London and UMIST, Manchester he joined University College Cork in 1996. His research interests are focused on the solid state properties of organic compounds. 